Eine hervorragend nationale Wissenschaft - RGA-E Band 29 - Seiten 199-310

(C) Copyright 2001 Walter de Gruyter $\cdot$ Berlin $\cdot$ New York

\title{
Deutsche Vorgeschichte als Geschichtswissenschaft - Der Heidelberger Extraordinarius Ernst Wahle im Kontext seiner Zeit $^{1}$
}

von DieTrich Hakelberg

\section{Einleitung}

Die Gelehrten, die sich in der ersten Hälfte des 19. Jahrhunderts mit einheimischen Altertümern und Denkmalen beschäftigten, vereinten archäologische und historische Methoden, um quellenübergreifend zu einer umfassenden, bis in die prähistorische „heidnische“ Zeit zurückreichenden Nationalgeschichtsschreibung zu gelangen. Diese oft noch einem aufklärerischen Patriotismus verpflichtete „vaterländische Altertumskunde“ ist als Ausgangspunkt für die wissenschaftsgeschichtliche Entwicklung der ur- und frühgeschichtlichen Archäologie im 20. Jahrhundert von außerordentlicher Bedeutung. Traditionell wurden der Widerstand gegen die französische Hegemonie und die Befreiungskriege als Auslöser für das zunehmende Interesse an „vaterländischen“ Altertümern angesehen. Die zahlreichen Gründungen von Altertumsvereinen

1 Der vorliegende Aufsatz entstand im Rahmen des Forschungsprojektes C4 (b) Ethnische Einheiten im frühgeschichtlichen Europa - Archäologische Forschung und ibre politische Instrumentalisierung innerhalb des Sonderforschungsbereiches 541 Identitäten und Alteritäten. Die Funktion von Alterität für die Konstitution und Konstruktion von Identität an der Albert-Ludwigs-Universität Freiburg i. Br. (http://www.phil.uni-freiburg.de/SFB541/C4/). Für die kritische Durchsicht meines Manuskriptes und zahlreiche Anregungen möchte ich besonders PD Dr. Christian Jansen (Fakultät für Geschichtswissenschaft, Ruhr-Universität Bochum) und Dr. Michael Strobel (Landesdenkmalamt Baden-Württemberg, Stuttgart) danken. Prof. Dr. Siegmar von Schnurbein (Römisch-Germanische Kommission, Frankfurt a. M.) und die Mitarbeiter des Bundesarchivs Berlin, der Universitätsbibliothek Heidelberg (Handschriftenabteilung) und des Universitätsarchivs Heidelberg machten mir wichtige Quellen zugänglich; Dr. Sebastian Brather, Hubert Fehr M.A., PD Dr. Wolfgang Pape und Prof. Dr. Heiko Steuer (Institut für Ur- und Frühgeschichte der Universität Freiburg) förderten die Arbeit durch Diskussion und Kritik. Für die Richtigkeit aller Angaben, Zitate und die Darstellungsweise bin ich selbst verantwortlich. Um Mißverständnisse im Umgang mit dem wissenschaftlichen Selbstverständnis einer vergangenen Epoche zu vermeiden, habe ich auf Paraphrasen weitgehend verzichtet und die Gelehrten in Zitaten selbst zu Wort kommen lassen. 
fanden besonders im Bildungsbürgertum der Zeit ihren Rückhalt. Ihren Antrieb verdankte diese antiquarische Altertumskunde einem wesentlichen Inhalt des politischen Liberalismus, dem Versuch, ein deutsches Nationalbewußtsein zu schaffen oder wenigstens historisch zu definieren. Bis zur Jahrhundertmitte hatte sich jedoch die Erkenntnis verfestigt, daß aufgrund der archäologischen Überlieferung nicht daran zu denken sei, mit den Germanen des Tacitus das aus den Schriftquellen bekannte „Ahnenvolk“ der Deutschen anhand archäologischer Funde zu identifizieren. Nicht zuletzt aufgrund der Ereignisse von 1848/49, als die geeinte, auf einem selbstbewußten „deutschen Volk" gegründete Nation als Ziel liberaler Politik an der Revolution scheiterte, kam es um $1850 \mathrm{zu}$ einem Paradigmenwechsel in der Altertumskunde. Die Gelehrten waren desillusioniert, in der Altertumskunde trat nun zum „Volk“ die „Kultur“ als zentraler Begriff hinzu. Neue Entdeckungen, wie die dänischen Muschelhaufen (ab 1848), die Pfahlbauten an den Voralpenseen (1854) und die fossilen Menschenreste im Neandertal (1856) kontrapunktierten die Entwicklung der Altertumskunde zu einer „Kulturwissenschaft“.2 Obwohl sich die Gelehrten schon in der ersten Jahrhunderthälfte vorwiegend mit Grabfunden beschäftigt hatten, richtete sich das Interesse mit dem Forschungsfortschritt in den Geo- und Biowissenschaften nun auch auf die Überreste des Menschen selbst. Mediziner begannen sich für die rassenanthropologische Untersuchung von Skelettresten zu interessieren und versuchten, die ethnische Identifikation auf diesem Wege vorzunehmen. Weder die „vaterländische" antiquarische noch die humananthropologisch ausgerichtete Altertumskunde des 19. Jahrhunderts sind bislang differenzierter erforscht.

Um die Existenz ihres in der Wissenschaftslandschaft noch unetablierten Faches gesellschaftlich zu rechtfertigen, rekurrierten Prähistoriker um 1930 auf die ihnen um rund ein Jahrhundert vorausgehende „vaterländische“ Altertumskunde und sahen in ihr den Ausdruck einer nationalen Aufbrucbszeit, die sie mit der Gegenwart parallelisierten. Ein Protagonist war hier der Heidelberger Prähistoriker Ernst Wahle (1889-1981), der über eigene Arbeiten und über die Vergabe von Dissertationen verdienstvolle Impulse für die Erforschung der Wissenschaftsgeschichte seines Faches vom 16. bis zum 19. Jahrhundert gab. ${ }^{3}$ Wie die Gelehrten zu Beginn des 19. Jahrhunderts den Wert der

2 Vgl. hierzu: Smith 1991.

3 Wahle 1928, Stemmermann 1934, Wahle 1933, Kirchner 1938, teils darauf aufbauend Gurnmel 1938 (dazu extrem kritisch: Wahle 1940); Scheidter 1944, Kirchner 1972, ferner Wahle 1950/1951. 


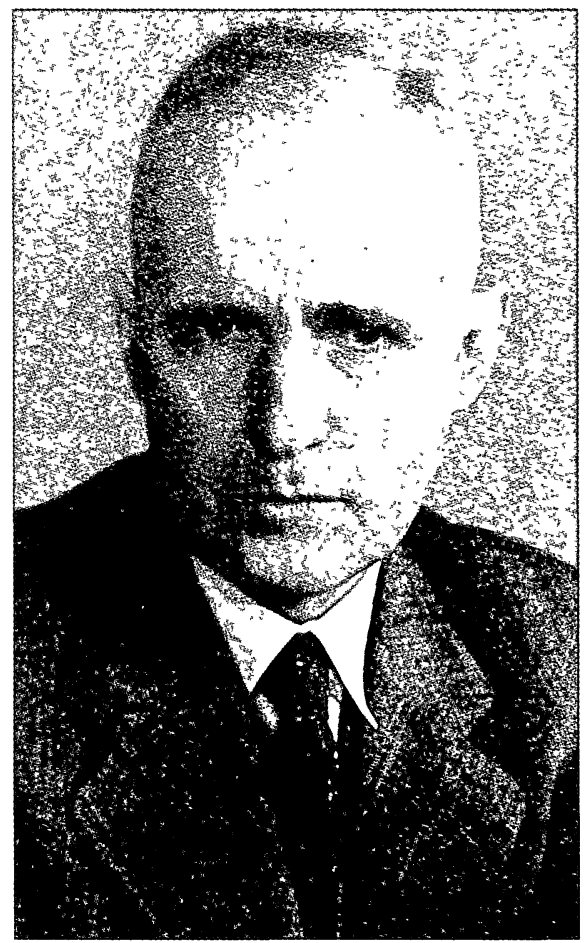

Abb. 1. Der Prähistoriker Ernst Wahle (1889-1981). Photographie vor 1945 (Universitätsbibliothek Heidelberg, Heid. Hs. 3989 1,1).

einheimischen Altertümer vor den griechischen und römischen hervorhoben, so strebte auch Wahle nach einer Emanzipation der Vorgeschichte von der klassischen Altertumswissenschaft. Aus einem nationalen Impetus heraus wollte er das Fach Vorgeschichte als selbständige Geschichtswissenschaft vermitteln, ${ }^{4}$ wie es auch Gustaf Kossinna (1858-1931) gefordert hatte. „Geschichte“ war dabei stets Volks- bzw. Völkergeschichte. ${ }^{5}$ Typologie und Chronologie treten in den kaum illustrierten größeren Arbeiten Wahles gegenüber seiner "historischen Betrachtungsweise“ in den Hintergrund, was nicht unumstritten war. ${ }^{6}$ „Kultur“ aus einer historischen Perspektive heraus zu betrachten, war allerdings schon im 19. Jahrhundert ein typisch deutscher

6 Wahle 1924, VII, dazu Schuchhardt 1924. 
Ansatz in den Kulturwissenschaften gewesen. ${ }^{7}$ Über die vorgeschichtliche Forschung, so schrieb Wahle am Schluß seines Buches Vorgeschicbte des deutschen Volkes von 1924, bestünde die Möglichkeit, den „Wurzeln des deutschen Volkstums nachzugeben", auch wenn das eigentliche „Werden des deutschen Volkes" in die historische Zeit falle. Bei der Unterschiedlichkeit der Quellen wird ein interdisziplinärer Ansatz gefordert, denn „geschichtliche und vorgeschichtliche Forschung [gehören] zusammen". 8 Die Suche nach den Ursprüngen deutschen „Volkstums“ und das Selbstverständnis der Vorgeschichtsforschung als historische Wissenschaft fanden nach Wahle schon Ausdruck im „nationalistischen Gepräge" der „vaterländischen" Altertumskunde des 19. Jahrhunderts, der deshalb sein forschungsgeschichtliches Interesse galt.

Die kulturellen Abgrenzungsprozesse zwischen den Nationen nach 1814 wurden durch die zunächst noch vagen Vorstellungen begünstigt, daß Völker und moderne Nationen als Abstammungsgemeinschaften auch charakterlich und biologisch zu unterscheiden seien. Von Anfang an äußerte sich dies auch in einer Bewertung von Völkern oder Rassen und deren Kulturniveau. Als Protagonist des theoretischen Rassismus gilt Joseph-Arthur Comte de Gobineau, der mit seinem Buch Essai sur l'inégalité des races bumaines (Paris 1853-55) in deutschen Übersetzungen durch Ludwig Schemann (1898 ff.) bis in die Zeit des Nationalsozialismus wirkte. ${ }^{9}$ Für das zunehmend biologistische und archaisierende Verständnis von „Volk“ und „Rasse“ in der zweiten Hälfte des 19. Jahrhunderts wurde bereits ein Kulturpessimismus, wie ihn Fritz Stern diagnostizierte, unter dem Eindruck der Industrialisierung verantwortlich gemacht. Altertumskunde und Anthropologie hatten Einfluß auf den wissenschaftlichen „Rassendiskurs", waren aber andererseits auch seinen Wirkungen ausgesetzt. ${ }^{10}$ Der ab 1850 auch in der Altertumskunde an Bedeutung gewinnende Rassegedanken nahm in der völkischen Vorgeschichtswissenschaft des 20. Jahrhunderts eine zentrale Stellung ein. Der „Langschädel“ galt als germanisches „Rassemerkmal“. Die darwinistische Vorstellung vom ständigen Überlebenskampf der Völker und Rassen, aus dem siegreich nur die Besten hervorgehen konnten, war typisch für die völkische Ideologie und bestimmte auch das Geschichtsbild der deutschen Vorgeschichte. Gustaf Kossinna stand mit seiner Forderung nach einer spezifisch deutschen Altertumskunde schon Ende

Smith 1991, 235.

Wahle 1924, 132-133.

Umfassend hierzu: Sommer/Conze 1984.

10 Wiwjorra 1996, 186-189. 
des 19. Jahrhunderts am Anfang einer radikalnationalistischen völkischen Vorgeschichtswissenschaft. Es sei keinem damit gedient, nur die Schwächen und Mängel Deutschlands zu kennen, „vielmebr sebnen wir uns nach Betonung unseres deutsch-nationalen Volkstums im Gegensatz zu den internationalisierenden Bestrebungen, welche uns unsere gesunde völkische Eigenart zu verwischen droben." 11

Ideologien völkischer Couleur betonten „bei der Bestimmung nationaler Identität die scheinbar natürlichen, angestammten Momente ethnischer, sprachlicher, religiös-kultureller Art wesentlich stärker [...] als die unmittelbar sozialen und bistorischen. " 12 Das Volk als Abstammungsgemeinschaft ist der zentrale Bestandteil völkischer Ideologie, „die Völker als überindividuelle und überbistorische Wesenbeiten mit einer ererbten spezifischen Prägung (Nationalcharakter, bzw. -geist) seben und die Erbaltung des Volkes bzw. seines Charakters böber bewerten als die individuellen Menschenrecbte. ${ }^{\text {"13 }}$ Kurt Sontheimer sah unter den Begriffen rechten verfassungsfeindlichen Denkens den Volksbegriff als den politisch wirksamsten an. Die Inflation im Gebrauch des Volksgedankens und seiner Ableitungen, wie den Vokabeln „völkisch“ und „Volkstum“ zur Zeit der Weimarer Republik, war auf seine zunehmende politische Programmatisierung zurückzuführen und ging dabei mit einem vehementen Antisemitismus einher. ${ }^{14}$ Ein völkischer Extremist des Kaiserreichs, Max Robert Gerstenhauer (1873-1940), ${ }^{15}$ der rassebewußt seinen Kopfindex selbst maß und sich „ganz und gar [als] ein Sobn des thüringischen Volksstammes" betrachtete, schrieb 1933: „Echte völkische Gesinnung schließt konservative Gesinnung in sich, indem sie dabin zielt, die rassischen und geistig-sittlichen Werte der Volkbeit $z u$ erbalten. "16 Solche national-konservativen Wertvorstellungen sah die Rechte durch Demokratie und Republik massiv gefährdet. Das „Völkische“ nahm nach dem Untergang des Kaiserreiches zunehmend den Platz der verherrlichten Monarchie in der gestörten nationalen Identität der Konservativen ein. Vordenker der „konservativen Revolution“ suchten daher im „Volkstum“ die Quelle eines neuen deutschen Nationalbewußtseins ${ }^{17}$ - und genau in diesem

\footnotetext{
11 Kossinna 1912, 84.

12 Hartung 1996, 25.

13 Jansen 1993, 200, Anm. 2.

14 Sontheimer $1994^{4}, 244$.

15 Gerstenhauer war seit 1921 „oberster Leiter des Deutschbunds“; vgl. Gerstenhauer 1933, 63; zum „Deutschbund“: Fricke 1996.

16 Gerstenhauer 1933, 6.

17 Broszat 1958, $59 \mathrm{f}$.
} 
Punkt versuchte sich die deutsche Vorgeschichtswissenschaft $\mathrm{zu}$ profilieren: der Nachweis hehren germanischen "Volkstums“ und seine Tradition mußten Forschungsgegenstand einer deutschen Vorgeschichte sein, die sich den „Forderungen der Gegenwart" stellen wollte.

Völkische Diktion in der Schriftsprache kann als Indikator für die Annahme eines allgemeinen Verfalls traditioneller Werte („Kulturpessimismus“) und "nationaler Opposition“ seit 1918 dienen und gibt damit Hinweise zum Selbstverständnis eines Wissenschaftlers in der Weimarer Zeit. Verschiedene Wissenschaftstexte, Publikationen und Selbstzeugnisse können über eine Zeitspanne von Jahrzehnten hinweg daraufhin untersucht werden. Die völkische Diktion umfaßt Sprachstil, Topoi und Ideologeme, die lange vor 1933 aus der „völkischen Bewegung“ übernommen wurden. Die Betonung des Volksgedankens wird hier stilistisch durch Schwulst und Pathos erreicht. Über Publikationen und Selbstzeugnisse des Wissenschaftlers sind damit nicht nur Rückschlüsse auf seine Sozialisation und Lebenswelt, sondern auch auf seine Sprachhandlungsintention ${ }^{18}$ möglich. Dabei ist hervorzuheben, daß die Veröffentlichung völkischer Diktion in wissenschaftlichen Publikationen vor 1933 nicht mit totalitärem Druck erklärt werden kann, vielmehr als Ausdruck konservativen, antiliberalen und antiwestlichen Selbstverständnisses anzusehen ist.

Die Mentalitätengeschichte hat sich bisher nur wenig mit dem 19. und 20. Jahrhundert befaßt, obwohl für das 20. Jahrhundert Begriffe wie "Zeitgeist" und "Weltanschauung“ wohl gleichartige Dispositionen, möglicherweise aus anderem Blickwinkel, beschreiben sollen. ${ }^{19}$ Die mentalitätsgeschichtlichen Untersuchungen, die weitgehend aus der Schule der Annales hervorgegangen sind, erstreckten sich auf die Bestimmung kognitiver, $d$. h. mehr oder weniger bewußter Vorstellungen, ethischer, d. h. praktischer Verhaltensweisen sowie von Affekten und Sensibilitäten: „Mentalitäten umschreiben kognitive, ethische und affektive Dispositionen. " 20 Es wird davon ausgegangen, daß diese drei Dispositionen auf die Publikationen von Gelehrten gleich welcher Zeit wirkten und wirken und damit wissenschaftsgeschichtlich von Interesse sind. Gerade weniger prominente, über die Fächergrenzen hinaus wirkungslos gebliebene und politisch in der Öffentlichkeit kaum hervorgetretene Wissenschaftler bieten sich für exemplarische Darstellungen des bildungsbürgerlichen Selbstver-

18 Vgl. hierzu Reichmann/Wegera 1988, XI-XII.

19 Raulff $1989^{2}, 11$.

20 Raulff $1989^{2}, 10$. 
ständnisses von Gelehrten in der Zwischenkriegszeit an. ${ }^{21}$ Die deutsche Bürgertumsforschung hat sich der Weimarer Republik nur wenig zugewandt, weil die Annahme besteht, es gebe schon seit dem Systemwandel 1918 kein eigentliches deutsches Bürgertum mehr. Dabei stellt sich die Frage, inwieweit die um sich greifende antibürgerliche völkische Ideologie mit ihrer Forderung nach einer klassenübergreifenden „Volksgemeinschaft" einerseits und die staatsbürgerliche Demokratie andererseits für das Verschwinden des traditionellen Bildungsbürgertums der Kaiserzeit verantwortlich waren. ${ }^{22}$ Die Frage nach der allmählichen Auflösung des Bürgertums als Klasse bis 1933 ist im Hinblick auf das Selbstverständnis der konservativen Gelehrten dieser Zeit, die ja mehrheitlich aus bildungsbürgerlichen Milieus des Kaiserreiches stammten, aufschlußreich.

Am Beispiel des Prähistorikers Ernst Wahle soll versucht werden, den Werdegang eines Wissenschaftlers über archivalische Quellen und eine textkritische Untersuchung seiner Publikationen gesellschafts- und wissenschaftsgeschichtlich zu verfolgen. Eine biographische Skizze vermittelt zunächst einen chronologischen Überblick. Schon vor dem ersten Weltkrieg in Heidelberg studierend, hat Wahle diese Universität auch als Hochschullehrer bis zu seiner Emeritierung nicht verlassen. Anhand der Vorlesungsverzeichnisse und der Quästurakten ließ sich ein umfassender Überblick über die Inhalte der Lehrveranstaltungen erstellen (Anhang). Unter den insgesamt 644 Publikationen Wahles sind 289 teils sehr kurze Rezensionen, der Rest sind monographische Arbeiten und Zeitschriftenaufsätze. ${ }^{23}$ Publikationen, die retrospektiv vom Verfasser selbst als besonders wichtig für die Entwicklung seiner Forschungen herausgestellt wurden oder Hinweise auf sein politisches Selbstverständnis zu geben versprachen, sowie Briefe, Vortragsmanuskripte und andere Selbstzeugnisse wurden auf Inhalte und Diktion hin ausgewertet. Eine autobiographische Selbstdarstellung, die Wahle am 18. Februar 1945 für die Kaiserlich Leopoldinisch-Carolinisch Deutsche Akademie der Naturforscher zu Halle a. S. niederschrieb, zeigt den Werdegang des Verfassers und dessen Selbstverständnis weitaus authentischer, als eine gedruckte Autobiographie von $1980 .^{24}$

\footnotetext{
21 Jansen 1992a, 13.

22 Möller 1997, 299 f., 320-322.

23 Gropengießer 1966, Wahle 1980, 123-125, Gropengießer 1982, 360-361.

24 UBH Heid. Hs. 3989, 1,1, Selbstdarstellung vom 18.2.1945 [liegt in einem hss. und einem masch. Mss. vor]; Wahle 1980.
} 
Bei der Betrachtung von Wahles gesellschaftlichem und politischem Umfeld und der politischen Betätigung von Hochschullehrern an der Universität Heidelberg in der Zwischenkriegszeit waren zwei grundlegende Arbeiten von Christian Jansen unentbehrlich, die sich mit der Lebenswelt und den politischen Denkstilen der Heidelberger Hochschullehrer beschäftigen und eine „Sozialgeschichte der Ideen" anstreben. Der Untersuchung der politischen Denkstile legte Jansen die Wissenssoziologie des Heidelberger Soziologen Karl Mannheim aus den 1920er Jahren zugrunde. ${ }^{25}$

\section{Biographischer Überblick}

Am 25. Mai 1889 wurde Ernst Karl Bernhard Hermann Wahle in Magdeburg geboren und wuchs in einem bildungsbürgerlichen, konservativen und kaisertreuen Elternhaus auf. Er habe, so schrieb er noch 1980, seine „Prägung ganz im kaiserlichen Deutschland erbalten, und so bestimmt sie mein Tun und Lassen auch beute noch". ${ }^{26}$ Der Vater Hermann hatte Mathematik und Naturwissenschaften studiert, promoviert und war Oberlehrer und Schuldirektor an der städtischen evangelischen Realschule im sächsischen Delitzsch, die auch der Sohn besuchte. Schon vor dem Ersten Weltkrieg war Hermann Wahle im Alldeutschen Verband und seinen Filialvereinen (Flottenverein, Kolonialverein, Webrverein), ${ }^{28}$ ferner im Reichsverband gegen die Sozialdemokratie und in der 1917 gegründeten Vaterlandspartei Wolfgang Kapps aktiv geworden. ${ }^{27}$ Der wilhelminische Militarismus prägte die Kindheit Ernst Wahles, und der Vater war dem Sohn „ein Muster von Pflichttreue“. 29 Das "nationale Engagement" seines Vaters hielt Ernst Wahle für unpolitisch, es entspringe aus dem Gefühl der Verpflichtung für die Allgemeinheit, denn er sei Mitglied in „nationalen Verbänden, nicht aber in einer bestimmten politischen Partei" gewesen. „Politische Versammlungen gab es eigentlich nur vor den Wablen, und da trat dann der Vater auch für seine Überzeugung ein, so wie er im Frübjabr 1919 die Deutschnationale Volkspartei mit gründen half und als Vorsitzender in einer

Jansen 1992a, 1992b.

Wahle 1980, 37.

27 UBH Heid. Hs. 3989, Selbstdarstellung 1945, 1-2; UBH Heid. Hs. 3989, 1,1 [autobiographische Notizen].

28 Zum Alldeutschen Verband: Peters 1996, hier 304.

29

Wahle 1980, 45, 111. 
ibrer ersten Veranstaltungen niedergeschrien wurde. Vor dem Weltkrieg war man auch im Reichsverband gegen die Sozialdemokratie tätig, viel Geld ihm gebend und für ibn werbend. " ${ }^{30}$ „So wurde ich“, schrieb Wahle 1945, „im christlich-deutschen Sinne des Beamtenstandes jener Zeit erzogen, in dem Bewußtsein der Ver. pflichtung gegenüber der Allgemeinheit und der Notwendigkeit, sich einmal obne fremde Hilfe im Berufsleben durchzusetzen, in der Treue zu den aus der Vergangenheit überkommenen sittlichen und politischen Werten, zugleich aber auch mit dem Blick auf die Forderungen der Zeit, die sich aus dem Wandel der außenpolitischen Lage wie dem Aufkommen des vierten Standes ergaben. ${ }^{\text {" } 31}$ In ihrem Selbstverständnis als Bildungselite befürchtete auch die Familie Ernst Wahles wie viele andere Angehörige des Bildungsbürgertums eine soziale Deklassierung durch die politische Emanzipation der Arbeiterklasse. Angehörige des protestantischen Bildungs- und Besitzbürgertums waren die eigentliche Trägerschicht des Alldeutschen Verbandes. ${ }^{32}$ In anderen Agitationsverbänden, wie dem Deutschen Webrverein und dem Reichsverband gegen die Sozialdemokratie, kämpfte der bürgerliche Gesinnungsmilitarismus gegen den „inneren Feind“ und pflegte nicht zuletzt auch antisemitisches Gedankengut. ${ }^{33}$ Mit der radikalnationalistischen Einstellung verband sich soziales Engagement während des Ersten Weltkrieges: „Man sab also das soziale Problem, und batte an gelegentlichen Beispielen des tägl[ichen] Lebens die Notwendigkeit, die bestebende Fürsorge zu vergrößern (obne damit die Masse verbätscheln zu wollen). Man sab weiter die großen nationalen Probleme s.[o]zus.[agen] im Alld.[eutschen] Lichte." So engagierte sich Wahles Mutter Anna im Frauenverein: „Besuche zur Ermittlung der soz. Verbältnisse, Essenkochen an best. Wochentagen, Kriegsdienst (es ist in Delitzsch niemand Hungers gestorben, und wer ernstlich nach Arbeit suchte, bat sie immer gefunden). "34 Am „Zusammenbruch" 1918 hätten seine Eltern, so Wahle, besonders schwer getragen.

1908 hatte sich Wahle für Geschichte und Germanistik an der Universität Halle-Wittenberg immatrikuliert. Im gleichen Jahr wechselte er an die Friedrich-Wilhelms-Universität zu Berlin und schrieb sich für das Fach Philosophie ein. Hier besuchte er Lehrveranstaltungen zur Philosophie, Geschichte, An-

30 UBH Heid. Hs. 3989 1,1 [12 Blätter mit autobiographischen Notizen].

31 UBH Heid. Hs. 3989 1,1, Selbstdarstellung 1945, 2-3.

32 Peters 1996, 306.

33 Vgl. Berg (Hrsg.) 1991, 12 ff., 501-503.

34 UBH Heid. Hs. 3989 1,1 [12 Blätter mit autobiographischen Notizen]; vgl. zur bürgerlichen Frauenbewegung und kommunalen Fürsorge: Sachße/Tennstedt 1991, 434-438. 
thropologie, Völkerkunde, Geologie und Geographie, u. a. bei Hans Virchow (1852-1940) und Felix von Luschan (1854-1924), besonders aber bei Gustaf Kossinna und Hubert Schmidt (1864-1933):

WS 1908/09

Römer und Germanen an Rhein und Donau (Kossinna)

Archäologische Uebungen (Kossinna)

Uebersicht über die europäische Vor- und Frühgeschichte (Schmidt)

Uebungen in der vorgeschichtlichen Archäologie (Schmidt)

SS 1909

Vorgeschichtliche Kultur Deutschlands (Kossinna)

Uebungen zur vorgeschichtlichen Archäologie (Kossinna)

WS $1909 / 10$

Das indogermanische Urvolk (Kossinna)

Uebungen über Tacitus Germania (Kossinna)

SS 1910 beurlaubt

WS $1910 / 11$

Geschichte der Bronzezeitkulturen Europas (Kossinna)

Uebungen zur vorgeschichtlichen Archäologie (Kossinna) ${ }^{35}$

In Kossinnas Deutsche Gesellschaft für Vorgeschichte trat Wahle noch im Gründungsjahr 1909 ein. ${ }^{36}$ Der Betonung des "nationalpolitischen Gehaltes der germanischen Frübzeit" mit der Darstellung "altgermanischer Kulturböbe" in Kossinnas völkischen Publikationen ${ }^{37}$ stimmte der junge Wahle $\mathrm{zu}$, obwohl ihm die Einseitigkeit der typologischen Methode oder „Formenkunde" bei einer "geschichtlichen Betrachtungsweise" bald bewußt wurde. ${ }^{38} \mathrm{Da}$ Wahle aufgrund seines Schulabschlusses und der gewünschten Fächerkombination keine Aussicht hatte, in Berlin zur Promotion zugelassen zu werden, wechselte er zum Sommersemester 1911 nach Heidelberg, ${ }^{39}$ wo er sich wiederum im Fach Philosophie immatrikulierte und 1913 bei dem Geographen Alfred Hettner (1859-1941) und dem klassischen Archäologen Friedrich von Duhn (18511930) mit der Arbeit Ostdeutschland in jungneolithischer Zeit, ein präbistorisch-

35 UBH Heid. Hs. 3989 1,2 [Abgangszeugnis].

36 Vgl. den Beitrag von Wolfgang Pape, in diesem Band.

37 Kossinna 1913.

38 UBH Heid. Hs. 3989 1,1, Selbstdarstellung 1945, 21.

39 UBH Heid. Hs. 3989, 1,2 [Abgangszeugnis]. 
geographischer Versuch promoviert wurde. Trotz anfänglicher Abneigung gegenüber dem Verbindungsleben war Wahle seit 1910 im Verein deutscher Studenten, im Deutschvölkischen Studentenverband und im Ostmarkenverein aktiv geworden. ${ }^{40}$ Kurz vor dem Krieg trat Wahle 1913 mit Rezensionen von Gustaf Kossinnas Der germanische Goldreichtum in der Bronzezeit und Heinz Hungerlands Deutsche Stamm-, Sprach-, und Literaturgeschichte in der völkischen Zeitschrift Deutscher Volkswart. Monatsschrift für volksdeutsche Erziebung an die Öffentlichkeit. ${ }^{41}$ Kossinnas völkische Absichten wurden gewürdigt: „Möge das Buch dazu beitragen, die Kenntnis der vorzeitlichen Germanen in weite Schichten unseres Volkes zu tragen, die Verehrung der Vorfabren zu wecken und $z u$ vertiefen, und die Liebe zur alten Stammesheimat zu fördern. ${ }^{\circ 42}$ In radikalere Äußerungen der völkischen Publizistik einzustimmen - wie sie gerade im Deutschen Volkswart begegnen - fühlte sich Wahle offenbar nicht berufen.

Seines schlechten Gesundheitszustandes wegen war Wahle ärztlich abgeraten worden, sich 1914 freiwillig zu melden. ${ }^{43} 1915$ wurde er dann doch zum Kehler Ersatz-Pionierbataillon Nr. 14 eingezogen. Den Krieg machte er in Galizien, vor Ypern und in der Picardie mit, wurde Leutnant d. R. und erhielt das Eiserne Kreuz I. und II. Klasse. ${ }^{44}$ Nach einer schweren Verwundung durch eine englische Handgranate im August 1917 war der Krieg für ihn zu Ende. ${ }^{45}$ In einem Aufsatz in Band 10 der Zeitschrift Mannus von 1918, der Kossinna zu seinem 60 . Geburtstag gewidmet war, stellte Wahle die Einwirkungen des Krieges auf Kulturgüter im allgemeinen und auf die vor- und frühgeschichtlichen Bodenfunde im besonderen dar. Der moderne Krieg greife im Gegensatz zu früheren Kriegen durch Grabennetze und Einbauten leider tief in den Boden ein und in der Kampfzone des Stellungskrieges finde eine „verschieden starke Umwüblung des Bodens durch Geschosse statt. ${ }^{\circ 46}$ „Aber auch die Durchpflügung des Bodens in diesem Maße wird in Schatten gestellt durch die Ver-

40 UBH Heid. Hs. 3989 1,1, Selbstdarstellung 1945, 3; BAB R4901 (Reichsministerium für Erziehung, Wissenschaft und Volksbildung: Kartei aller Hochschullehrer; alt R 21)/10021, dort von der Hand Wahles unter "Mitgliedschaft in nationalen Verbänden ": „Verein deutscher Studenten (seit 1910), Akad. Ortsgruppe des Ostmarkenvereins, Vereinf. d. Deutschtum im Ausland (seit 1920), Offiziersverein Pion. Batl. 14 (seit 1920), SA-Res. (seit Gründung), NSKOV, NS-Kulturgemeinde, Alldeutscher Verband (1916-1925). “

41 Wahle 1913/14a, ders. 1913/14b.

42 Wahle 1913/14a, 159.

43 Wahle 1980, 26.

44 UBH Heid. Hs. 3989, Selbstdarstellung 1945, 8-9.; UBH Heid. Hs. 3989 1,2a.

Wahle 1918a, 118. 
bältnisse, wie sie in den Großkampfgebieten der Westfront seit den Tagen des Sturmes gegen Verdun, an der Somme und der Aisne [...] in Erscheinung getreten sind. Kennzeichen dieser Gebiete ist neben ibrer räumlichen Ausdebnung über ganze weite Landstriche die Stärke der Umwälzung der obersten Erdschicht, welche allen Pflanzenwuchs verschwinden läßt und an seine Stelle den erdfarbenen Ton des locker aufgewüblten, bei feuchter Witterung tief verschlammten Bodens setzt." Wahles Schlußfolgerungen sind bizarr: „Die Überlegung, wieviel vorgeschichtliches Material ein Kampfgebiet bisher geliefert hat und in welchem Maße daselbst der Krieg tobte, läßt relativ vermuten, wieviel wissenschaftliche Werte dort vernichtet worden sind. [...] Der einzige Schutz der noch im Boden rubenden vorgeschichtlichen Denkmäler wird somit in unablässiger, zielbewußter Friedens. arbeit zu suchen sein. ${ }^{\text {c47 }}$ Auch mit dem antiken Topos vom „Krieg als Vater aller Dinge“, der hier bei Wahle durchscheint, war die Jugend des Kaiserreiches zum Krieg erzogen worden. Der Krieg gegen einen gemeinsamen inneren und äußeren Feind hätte die deutsche Nation konsolidieren sollen, die Niederlage wurde von den Völkischen nie akzeptiert und so war für sie der Krieg auch nach Versailles nicht beendet: „Für die Zukunft ist eine Milderung oder gar ein Aufhören der Kriegfübrung nicht zu erwarten ". ${ }^{8}$

1919 publizierte Wahle eine Würdigung Kossinnas in der Zeitschrift Neues Leben. Monatsschrift für Deutsche Wiedergeburt. ${ }^{49}$ Ernst Hunkel, der Herausgeber und Mitbesitzer dieses „deutschgläubigen“ Blattes, war wie Wahle und der bereits erwähnte Gerstenhauer Mitglied im Verein deutscher Studenten gewesen und soll seine völkische Orientierung in dieser Verbindung erhalten haben. ${ }^{50}$ Wie sein Vater war Wahle seit 1916 Mitglied im Alldeutschen Verband und seit 1919 auch in der neugegründeten Deutschnationalen Volkspartei (DNVP) ${ }^{51}$

Schon 1914 war Wahle von der Stadt Heidelberg beauftragt worden, für $200 \mathrm{M}$ im Monat die vor- und frühgeschichtliche Abteilung der städtischen Sammlungen (des späteren Kurpfälzischen Museums) neu einzurichten; eine Arbeit, die er 1919 wiederaufnahm und 1921 beendete. ${ }^{52} 1919$ lud Wahle den Direktor der Römisch-Germanischen Kommision in Frankfurt (RGK), Fried-

\footnotetext{
47 Wahle 1918a, 118-120.

48 Wahle 1918a, 117.

49 Wahle $1918 \mathrm{~b}$.

50 Ulbricht 1996, 293-294.

51 BAB R4901 (Reichsministerium für Erziehung, Wissenschaft und Volksbildung: Kartei aller Hochschullehrer; alt R 21)/10021.

52 Wahle 1980, 25; UBH Heid. Hs. 3989, Selbstdarstellung 1945, 8-9.
} 
rich Koepp (1860-1944), zur Besichtigung der Sammlung ein: „Es mag ja unzeitgemäß erscheinen, gerade jetzt mit derartigen Sachen zu kommen, wo die Aussichten für die Zukunft unseres Volkes immer trüber werden. Allein, es ist wobl immer noch besser, mit allen Plänen sich auf die Möglichkeit besserer Verbältnisse einzustellen, anstatt müßig zu sein. "53

Auf Anregung seiner Lehrer hatte sich Wahle nach dem Krieg entschlossen, die Hochschullaufbahn einzuschlagen und habilitierte sich 1920 mit einer Arbeit über die Besiedlung Südwestdeutschlands in vorrömischer Zeit, wiederum bei Alfred Hettner. ${ }^{54}$ Am 29.4.1920 wurde ihm die Venia legendi für „Prähistorie“ erteilt. ${ }^{55}$ Friedrich von Duhn legte Wahle in Anbetracht seiner angespannten finanziellen Situation 1920 nahe, sich doch um ein Privatdozentenstipendium des badischen Kultusministeriums in Karlsruhe zu bewerben, das freilich nur $3000 \mathrm{M}$ im Jahr betrage. Wahle tue am besten daran, zunächst einmal mit dem Dekan zu sprechen. ${ }^{56}$ Dieser teilte Wahle mit, daß das fragliche Privatdozentenstipendium bisher in noch keinem Falle vergeben worden sei, wie auch seine Höhe nicht feststünde, und er bat Wahle, eine Eingabe unter Darlegung seiner Beweggründe und Verhältnisse an die Fakultät zu richten. ${ }^{57}$ Zusammen mit seinem späteren Schwager, dem Historiker Friedrich Baethgen (1890-1972), war Wahle der erste Stipendiat, der im Wintersemester 1920/21 in den Genuß dieses Privatdozentenstipendiums, später auch Unterhaltszuschuß genannt, in Höhe von $4000 \mathrm{M}$ jährlich kam, ${ }^{58}$ das für bedürftige junge Gelehrte mit „Aussicht auf eine erfolgreiche akademische Lauf. babn" bestimmt war und diesen die Habilitation ermöglichen oder ihre Privatdozentur materiell absichern sollte. ${ }^{59}$ Wahle hatte keinen Lehrauftrag und damit bis auf die Kolleggeldeinnahmen aus seinen Lehrveranstaltungen kein festes Einkommen. ${ }^{60}$ 1920/21 hatte er daher in erheblichen existenziellen

53 ARGK Fasz. 1.268: Prof. Dr. Ernst Wahle, Heidelberg, 1918-42; hs. Postkarte an Koepp (Heidelberg, 21.6.1919).

54 Habilitation in der philosophischen Fakultät für das Fach der Prähistorie, UAH PA 6212, 9, Schwoerer an den engeren Senat der Universität Heidelberg (12.2.1920); Wahle 1921; Wahle 1980, 86-88.

55 UBH Heid. Hs. 3989 1,2 [Urkunde]; UBH Heid. Hs. 3989 2,8 [Handzettel zur Probe-Vorlesung]; Heid. Hs. 3989, Selbstdarstellung 1945, 10.

56 UBH Heid. Hs. 3989, 2,8, Duhn an Wahle (29.10.1920).

57 UBH Heid. Hs. 3989, 2,8, Mitteilung an Wahle (15.11.1920).

58 UAH PA 6212, 15, No. A 22835 Schwoerer an Wahle (24.12.1920). Wahles Privatdozentenstipendium wurde letztmalig 1932 für zwei Jahre gewährt; die Zahlung wurde erst mit seiner Ernennung zum planmäßigen Professor 1934 eingestellt (Wahle 1980, 99).

60 Vgl. Jansen 1992b, $57 \mathrm{ff}$. 
Nöten begonnen, sich auch um die Schaffung einer Stelle in der Bodendenkmalpflege des badischen Staates, beim Ministerium des Kultus und Unterrichts in Karlsruhe, zu bemühen. Dabei wurde er von Hans Rott (1876-1942), dem Direktor des Badischen Landesmuseums, wie auch von Karl Schumacher (1860-1934), dem Direktor des Römisch-Germanischen Zentralmuseums in Mainz, unterstützt. ${ }^{61}$ Wie groß Wahles materielle Not im Jahr 1922 gewesen sein muß, zeigen die freiwilligen Zuwendungen Schumachers in Höhe von $1000 \mathrm{M}$ und weiteren $500 \mathrm{M}$, dazu kam noch eine finanzielle Unterstützung von Wahles Vater. ${ }^{62}$ Wahles Anliegen, beim Staat als Bodendenkmalpfleger Anstellung zu finden, stieß im badischen Kultusministerium, das 1919-1922 von Kultusminister Hermann Hummel (1876-1952) von der Fortschrittlichen Volkspartei geleitet wurde, auf Ablehnung. Nach einer Unterredung mit dem Ministerialreferenten Bartning im Kultusministerium am 14.2.1922 schrieb Wahle an Schumacher, er habe die Sache jetzt satt und werde zu „schärferer Tonart" übergehen: „Ein deutschnationaler Abgeordneter wird bei Besprechung des Haushaltsplanes in der Kommission Gelegenbeit nebmen, in diesen Stall des Augias bineinzuleuchten; ich hoffe eben noch einen Abgeordneten einer zweiten Partei zu gewinnen. ${ }^{\text {" } 33}$

Auch der Freiburger Geologe Wilhelm Deecke (1862-1934) hatte im Frühjahr 1922 auf die seit dem Ausscheiden Ernst Wagners (1832-1920) im Jahr 1919 verwaiste badische Bodendenkmalpflege hingewiesen. Das badische Kultusministerium berief daraufhin einen Ausschuß für die Ur - und Frühgeschichte Badens mit Deecke als Vorsitzendem. Diesem Gremium gehörte, neben dem Freiburger Althistoriker Ernst Fabricius (1857-1942) und dem Humananthropologen und späteren Rassenhygieniker Eugen Fischer (1874-1967), auch Hans Rott an. ${ }^{64}$ Wahle echauffierte sich, daß ihm lediglich der Bereich nördlich der Kinzig zugeteilt worden war und er die Kompetenzen mit dem Freiburger Gymnasialprofessor Friedrich Leonhard (1857-1941), der seit 1899 Mitarbeiter der Reichslimeskommission gewesen war, teilen mußte. Diesem oblag die Zuständigkeit für das Gebiet südlich der Kinzig. ${ }^{65}$ Wahle argwöhnte

61. UBH Heid. Hs. 3989, 2,8, Wahle an Rott (4.4.1920).

62 UBH Heid. Hs. 3989, 2,8, Schumacher an Wahle (2.1.22); Schumacher an Wahle (5.4.22); Wahle an Rott (7.4.22); Wahle an Schumacher (14.4.22).

63 UBH Heid. Hs. 3989, 2,8, Wahle an Schumacher (17.2.1922).

64 UBH Heid. 3989 1,2 [gedruckte Bekanntmachung No. A. 13731]. Vgl. auch Speitkamp 1996, 232-233. Dauber 1983, 49, nennt als Ausschußmitglieder Fabricius, den Klassischen Archäologen Hans Dragendorff (1870-1941) und Karl Schumacher.

Wahle 1980, 76-82. 
hinter der Ernennung Leonhards „Schiebung“, da dieser für die Tätigkeit fachlich gar nicht kompetent sei. Über die „Zweiteilung“ des badischen Zuständigkeitsbereiches sei ihm „von zentrümlichen, also politischen Machen[schaften] Nacbricht zugegangen. ${ }^{\text {"66 } 6} \mathrm{Daß}$ die Aufteilung auf Fabricius' Vorschlag vorgenommen worden war, erfuhr Wahle erst später durch das zeitweilige Gremiumsmitglied Schumacher. Fabricius hatte sich danach direkt bei Bartning im Karlsruher Ministerium für Leonhard eingesetzt und dieser hatte, so Wahle an Schumacher, „obne weiteres zugestimmt, obne an mich zu denken! Übrigens soll das Zentrum gegen Herrn B. Sturm laufen wegen eines Berichtes, den er über Miesmacherei dieser Partei im Jabre 1917 in seiner damal. Dienststellung bei dem Stellv. 14. Generalkommando abgefaßt baben soll. Ob es ibm an den Kragen gebt? Oder ob Demokraten und Sozzen ibn balten? ?67 $^{\text {E }}$ Erst nach über einem Jahr völliger Ungewißheit wurde Wahle 1922 zum Oberpfleger der frühgeschichtlichen Denkmäler im nördlichen Baden bestellt, eine weiterhin völlig ungesicherte Anstellung. Im gleichen Jahr erhielt er einen Lehrauftrag „zur Abbaltung einer zweistündigen Vorlesung über Vorgeschichte und deutsche Archäologie unter Zusage der üblichen Unterrichtsgeldgarantie" an der Universität Heidelberg und bekam damit zu seinen Kolleggeldeinnahmen feste Bezüge. ${ }^{68}$ Er schrieb daraufhin: „Der Lebrauftrag jetzt bringt mich über die unmittelbare Not, aber er ist von einer anderen Abteilung des Ministeriums bearbeitet worden, nämlich von der Hocbschulabteilung, zu der ich volles Vertrauen habe. Die Frage der vorgeschichtlichen Denkmalpflege ist zwar insofern einen Schritt weiter gekommen, als ich jetzt sowohl vom Ministerium wie Landesmuseum alles Einschlägige zur Bearbeitung erbalte; aber die Organisation, meine persönliche Stellung innerbalb dieser und meine Honorierung scbweben immer noch in der Luft. ${ }^{\circ 69}$ Die Vergütung für Wahles bereits im voraus geleistete bodendenkmalpflegerische Arbeit von Oktober bis Ende Dezember 1921 war im Februar 1922 vom Kultusministerium in das bereits erwähnte, mit 4000 Mark jährlich dotierte Privatdozenten-Stipendium umgewandelt worden, das

66 UBH Heid. Hs. 3989, 2,8, Wahle an Schumacher (22.5.1922); Wahle an Schumacher (19.6.1922).

67 UBH Heid. Hs. 3989, 2,8, Wahle an Schumacher (19.6.1922)

68 UAH PA 6212, 19: No. A. 4574, Bartning an Wahle (13.3.1922); UAH PA 6212; 1 [Standesliste]; Wahle schrieb 1930: „Im Frübjabr 1922 wurde die venia legendi in einen Lebrauftrag umgewandelt. " (Wahle 1930a, 226); vgl. auch Jansen 1992b, $61 \mathrm{ff}$.

69 ARGK Fasz. 1.268: Prof. Dr. Ernst Wahle, Heidelberg, 1918-42, maschr. Brief an Koepp (?) (25.3.1922) Eing. 27. III. Nr. 689. 
vermutlich auch erst 1922 rückwirkend gezahlt wurde. ${ }^{70}$ Die festen Bezüge, die Wahle aus seinem Lehrauftrag erhielt, wurden durch ständig erhöhte Teuerungs- und Sonderteuerungszuschläge teils auch rückwirkend der Inflation angepaßt; was diesbezüglich mit dem Privatdozentenstipendium geschah, konnte nicht ermittelt werden. Für seinen Lehrauftrag sollte Wahle im Juli 1923 Bezüge in Höhe von 1.867.375 M erhalten, die im Oktober rückwirkend auf 4.812.250 M angehoben wurden. ${ }^{71}$ Mitte 1923 war die Kaufkraft eines solchen Lehrauftragshonorars fast auf Null gesunken. ${ }^{72}$ Wahles Bezüge wurden 1923 von bisher 70\% der Anfangsbezüge der Besoldungsgruppe X auf $100 \%$ hochgesetzt, wobei die Differenz von $30 \%$ als Entschädigung für die bodendenkmalpflegerische Arbeit Wahles galt. ${ }^{73} \mathrm{Zu}$ der merkwürdigen Verquickung des Lehrauftrages an der Universität mit der bodendenkmalpflegerischen Tätigkeit schrieb Wahle: „Die im Laufe der Zeit eingetretene Beschränkung der staatlichen Mittel bat es mit sich gebracht, daß die Betätigung auf dem Gebiet der Denkmalpflege heute von dem Unterrichtsministerium als eine Voraussetzung für die Finanzierung des Lebrauftrages angeseben wird. "74 Seit 1927 erhielt Wahle eine monatliche Vergütung von $500 \mathrm{RM}$, von denen „350 RM als Privatdozentenstipendium (Unterhaltszuschuß) zwecks Förderung Ibrer wissenschaftlichen Weiterbildung und [...] 150.- RM als teilweise Entschädigung für Ibre Tätigkeit auf dem Gebiete der ur- und frühgeschichtlichen Denkmalpflege anzuseben" seien. Hinzu kam noch eine 1928 bewilligte jährliche „Zusatzvergütung" von 600 RM. ${ }^{75}$ Dem von national-konservativer Seite vorgetragenen Bedürfnis nach der Pflege „deutscher Vorgeschichte“ wollte das Ministerium damit wohl auf möglichst billigem Wege entgegenkommen und die Einrichtung eines Lehrstuhles an der Universität Heidelberg vermeiden. „... die wirtschaftliche Grundlage der Vertretung des Faches" sei, so Wahle 1930, „nur durch die Verbindung der Lebrtätigkeit mit einer anderen Aufgabe [der Bodendenkmalpflege, D. H.] gegeben. "76

70 UBH Heid. Hs. 3989, 1,1, Selbstdarstellung 1945, 10; Heid. Hs. 3989, 2,8; Mitteilung des Kultusministeriums an Wahle vom 8.2.1922; No. A 23762.

71 UAH PA 6212, 23 (No. 21725), 31 (No. 10331), o. N. (No. 9191); UAH PA 6214, No. 17955, jeweils Engerer Senat an die Universitätskasse, die Bezüge des Privatdozenten Dr. Ernst Wahle betreffend (1922-1923). Die Beamtengehälter wurden ab 1. Oktober 1922 vierzehntägig, ab 1. August 1923 wöchentlich erhöht (Jansen 1992b, 69). Jansen 1992b, 70.

73 UAH PA 6212, 33, No. 26646, Mitteilung des Kultusministeriums (Asal) an Wahle (1.10.1923).

74 Wahle 1930b, 226.

75 UAH PA 6212, 69, Schwoerer an Wahle (19.6.1928).

76 Wahle $1930 \mathrm{~b}, 226$. 
Vermutlich war es der Direktor der RGK, Friedrich Koepp, gewesen, der Wahle seines Auftretens dem Ministerialreferenten Bartning gegenüber und möglicherweise seiner politischen Intervention wegen getadelt hatte, denn Wahle schrieb im März 1922 an die RGK: „Da Sie in diesem [Brief] mein Verbalten Hrn. B[artning]. gegenüber gelegentlich der letzten Unterredung der Kritik unterziehen, sei es mir gestattet, in wenigen Sätzen mich zu rechtfertigen. Die Unterredung kann nämlich nicht losgelöst werden von all dem, was ibr im Verlaufe von 10 Monaten und letzten Endes mebreren Jabren vorausging. Das bitte ich der beiliegenden Übersicht entnehmen zu wollen, um deren gelegentliche Rückgabe ich bitten muß. Ich gebe zu, daß ich nicht gerade respektvoll war und so Herrn Althoff7 nicht bätte gegenübertreten dürfen. Mein Verbalten war eine Folgeerscheinung, ein Ausdruck rechtschaffenen Ärgers über neudeutsche Verbältnisse und nicht von einem Temperament geleitet, welches ich gar nicht besitze. [...] Aber seien Sie bitte davon überzeugt, daß man Althoff niemals solche Tatsachen nachgesagt hat, wie Hrn. B[artning], über die ich schweige, nicht, weil sie nicht in einen Brief passen, sondern weil ich zum Schweigen darüber verpflichtet bin. Das alles erklärt vielleicht meine Stellungnabme. "78 Im April 1922 unterrichtete Wahle schließlich Schumacher vom Stand der Dinge und deutete an, daß ihm Prestige wichtiger als Geld sei: „Freilich vermisse ich noch recht die eigentliche Beauftragung durch ein Anstellungsverbältnis; diese betr. Abteilung des Min. arbeitet entsetzlich. Wenn es die Abteilung für Hochschulwesen wäre! Letztere hat mir jüngst einen zweistündigen Lebrauftrag erteilt, auch pekuniär eine kleine Besserung, vor allem aber eine solche, moralischer' Art. Bei der anderen Abteilung aber werde ich noch einige Zeit warten müssen. Ob die parlamentarische Unterstützung etwas nützen wird, fragt sich, da ich die Ehre habe, nur mit der Opposition verschwägert, ${ }^{79} d . h$. bekannt $z u$ sein. Das ist in diesem Falle besonders ärgerlich, als ich gerade von einem Kollegen des Herrn B[artning]. erfuhr, daß dieser Herr wenn sonst nicht, so doch sicher auf parlamentarischen Druck seitens der Mebrheit reagiere. Bis jetzt habe ich es noch nicht fertig gebracht, mit irgendwelchen Kreisen der Demokratie, oder etwa des Zentrums mich in Verbindung zu setzen. Aber es wird mir doch nichts anderes übrig bleiben. ${ }^{180}$ Bis zum Novem-

77 Gemeint ist hier vermutlich der prominente preußische Hochschulpolitiker und -reformer Friedrich Theodor Althoff (1839-1908, vgl. NDB 1, 222-224).

78 ARGK Fasz. 1.268: Prof. Dr. Ernst Wahle, Heidelberg, 1918-42, Wahle an Koepp (?) (25.3.1922) Eing. 27. III Nr. 689.

79 Wahle hatte 1921 die Schwester des in der DNVP aktiven Historikers Friedrich Baethgen geheiratet (Drüll 1986, 282).

80 UBH Heid. Hs. 3989, 2,8, Wahle an Schumacher (4.4.22). 
ber scheint dies erfolglos geblieben zu sein, denn Wahle schrieb im November 1922 an Friedrich Drexel (1885-1930) von der RGK: „Dank Unterstützung von Herrn Fabricius bin ich als Denkmalpfleger äbnlich den preußischen Privatdozenten jetzt gestellt. Weiteres erhoffe ich von einem jüngst in die Wege geleiteten Vorstoß auf politischem Wege. Ich scheute lange vor letzterem, aber die Entwicklung der Dinge seit dem Sommer hat mich dazu gezwungen. " 81

1924 erhielt Wahle einen Ruf an die Deutsche Universität in Prag, worauf ihn der Dekan Friedrich Panzer durch die Beantragung eines planmäßigen Extraordinariates halten wollte. ${ }^{82}$ Der badische Kultusminister Willy Hellpach (1877-1955), ${ }^{83}$ Mitglied der DDP und später ebenfalls Heidelberger Hochschullehrer, lehnte die Bewilligung einer planmäßigen außerordentlichen Professur jedoch $\mathrm{ab}^{84}$ und verlieh nur eine nichtplanmäßige. Es handelte sich also nicht um ein wirkliches Extraordinariat, sondern nur um eine Rangerhöhung, die nicht mit einer festen Anstellung verbunden war. ${ }^{85}$ Normalerweise wurden Privatdozenten erst nach einer sechsjährigen Bewährungsfrist zu außerordentlichen Professoren ernannt. Aber auch ein solches Extraordinariat war eine Beförderung ohne rechtliche und materielle Verbesserungen, denn in der universitären Selbstverwaltung besaßen die Extraordinarien seit 1919 nur ein begrenztes Mitbestimmungsrecht. Neu entstehende Fächer wurden mit planmäßigen Extraordinariaten ausgestattet, die dann später in Lehrstühle umgewandelt werden konnten ${ }^{86}$ - einen Gang, den auch Wahle erhofft hatte, der aber nie Wirklichkeit wurde. Dennoch lehnte Wahle den Ruf an die Deutsche Universität nach Prag erst 1927 ab; vermutlich deshalb, weil in Heidelberg in Anbetrảcht der bereits investierten Vorarbeit für seine

81 ARGK Fasz. 1.268: Prof. Dr. Ernst Wahle, Heidelberg, 1918-42; Wahle an Drexel (29.11.1922).

82 Wahle $1980,89$.

83 Willy Hellpach galt als eher konservativ eingestellter Demokrat innerhalb der linksliberalen DDP und wurde im Nationalsozialismus als vormalige „Systemgröße“ angefeindet. Seit 1922 war er Kultusminister in Karlsruhe, nach der Wahlniederlage der DDP 1925 erhielt er eine ordentliche Honorarprofessur an der Universität Heidelberg (Gundlach 1985, 166-167; Lankenau 1986, 370-371). Zu einer differenzierten Analyse von antiliberalen und antiparlamentarischen Elementen in Hellpachs politischem Wirken künftig Jansen 2000.

84 Vgl. Wahle 1980, 89, 95.

85 Verleihung der Amtsbezeichnung „außerordentlicher Professor": UAH PA 6212, 45, Schwoerer an den Engeren Senat der Universität Heidelberg No. A. 14227 (23.7.1924); vgl. auch die Personalnachrichten im Amtsblatt des Badischen Ministeriums des Kultus und Unterrichts Nr. 36, 8. August 1924, 110. 
Karriere doch bessere Voraussetzungen bestanden. ${ }^{87}$ Bereits 1926 hatte es einen erneuten Versuch von Seiten der Fakultät gegeben, für Wahle ein planmäßiges Extraordinariat zu erhalten - ohne Erfolg. Noch 1932 lehnte das Kultusministerium in Karlsruhe die Einrichtung eines selbständigen Instituts für Vor- und Frühgeschichte ab, weil dafür ein „sachliches Bedürfnis" fehle. ${ }^{88}$ Der Engere Senat ließ daraufhin, dem Wunsch Wahles entsprechend, wenigstens einen eigenständigen Lebrapparat für Vorgeschichte im Vorlesungsverzeichnis führen; ${ }^{89}$ die Lehrveranstaltungen fanden im Archäologischen Institut statt, wo sich auch eine Bibliothek zur Vorgeschichte befand. Erst mit dem Jahr 1933 wurden die Bedingungen für Wahles Karriere günstiger. Der mit Wahle gut bekannte Heidelberger Volkskundler Eugen Fehrle (1880-1957), von dem noch mehrfach die Rede sein wird, beförderte als NS-Hochschulreferent im Kultusministerium Karlsruhe die "deutschkundlichen" Wissenschaften und schrieb im Dezember 1933: „Der bisher dem archäologischen Institut angegliederte ,Vorgeschichtliche Lebrapparat' soll künftig die Bezeichnung ,Lebrstätte für Frühgeschichte' fübren und ab 1. April 1934 unter Leitung des Professors Dr. Wable als solche selbständig bestehen. ${ }^{\circ 90}$ Am 1.12 .1933 trat Wahle dem Nationalsozialistischen Lebrerbund (NSLB) bei, ${ }^{91} 1934$ dann Reinerths Fachgruppe für deutsche Vorgeschichte, die in Rosenbergs Kampfbund für deutsche Kultur organisiert war. ${ }^{92} 1934$ und 1935 verlangte der Rektor Wilhelm Groh (1890-1964), nun „im Hinblick auf die Bedeutung des Faches", so Wahle rückblickend, „den Titel und die akademischen Rechte eines ordentlichen Professors " für ihn. ${ }^{93} \mathrm{Der}$ Wahle nahestehende Indogermanist Hermann Güntert (1886-1948) kam als Dekan bei Groh wiederholt um die Ernennung Wahles zum „persönlichen Ordinarius" ein. Wahle, so Güntert, sei ein anerkannter verdienter Gelehrter, der längst ein Ordinariat verdient habe. „Stets völkisch und national eingestellt,

87 Wahle 1980, 89; vgl. Drüll 1986, 282.

88 UBH Heid. Hs. 3989, 2,8, Kultusministerium an Wahle No. A 5470 (3.4.1932).

89 UBH Heid. Hs. 3989 2,8, Dekan Ernst Hoffmann an Wahle (3.6.1932); Wahle 1980, 97.

90 UAH KE 8, No. A. 31441, Fehrle an die Universitätskasse Heidelberg (13.12.1933).

91 BAB (ehem. BDC), Nr. 285091 [NSLB-Karteikarte]; keine Angabe von Wahles Hand in BAB R 4901 (alt R 21)/10021 [Reichsministerium für Wissenschaft, Erziehung und Volksbildung: Kartei aller Hochschullehrer]; widersprüchliche Angabe in UAH PA 6212, 179.

Vgl. den Beitrag von Wolfgang Pape, in diesem Band. Im Reichsbund für deutsche Vorgescbicbte hatte Wahle nach einem bislang unbestätigten SD-Bericht eine Funktion als Landesleiter inne (ebda., Anm. 16). Der 1929 von Alfred Rosenberg gegründete Kampfbund für deutsche Kultur hatte es sich zur Aufgabe gemacht, die Werte "deutschen Wesens" inmitten des Kulturverfalles zu verteidigen und die „arteigene Äußerung deutschen kulturellen Lebens zu fördern." 
hat er unter der früberen liberalistisch-demokratischen Richtung einiger dem Fach nabestehender Mitglieder der Fakultät sebr zu leiden gehabt und wurde bewußt

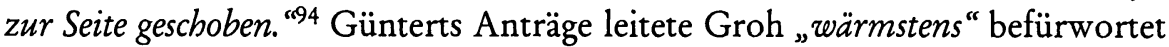
nach Karlsruhe weiter und verwies allerdings darauf, daß „durch die nachgesuchte Umwandlung [des Extraordinariates in ein Ordinariat, D. H.] ein finanzieller Mehraufwand nicht entsteht. ${ }^{95}$ Es sollte sich also lediglich um eine rechtliche und Statusverbesserung handeln, nicht aber um eine finanzielle Höherbewertung. Obwohl kein Ordinarius, wurde Wahle auf den Vorschlag Günterts hin 1935 von der Heidelberger Akademie der Wissenschaften als Mitglied aufgenommen. ${ }^{96}$ Im gleichen Jahr beantragte Güntert bei Groh nur noch ein Extraordinariat. Wahle als Inhaber des Extraordinariates sollten aber die Rechte eines ordentlichen Professors übertragen werden. Den Anträgen für eine Beförderung zum Ordinarius war nach Aussage Fehrles vom Kultusministerium deshalb nicht stattgegeben worden, um „Herrn Professor Wable vor einer möglichen Gegnerschaft zu scbützen. ${ }^{\text {"97 }} 1935$ schließlich erhielt Wahle seine von Gauleiter Robert Wagner unterzeichnete und auf 1934 vordatierte Ernennungsurkunde, die sich allerdings nicht auf eine außerordentliche Professur bezog, sondern nur auf einen „planmäßigen Professor (wissenschaftlichen Hilfsarbeiter)" lautete. ${ }^{98}$ Groh reagierte der Titelzurücksetzung wegen aufgebracht, aber mit dieser Planstelle hatte der mittlerweile 45jährige Wahle erstmals eine gesicherte Anstellung und feste Bezüge. ${ }^{99}$ Verbunden damit war die von Fehrle maßgeblich mit vorangetriebene Einrichtung der Lebrstätte für Frühgeschichte im obersten Stockwerk des neuerrichteten Deutschen Hauses der Universität, ${ }^{100}$ in dem, neben der Germanistik, auch andere politisch motivierte Institutsgründungen, wie die für Volkskunde und für Kriegsgeschichte untergebracht waren. Erst als die badische Hochschulverwaltung an das Deutsche Reich übergegangen ${ }^{101}$ und Groh in das Reichsministerium für Wissen-

94 UAH PA 6212, 89, Güntert an Groh (25.9.1934), UAH PA 6212, 111, Güntert an Groh (29.3.1935).

95 UAH PA 6212, 127, Groh an das Ministerium (21.10.1935).

96 Sitzungsberichte der Heidelberger Akademie der Wissenschaften, Jahresheft 1935/36, V; Wahle 1980, 97-99. Nach der politischen Aufwertung des Faches, so Wennemuth (1994, 381), sei die Wahl Wahles zum Akademie-Mitglied logisch und, anders als im Fall des Volkskundlers Eugen Fehrle, nicht mit politischen Absichten verbunden gewesen.

98 UBH Heid. Hs. 3989, 1,2 [Ernennungsurkunde] (18.6.1934).

99 UBH Heid. Hs. 3989, 1,1, Selbstdarstellung 1945, 10; Wahle 1980, 99.

100 UBH Heid. Hs. 3989, 1,1, Selbstdarstellung 1945, 11; Wahle 1980, 100.

101 UBH Heid. Hs. 3989, 1,1, Selbstdarstellung 1945, 10. 
schaft, Erziebung und Volksbildung nach Berlin aufgestiegen war, ${ }^{102}$ wurde der "wissenschaftliche[n] Hilfarbeiter, nichtbeamtete[n] außerordentliche Professor" 1937 vom „Fübrer und Reichskanzler" zum „außerordentlichen Professor" ernannt. ${ }^{103} 1938$ wurde Wahle das ,neu errichtete planmäßige Extraordinariat für Vor- und Frühgeschichte" verliehen; gleichzeitig wurde er offiziell zum Leiter „der Lebrstätte für Frühgeschichte der Universität Heidelberg“ ernannt. ${ }^{104}$ Erst jetzt gab Wahle seine Tätigkeit in der badischen Bodendenkmalpflege auf. Die fortgesetzten Bemühungen der Fakultät, für Wahle ein Ordinariat zu erhalten, scheiterten offenbar aber weiterhin am badischen Kultusministerium. ${ }^{105}$ Wegen des Aufnahmestops von 1933 war Wahle wie viele andere Prähistoriker erst 1937 in die NSDAP eingetreten, ${ }^{106}$ und erst 1944 wurde er Beamter auf Lebenszeit. ${ }^{107}$ Ein Ordinariat hatte er damit aber noch immer nicht erhalten. Im gleichen Jahr nahm ihn die Kaiserlich Leopoldiniscb-Carolinisch Deutsche Akademie der Naturforscher zu Halle a. S. als Mitglied auf. ${ }^{108} \mathrm{Gemäß} \mathrm{dem}$ Erlaß der amerikanischen Militärregierung wurde Wahle 1945 entlassen, aber nach seiner Entnazifizierung 1946 wiedereingesetzt. ${ }^{109}$ Noch zehn Jahre lehrte der Prähistoriker an der Universität. ${ }^{110} 1957$ emeritiert, starb Ernst Wahle am 21.1.1981 im Alter von 91 Jahren in Heidelberg.

\section{Gelehrte Kollegen, Politik und Gesellschaft}

Die kriegserfahrenen jüngeren Akademiker aus Wahles Generation fühlten sich nach Versailles in ihrem nationalen und gesellschaftlichen Selbstbewußt-

102 Wolgast 1986, 151-152.

103 UBH Heid. Hs. 3989, 1,2 [von Hitler und Rust unterzeichnete Ernennungsurkunde vom 16.6.1937].

104 UBH Heid. Hs. 3989, 2,8, Mitteilung des Reichs- und Preußischen Ministers für Wissenschaft, Erziebung und Volksbildung an Wahle (15.1.38) Geschäftszeichen WP 34, Vb (a); Wahle 1980, 102-103.

105 UBH Heid. Hs. 3989, 1,1, Selbstdarstellung, 10.

106 BAB (ehem. BDC), NSDAP-Mitgliederkartei Nr. 5055159 (danach wurde die Aufnahme erst am 29.10.1937 beantragt); vgl. auch den Beitrag von Wolfgang Pape, in diesem Band.

107 UBH Heid. Hs. 3989, 2,8, Mitteilung des Reichsministeriums für Erziebung, Wissenschaft und Volksbildung (7.6.44) und des Rektors (12.7.44); BAB (ehem. BDC), Kartei des Reichserziehungsministeriums (Karteikarte „Personalakte W 323\%), Antrag vom 22.2.44 des „Bad. Min. Straßburg“.

108 UBH Heid. Hs. 3989 1,2, Präsident Emil Abderhalden an Wahle (27.4.1944).

109 UAH PA 6213, Spruch der Berufungskammer Heidelberg, Az. 59/4/4507, 2736 (15.1.1947); vgl. Drüll 1986, 282.

110 Zur Zeit nach 1945 vgl. unter 7. 
sein nachhaltig gekränkt. Als Universitätsangehörige waren sie meistens Repräsentanten des 1918 abgeschafften gesellschaftlichen wie politischen Systems. Diese konservativen Intellektuellen verklärten die Monarchie, lehnten die Moderne $\mathrm{ab}$ und ihre restaurative Haltung fand Ausdruck in einer nationalen Opposition, die vehement gegen Demokratie und Republik gerichtet war. Solche Hochschullehrer, die oft schon als Studenten und vor dem Krieg in "alldeutschen" und „völkischen" Vereinigungen gewesen waren, fanden in der 1919 gegründeten radikal-nationalistischen und antisemitischen Deutschnationalen Volkspartei (DNVP) eine politische Heimat. ${ }^{111}$

Die schwierige wirtschaftliche Situation der jüngeren Hochschullehrer nach dem Krieg und die Demütigung ihres Selbstverständnisses als vormalige Bildungselite begünstigten verfassungsfeindliche Haltungen. Die auf der untersten Stufe der Universitätshierachie stehenden außerplanmäßigen Nichtordinarien hatte keine festen Bezüge, sondern erhielten nur die Kolleggelder, die die Studenten für den Besuch der Lehrveranstaltungen zu zahlen hatten. Die Einnahmen dieser Dozenten waren daher von der Frequentierung ihrer Lehrveranstaltungen und damit von ihrer Beliebtheit und der ihres Faches abhängig. Wenn so auch einige Nichtordinarien an den Kolleggeldern sehr gut verdienten, so lagen die Kolleggeldeinahmen der meisten Dozenten doch bei unter 1000 RM im Jahr. ${ }^{112}$ Das unetablierte Fach der Vorgeschichte war in dieser Hinsicht natürlich sehr wenig lukrativ. Wahle erhielt an Kolleggeldern $180 \mathrm{M}$ im SS 1920, $212 \mathrm{M}$ im WS 1920/21, $201 \mathrm{M}$ im SS 1921 und $300 \mathrm{M}$ im WS 1921/22. ${ }^{113}$ Privatdozenten ohne Lehrauftrag waren daher für ihr Auskommen auf die Bewilligung von Privatdozentenstipendien angewiesen, wie ja auch Wahle im Jahr 1921 unter den ersten Heidelberger Stipendiaten gewesen war. Der mit Wahle gut bekannte Privatdozent der Philosophie Hermann Glockner (1896-1979) gehörte zu den späteren Stipendiaten: er lebte mit seiner Frau in zwei Zimmern ohne fließendes Wasser; die Hälfte des Stipendiums mußte für die Miete ausgegeben werden, und die Anschaffung von Büchern war ihm erst möglich, als er Japaner unterrichtete. ${ }^{114}$ Privatdozenten und außerordentliche Professoren mit einem Lehrauftrag erhielten neben den Kolleggeldern auch feste Bezüge (Lehrauftragshonorare), wie Wahle ab 1922.

111 Hierzu Ringer 1987, 186-187.

112 Jansen 1992b, 66 mit Tabelle 27.

113 UAH Rep. 27/1373 [Quästurakten].

114 Jansen 1992b, 61-66. 
Die Inflation verschlechterte die materielle Situation aller Hochschullehrer. Bücher wurden zu Luxusgütern und an Publikationen war oft gar nicht zu denken. ${ }^{115}$ Während der Inflationszeit fragte Wahle bei der RGK wiederholt um die Zusendung von Besprechungsexemplaren oder Publikationen zu ermäBigtem Preis an: „Hoffentlich nebmen Sie es mir nicht übel, wenn ich diesen Zeilen etwas sebr materielles angliedere, was mir schon einige Zeit am Herzen liegt. Bücher kann ich mir schon längere Zeit nicht mebr kaufen und finde so manche bösen Lücken (!) in meiner Bücherei. Sollte das eine oder andere der von mir zu nennenden Werke Ibnen zur Besprechung in der Germania geeignet erscheinen, dann ist es Ibnen vielleicht möglich, mir diese zuzuwenden. "116 Auf Dozenten ohne Planstelle wie Wahle wirkte sich die Inflation materiell, gesellschaftlich und psychologisch viel gravierender aus, als auf die abgesicherten Ordinarien, die lediglich ihren Lebensstil hatten einschränken müssen, aber deshalb nicht weniger unzufrieden waren. ${ }^{117}$ Zwar waren 1923 die Ersparnisse aller Heidelberger Hochschullehrer dahin, ihre Bezüge aber stiegen nach der Währungsreform so rapide an, daß sie für Assistenten noch 1923, für die Ordinarien 1926 nominell Vorkriegsniveau erreichten. Vom wirtschaftlichen Aufschwung in den "guten Jahren" der Republik profitierten die meisten Hochschullehrer überdurchschnittlich. ${ }^{118}$ Auf die Lehrauftragshonorare außerplanmäßiger Nichtordinarien wie Wahle wirkten sich diese Gehaltserhöhungen nach der Währungsreform allerdings nicht aus. ${ }^{119}$

Auch wenn Inflation und Weltwirtschaftskrise für alle Hochschullehrer weitaus weniger folgenreich gewesen waren als für andere Bevölkerungsschichten, ${ }^{120}$ so wirkten die Krisen der 1920er Jahre besonders auf Leben und Forschung der Nichtordinarien stark politisierend - sie fühlten sich allgemein vom demokratischen Staat benachteiligt. Durch Existenzangst und als nicht voll akzeptierte und in die Universitätshierarchie integrierte Dozenten ließen sich gerade viele Nichtordinarien in eine Außenseiterrolle drängen. Der linksliberale Heidelberger Soziologe Karl Mannheim hatte in solchen außenseiterischen Intellektuellen potentielle Träger faschistischer Ideologie ausgemacht. Radikaler Organizismus, Nationalismus, völkisches Denken, Irrationalismus

115 Ringer 1987, 63.

116 ARGK Fasz. 1.268: Prof. Dr. Ernst Wahle, Heidelberg, 1918-42, Wahle an Drexel (?) (7.5.1923).

117 Ringer 1987, 62-63.

118 Jansen 1992a, 29; ders. 1992b, 69.

119 Vgl. Jansen 1992b, 68, Tabelle 28 (Spalten e und f).

120 Jansen 1992a, 29-30. 
und Führerkult als faschistische Ideologeme finden sich jedoch bei vielen Gelehrten der Zeit, ohne daß diese sich dadurch schon eindeutig einer rechten politischen Gruppierung zuordnen ließen. Auch in konservativen und liberalen Kreisen war solches Denken anzutreffen. Ein Zusammenhang zwischen dem Denkstil eines Hochschullehrers und seiner Parteipräferenz ist nach kollektivbiographischen Untersuchungen aber eindeutig belegbar. ${ }^{121}$

$\mathrm{Da}$ die privilegierte Stellung der kaiserzeitlichen Bildungselite in der Republik nivelliert worden war, blickten viele Gelehrte auf die Zeit des Kaiserreichs als eine "gute alte Zeit" zurück, kritisierten den neuen Staat und die moderne Gegenwart. So äußerte auch Wahle 1922: „Ich bänge an der Vergangenbeit, die man uns zerstört hat, und empfinde es als schmerzlich, daß eine wirkliche ,Regierung' feblt. "122 Die akademische Laufbahn dieser kulturpessimistischen Akademiker widersprach ihrem außenseiterischen Selbstverständnis aber durchaus. ${ }^{123}$ Mit einem Alter von 24 Jahren promoviert und mit 30 Jahren habilitiert lag Ernst Wahle schon unter den entsprechenden Durchschnittsaltern seiner Gelehrtengeneration (1882-1891); zwischen dem Erhalt der venia legendi und dem nichtplanmäßigen Extraordinariat lagen nur vier, statt durchschnittlich sechs Jahre. ${ }^{124}$ Der Krieg und die schwierigen wirtschaftlichen Bedingungen hatten sich offenbar auch auf Wahles Karriere letztendlich nicht nachteilig ausgewirkt. Die Gründe für die Hemmnisse in seiner Laufbahn in der Weimarer Republik, besonders für die Verweigerung des Ordinariates, lagen mehr in der geringen Bedeutung seines Faches und dessen völkischem Legitimationszwang, als in den ökonomischen Umständen der Zeit, wie unten noch zu zeigen sein wird.

Sowohl Wahle als auch sein Schwager Friedrich Baethgen waren Mitglieder der DNVP, ${ }^{125}$ deren Aufbau in Baden jedoch nur schleppend verlaufen war. Bei den Wahlen zur verfassungsgebenden Landesversammlung 1919 errang die Partei nur 7,03\% der Stimmen. Während sich im Reichstag die Abgeordneten der DNVP geschlossen gegen die Weimarer Verfassung aussprachen, stimmten ihre Abgeordneten im badischen Landtag für sie. ${ }^{126}$. Seit 1925 saß für die

121 Jansen 1992a, 67-69, mit Tabelle 4.

122 ARGK Fasz. 1.268: Prof. Dr. Ernst Wahle, Heidelberg, 1918-42, Wahle an Koepp (?) (25.3.1922).

123 Vgl. Jansen 1992a, 22-23.

124 Vgl. Jansen 1992b, 31, Tabelle 15.

125 Wahle war nach eigenen Angaben von 1919-26 Mitglied dieser Partei (BAB R 4901 [Reichsministerium für Erziehung, Wissenschaft und Volksbildung: Kartei aller Hochschullehrer]).

126 Trippe 1995, 56-57. 
DNVP der Heidelberger Historiker Paul Schmitthenner (1884-1963) im badischen Landtag, der einen strikt republikfeindlichen Kurs verfocht und das parlamentarische System verunglimpfte. ${ }^{127}$ Im Heidelberger Parteiorgan der DNVP, der Deutschen Zukunft, erschien 1924 auch eine Rezension von Wahles Buch Vorgeschichte des deutschen Volkes, in der es u. a. heißt: „Die Unkenntnis auch des gebildeten Deutschen über unsere Vorgeschichte ist groß. In Zeitungen und Zeitschriften liest man die abenteuerlichsten Hypothesen, meist stark gefärbt von der nicht völkischen oder auch . ${ }^{128}$ völkischen Einstellung des Verfassers. Im Gegensatz hierzu zeigt uns das vorliegende Buch unsere Kenntnisse, aber auch ibre Grenzen nach den Ergebnissen der heutigen Forschungsarbeit. - Wir Deutsche können das Buch mit Stolz lesen. Es sei warm empfoblen" (Auslassung und Hervorhebung original). ${ }^{129}$ Die Übernahme der von Wahle 1925 begründeten $\mathrm{Ba}$ dischen Fundberichte als Amtsblatt durch das badische Kultusministerium war der Deutschen Zukunft eine Notiz in der Ausgabe vom 5.7.1926 wert. ${ }^{130}$

Seine Wissenschaft, die deutsche Vorgeschichte, sah Wahle in der Weimarer Republik als ein seiner Ansicht nach nationales Anliegen zu wenig staatlich gefördert, die klassische Archäologie dagegen, wie schon in der zweiten Hälfte des 19. Jahrhunderts unter der Vorherrschaft eines neuhumanistischen Bildungsideals, bevorteilt. Obwohl Wahle die Möglichkeit bekommen hatte, seine Habilitationsschrift in den Berichten der RGK zu veröffentlichen und seit 1923 als korrespondierendes Mitglied dem Deutschen Archäologischen Institut (DAI) verbunden war, ${ }^{131}$ schrieb er 1934 rückblickend, durch die Vereinnahmung von Inhalten der Vorgeschichte strebe man im „Novemberstaat" danach, die Arbeit und den Machtbereich der RGK und des DAI „... durch die Einrichtung einer, Kommission für ostdeutsche Vorgeschichte` und

127 Schmitthenner, der 1934 wohl noch als DNVP-Parteimitglied in die NSDAP eingetreten war und den Rang eines SS-Brigadeführers erreichte, war auch der letzte Rektor der nationalsozialistischen Universität Heidelberg (Lennartz 1997, 626-629).

128 Beide Gedankenstriche in der Vorlage.

129 Deutsche Zukunft, 5. Jahrgang, 5. Oktober 1924, S. 163.

130 Dort heißt es auf S. 103 unter der Überschrift Politisches Mosaik: „Die von Prof. Dr. Wable Heidelberg begründeten und bisher herausgegebenen,Badischen Fundberichte sind von dem badi. schen Kultusministerium als ,Amtl. Nachrichtenblatt für die ur. und frühgeschichtliche Forschung' übernommen. (Schriftleiter: Geh. Rat Prof. Dr. Deecke, Freiburg)."

131 UBH Heid. Hs. 3989, 1,1 Selbstdarstellung 1945, 26. Als Wahle 1954 zum ordentlichen Mitglied des DAI ernannt werden sollte, äußerte er Bedenken und trat 1959 ganz aus - sehr wahrscheinlich eine ressentimentgeladene Nachwirkung seines Konflikts mit dieser Fachinstitution in der Vorkriegszeit (vgl. den Beitrag von Wolfgang Pape, in diesem Band). 
eines, Referates für nordische und östliche Vor-und Frühgeschichte" auf das ganze Reich auszudehnen. Wahle argwöhnte in dieser „organisatorischen Maßnabme“ des „Novemberstaats“ ein „Gegengewicht gegenüber der völkischen Richtung Kossinnas". ${ }^{132}$ Die deutsche Vorgeschichtsforschung werde nämlich in das „internationale Gebäude der ,Altertumskunde“ eingebaut, die „Füblung“ mit der Volks- und Kulturbodenforschung fehle vollkommen, „und da dem [Deutschen Archäologischen] Institut ein, völkerverbindender Charakter' innewobnt, so findet es um diese Zeit die lebhafte Unterstützung des Reichsaußenministers Stresemann. ${ }^{\text {"133 }}$

$\mathrm{Da}$ es neben den fachlichen auch große persönliche Differenzen zwischen Wahle und seinem „Hausherren“ im Archäologischen Institut, dem klassischen Archäologen Ludwig Curtius (1874-1954), gab, bevor dieser 1928 die Universität Heidelberg verließ und Direktor des DAI in Rom wurde, kann kaum verwundern. ${ }^{134}$ Curtius war Anfang der zwanziger Jahre zwar ebenfalls in der DNVP aktiv geworden und ein Sympathisant des italienischen Faschismus. ${ }^{135}$ Trotz seiner deutsch-nationalen Gesinnung stand er dem Nationalsozialismus ablehnend gegenüber, ${ }^{136}$ wenngleich er später nach außen hin offenbar Loyalität demonstrierte. ${ }^{137}$ Curtius hielt wohl den Gegenstand der völkischen Prähistorie Wahles für kaum vergleichbar mit den Schönheiten der klassischen Antike. Wenn Curtius als Forschungsgegenstand der völkischen Prähistorie primitives Barbarentum ansah, so deckte sich das offenbar mit seiner späteren Einschätzung des Nationalsozialismus. ${ }^{138}$ Gelehrte, „denen das Gefübl für das Erfassen geschichtlicher künstlerischer Charaktere von Völkern oder Einzelpersönlichkeiten feblt", verachtete er. ${ }^{139}$ So hatte er auch Wahle vor Gustaf Kossinna als dem „Vertreter einer höchst unklaren Romantik“ gewarnt und empfahl ihm 1927 süffisant, „endlich Füblung mit dem Institut“ zu suchen,

132 Wahle 1934, 9.

133 Wahle 1934, 10.

134 Faber 1995.

135 Curtius 1934.

136 „Das Nazitum fing nach 1923 an, sich in unseren eigenen deutschnationalen Reiben auszubreiten." (Curtius 1950, 382)

137 Junker 1997, 40.

138 Curtius äußerte sich Wahle gegenüber abfällig über dessen Fach, vgl. Wahle 1980, 91; Rosenberg schrieb in Sachen DAI an Martin Bormann (4.2.1936): „Der Leiter des Zweiginstituts in Rom, Prof. Curtius, ist ein typischer Vertreter des Liberalismus. Er hat keinerlei Hehl daraus gemacht, daß er den Nationalsozialismus persönlich und als Künstler als Barbarei ansebe ... " (zit. nach Bollmus 1970, 307, Anm. 61a).

Zit. nach Faber 1995, 138. 
denn sonst müsse er "lange warten". ${ }^{140}$ Wahle nannte Curtius „deutlich von Frankfurt infiziert" und schrieb es seinem Einfluß bei der RGK und beim Kultusministerium in Karlsruhe zu, daß er lange nicht über eine außerplanmäßige Professur hinauskam. Seine Beförderung zum planmäßigen außerordentlichen Professor hätte die RGK versucht zu vereiteln, und Curtius nannte Wahle gegenüber schon den Namen seines Nachfolgers. ${ }^{141}$ Aus den Korrespondenzen ist allerdings eine Verstimmung Wahles gegenüber der RGK, die er noch über 50 Jahre später so verbittert zu beschreiben imstande ist, zu dieser Zeit nicht zu erkennen. Die Briefe Wahles an Friedrich Drexel waren, schon bevor dieser 1924 Direktor der RGK wurde, stets höflich, fast freundschaftlich gehalten. Für die Jahre 1925-29 ist bisher allerdings kein Briefwechsel nachzuweisen. Neben dem von Wahle als intrigant beschriebenen Verhalten Curtius' spielte in der zunehmenden Verstimmung Wahles gegenüber DAI und RGK offenbar auch seine denkmalpflegerische Tätigkeit eine Rolle, denn er erwähnte mehrfach negativ das Aufsichtsrecht und den zunehmenden Machtanspruch der RGK in den 1920er Jahren. Dem DAI wie der RGK warf er vor, einem „dritten Humanismus zu buldigen", die Antike anstatt „bodenständigen Faktoren" als "ausschlaggebende Kraft für die Geschichte des Nordens" hinzustellen und so unzeitgemäß überholte humanistische Bildungsideale zu pflegen. ${ }^{142}$ Wahles heftige Stellungnahmen gegenüber der klassischen Archäologie nach 1933 fallen mit seinem Eintritt in Reinerths Fachgruppe für deutsche Vorgeschichte im Kampfbund für deutsche Kultur 1934 zusammen, wie auch seine Angriffe denen Reinerths für die „Belange einer nationalen deutschen Vorgeschichte" sehr ähnlich sind. ${ }^{143}$

Die Vermutung Wahles, die Ablehnung eines Ordinariates für deutsche Vorgeschichte 1924 sei auch auf den Einfluß Curtius' im Kultusministerium zurückzuführen, war vermutlich berechtigt. Curtius hatte als Freund Alfred Webers gute Kontakte zu Victor Schwoerer (1865-?), dem Referenten für Universitätsangelegenheiten im badischen Kultusministerium in Karlsruhe. ${ }^{144}$

140 Wahle 1934, 10; vgl. Wahle 1980, 91, dort schreibt Wahle, er wäre eines Tages von Curtius (dessen Namen er übrigens niemals nennt) gemahnt worden, seine „Beziebungen zur RömischGermanischen Kommission in Frankfurt enger zu gestalten, denn, sonst müsse ich lange warten ““.

141 Wahle 1980, 91-93.

142 UBH Heid. Hs. 3989, 1,1, Selbstdarstellung 1945, 26.

143 Bollmus 1970, 154.

144 Curtius 1950, 373-374. Wie Hellpach soll auch Schwoerer eine Schwäche „ü̈r Fachgelebrte mit bobem Eigendünkel, die sich selber böchst wichtig nebmen, in ibrer Fakultät sich zu Herren auf. werfen und in allen Berufungsfragen dreinreden" gehabt haben (zitiert nach Demm 1999, 77). 
Nachdem Wahle den Ruf an die Deutsche Universität in Prag erhalten hatte, schrieb ihm der Dekan Curtius, er hätte sich bei Schwoerer für ihn eingesetzt, jedoch die Antwort erhalten, daß „die Errichtung einer Professur für deutsche Vorgeschichte am Widerstand des Finanzministers und der Concurrenz anderer abgebauter, aber wiederzuerrichtender Professuren scheitere. "Doch scheine der Ministerialreferent zu wesentlichen Gehaltsaufbesserungen bereit. Scheinheilig äußerte Curtius abschließend_den Wunsch, „dass es gelingen moege, Sie uns bier zu erhalten. "145 Zudem schrieb offenbar Max Ebert 1925 aus Königsberg an Wahle, gegen ihn, Wahle, würde in Süddeutschland systematisch Stimmung gemacht. ${ }^{146}$ Nachdem die Fakultät 1926 einen erneuten Vorstoß unternommen hatte, Wahle ein Extraordinariat zu verschaffen, sprachen sich auf einer Fakultätskonferenz im Juli 19276 von 7 Professoren für die Beförderung aus, nur Curtius stimmte dagegen. ${ }^{147}$

Von 1922-1926 wohnte das Ehepaar Wahle zusammen mit dem ledigen Curtius in einer Hausgemeinschaft im Palais Weimar (Hauptstraße 235), in dem dann ab 1927 das Institut für Sozial- und Staatswissenschaften Alfred Webers und Emil Lederers untergebracht war. ${ }^{148}$ Während Wahle auszog, blieb Curtius im Hause wohnen. Er gehörte zum engeren Freundeskreis von Marianne und Alfred Weber, nahm an deren Diskussionszirkeln im Palais Weimar teil, wie diese auch seinen "Salon" besuchten. ${ }^{149}$

Der am Institut für Sozial-und Staatswissenschaften lehrende Statistikdozent Emil Julius Gumbel (1891-1966) soll an dieser Stelle am Rande interessieren, da die Resolutionen zur „Affäre Gumbel“ zu einem Indikator des politischen Selbstverständnisses der Heidelberger Hochschullehrer wurden. ${ }^{150}$ Ein Zeugnis Ernst Wahles zur „Affäre Gumbel“ gibt es jedoch nicht. Gumbel war überzeugter Pazifist und Mitglied in der SPD. Er hatte seit 1924 u. a. wiederholt verkündet, in Anbetracht der 700000 zivilen Hungertoten des Ersten Weltkrieges eigne sich eine große Kohlrübe besser als Kriegerdenkmal als eine leichtbekleidete Jungfrau mit Siegespalmen. ${ }^{151}$ Die Hungertoten waren auch

145 UBH Heid. Hs. 3989 2,8, Curtius an Wahle (2.8.1925).

146 Wahle 1980, 92.

147 Wahle 1980, 95.

148 Vgl. hierzu: Jansen 1997. Wahle war bereits 1926 nach Rohrbach, in die Gartenstraße 18 gezogen (Verzeichnis der Vorlesungen sowie der Dozenten, Bebörden und Institute der Badischen Ruprecht-Karls-Universität zu Heidelberg, SH 1926, 48. Heidelberg 1926).

149 Demm 1999, 15, 19, bes. 64.

150 Heiber 1991, 67-82; Jansen 1991.

151 Jansen 1991, 35 mit Anm. 107. 
im Bewußtsein Wahles, der sie jedoch als Opfer der alliierten „Hungerblockade" sah. ${ }^{152}$ Gumbels Äußerung, die Toten des Weltkrieges seien auf dem Felde der Unehre gefallen, zog 1924 ein Disziplinarverfahren und seine Suspendierung nach sich. Der badische Kultusminister Willy Hellpach (DDP) hob die Suspendierung auf, nachdem Gumbel seine Äußerung bedauert hatte, und die Fakultät verzichtete daraufhin auf den Entzug der Venia legendi. Der bereits erwähnte Schwager Wahles, Friedrich Baethgen (DNVP), gehörte zusammen mit Karl Jaspers (DDP) und dem Juristen Alexander zu Dohna (DVP) dem dreiköpfigen Disziplinarausschuß der Fakultät an (der zu dieser Zeit Curtius als Dekan vorstand), der mit dem „Fall Gumbel“ befaßt war. Im Gegensatz zu Jaspers sprachen sich Baethgen und von Dohna ablehnend aus, doch sah man keine Handhabe für einen Entzug von Gumbels Lehrberechtigung. ${ }^{153}$ 1932, nach neuerlichen pazifistischen Äußerungen Gumbels und der Denunziation von Studenten, entzogen ihm Fakultät, Senat und der Kultusminister Eugen Baumgartner (Zentrum) endgültig die Venia legendi. Zumal jüdischer Konfession, konnte Gumbel schließlich 1933 von einem Lehraufenthalt in Paris nicht mehr nach Heidelberg zurückkehren. Sein Haus wurde von Studenten geplündert, seine Bibliothek verbrannt.

In Wahles bevorzugtem Kollegenkreis dominierten während der Weimarer Republik Gelehrte mit konservativer und deutsch-nationaler Geisteshaltung. Zusammen mit dem Philosophen Hermann Glockner und dem Indogermanisten Hermann Güntert ${ }^{154}$ gehörte Ernst Wahle zu einer Gruppe jüngerer Nichtordinarien, die sich den Namen Incalcata (die unverkalkte Akademie) gegeben hatte. ${ }^{155}$ Hier handelte es sich um eine lose Gruppierung fast ausnahmslos verfassungsfeindlicher Gelehrter, ${ }^{156}$ obwohl der Philosophiedozent Erich Rothacker, der auch zu diesem Zirkel gehört hatte, später behauptete, sie seien "politisch und fraktionell neutral" gewesen. ${ }^{157}$ Neben dem Germanisten Friedrich Panzer (1870-1956) nahmen offenbar auch dessen Sohn, der Geograph Wolfgang Panzer (1896-1983), ${ }^{158}$ Friedrich Baethgen, dessen Fach-

152 Wahle erwähnt in seiner Autobiographie, ein Mädchen im Hause seiner Eltern sei an der "Hungerblockade" gestorben (Wahle 1980, 45).

153 Jansen 1992a, $190 \mathrm{f}$.

154 Zu Güntert: Meid 1974; Drüll 1986, 94-95.

155 Rothacker 1963, 70 f., Glockner (1973, 163 f.) nennt den Namen Incalcata in seiner Erinnerung an diese Gruppe nicht.

156 Jansen 1992a, 41.

157 Rothacker 1963, 70.

158 Vgl. Fahlbusch 1999, 359. Wolfgang Panzer hatte im SS 1920 und im WS 1924/25 bei Wahle gehört (UAH Rep. 27/1373 [Quästurakten]). 
kollege Percy Ernst Schramm (1894-1970), der Volkskundler Eugen Fehrle, der Kunsthistoriker Hubert Schrade (1900-1967) und der Germanist Hans Teske (1902-?) ${ }^{159}$ an den Diskussionsrunden teil. ${ }^{160}$ In diesem Kreis finden wir auch den Doktorvater von Joseph Goebbels, den Neugermanisten Max von Waldberg (1858-1938), der 1933 aufgrund seiner jüdischen Herkunft auf die Venia legendi verzichtete. ${ }^{161}$ Auch ein weiteres Mitglied der Incalcata, der Romanist Leonardo Olschki (1885-1961), wurde 1933 ein Opfer des sog. Gesetzes zur Wiederherstellung der Berufsbeamtentums. Noch ein Jahr zuvor war er zusammen mit Glockner und Güntert unter den Unterzeichnern der erfolgreichen Resolution gewesen, Gumbel die Lehrberechtigung zu entziehen. ${ }^{162}$ In diesem Intellektuellenkreis der späten zwanziger Jahre saßen spätere Opfer, Förderer und Nutznießer des Nationalsozialismus zusammen, die sich durch gemeinsame politische, deutsch-nationale Ansichten geeint sahen. ${ }^{163}$ Es herrschte hier, wie allgemein an der Universität, ein nationalistischer Grundkonsens, über den hinaus man sich mit politischen und „weltanschaulichen“ Detailfragen nicht auseinandersetzte.

Durch die Bekanntschaften aus diesem Diskussionszirkel vom Ende der 1920er Jahre verfügte Wahle später über einflußreiche Beziehungen: Eugen Fehrle beispielsweise war von 1933 bis 1934 kommissarischer Leiter der Abteilung für Hochschulwesen im Ministerium des Kultus und Unterrichts in Karlsruhe $^{164}$ und unterstützte Wahle bei der Gründung des eigenen Institutes. ${ }^{165}$ Auch Rothacker machte Karriere. Er wurde 1933 Leiter der Abteilung Volksbildung im Reichsministerium für Volksaufklärung und Propaganda in Berlin ${ }^{166}$ und war maßgeblich an der Organisation der Bücherverbrennungen beteiligt. Er hatte Wahle offenbar mit einem Beitrag in seiner projektierten Geschichte

159 Teske hörte bei Wahle in den Jahren 1923-1926 (UAH Rep. 27/1373 [Quästurakten]). Zusammen mit Teske bot Wahle im SS 1930 eine gemeinsame Lehrveranstaltung an (vgl. hierzu den Anhang).

160 Glockner 1973, 163.

161 Wolgast 1987, 367-368, vgl. auch Lennartz 1997, 641.

162 Jansen 1992b, 403.

163 Ausnahme war der Historiker Hajo Holborn, der der Republik gegenüber loyal eingestellt war; vgl. Jansen 1992a, 41.

164 Drüll 1986, 68; vgl. Kater 1974, 287 und Heiber 1991, 393.

165 Aufgrund seines politischen Auftretens und seiner zweifelhaften fachlichen Qualifikation stand Fehrle in der Fakultät zu Beginn der 1930er Jahre isoliert da. Offenbar hatten nur wenige Gelehrte persönlichen Kontakt zu ihm, neben Wahle werden hier wieder Güntert und Friedrich Panzer genannt (Wennemuth 1994, 366 f.).

166 Jansen 1992a, 208. 
der Geisteswissenschaften eingeplant. ${ }^{167}$ Der Wahle wohlgesonnene erste Rektor der nationalsozialistischen Universität Heidelberg, Wilhelm Groh, wechselte 1937 ins Reichsministerium für Wissenschaft, Erziebung und Volksbildung nach Berlin ${ }^{168}$ und betrieb von dort aus Wahles Beförderung zum planmäßigen Professor und Direktor der Lebrstätte für Vor-und Frühgeschichte.

Wahles Lehrer Alfred Hettner dagegen - von dem Wahle nach eigenem Bekunden eine sehr hohe Meinung hatte ${ }^{169}$ - war der einzige Heidelberger Hochschullehrer, der es nach 1933 wagte, nach nationalsozialistischen Angriffen öffentlich zu kontern. Dem konservativen Ordinarius für Geographie war "liberalistisch-positivistische" Wissenschaft vorgeworfen worden, und Hettner hatte daraufhin seine Kritiker aufgefordert, ihre Vorstellungen von einer „liberalistischen" Wissenschaft erst einmal klar zu definieren und ihre eigene Methode wissenschaftlich darzulegen. Aus seiner Stellungnahme heraus sind ihm offenbar keine Nachteile entstanden. ${ }^{170}$

Die liberalen und demokratischen Ideen am Institut für Sozial- und Staatswissenschaften Emil Lederers und Alfred Webers waren auch in Heidelberg die Ausnahme, die wirkungsvollen Wissenschaftler an diesem Institut waren akademische und politische Außenseiter. ${ }^{171}$ Auch der sprichwörtlich liberale "Heidelberger Geist" hinderte die mehrheitlich "nationale Opposition" unter den Hochschullehrern nicht daran, in Lehre und Forschung die Bewahrung der traditionellen Werte von Nation, Reich und Vaterland zu proklamieren und die Demokratie intellektuell zu demontieren, wie dies auch an anderen Universitäten der Fall war. ${ }^{172}$ Wenn viele konservative Professoren der NSDAP in der Weimarer Republik noch fernblieben, wie etwa Wahle, so deshalb, weil ihnen das Gehabe und die Ausschreitungen des braunen Pöbels zu plebejisch oder abstoßend erschienen und ihrem Selbstverständnis einer Bildungselite absolut widersprachen. Sie kamen aus dem völkischen und alldeutschen politischen Milieu, das der intellektuellen „konservativen Revolution" zugeordnet wird, und behielten diese politische-Identität bei, bis die

167 UBH Heid. Hs. 3989, Selbstdarstellung 1945, 20.

168 Jansen 1992a, 208.

169 UBH Heid. Hs. 3989, Selbstdarstellung 1945, 8.

170 Jansen 1992a, 296-297. Auch der als national-konservativ charakterisierte Hettner äußerte in Publikationen nach 1918 deutlich antifranzösische Ressentiments (Oberkrome 1993, 62-63). Nach 1933 war Hettner „sich in seiner Immunität gegen modisches und nationalsozialistisches Vokabular politisch treugeblieben. "(Jansen 1992a, 297).

171 Jansen 1997.

172 Vgl. Ringer 1987, 186-187. 
Nationalsozialisten auch diese Konkurrenz am rechten Rand gleichschalteten. Dennoch war die "Ideologiekongruenz" von Nationalismus, Militarismus und Antisemitismus zwischen der in Intellektuellenkreisen favorisierten DNVP und der NSDAP nicht zu übersehen. ${ }^{173}$

\section{3. „Rassenkunde“ und Vorgeschichte}

Schon im Jahr 1925 finden wir Wahle mit einem umfassenden Beitrag unter dem Titel Die rassenkundliche Auswertung vorgeschichtlicher Forschungsergebnisse in der Allgemeinen Rassenkunde von Walter Scheidt (1895-1955) vertreten, die in der Reihe Rassenkunde im J. F. Lehmanns Verlag in München erschienen war. ${ }^{174}$ Als Herausgeber dieser Reihe zeichneten, neben Walter Scheidt, auch Gero von Merhart (1866-1959), Richard Thurnwald (1869-1954) und Ernst Wahle. Von der naturwissenschaftlichen Arbeitsweise der Rassenkunde, die „die auslesebedingte Häufung unmittelbar zugänglicher, mit den Mitteln naturwissenschaftlicher Beobachtung feststellbarer körperlicher und seelischer Merkmale untersucht", so Scheidt und Wahle einleitend, sei die geisteswissenschaftliche Arbeitsweise der Rassenkunde zu unterscheiden, „welche mit den Mitteln der Kulturgeschichte (im weitesten Sinn) geistig-äußerungsmäßige Merkmale von Menschen und Menschengruppen erschließt. " ${ }^{175}$ Nach der Definition des "Kulturkreises“ als einem Verbreitungsgebiet typologisch und chronologisch einheitlicher Funde stellt Wahle ganz im Sinne Kossinnas unter der Überschrift Kulturkreis und Rasse fest: „Der Träger eines jeden Kulturkreises ist ein Volk. "176 Rasse und Volk seien aber nicht generell ein- und dasselbe, und ob als Träger eines Kulturkreises eine Rasse in Betracht komme, sei im Einzelfall mit Hilfe anthropologischer Methoden zu prüfen. Die Rassenmischung seit dem Neolithikum sei dabei das Problem der Anthropologen, doch hätten sich schon im Paläolithikum die „Neandertalrasse" und die „Cro-Magnonrasse" vermischt. Im Jungpaläolithikum trete noch eine dritte Rasse mit „brachykephaler [kurzschädeliger, D. H.] Kopfform" hinzu, so daß schon für die Frühzeit menschlicher'Kulturentwicklung festzustellen sei, daß sich die Begriffe „Rasse“ und „Volk" nicht mehr deckten. Gemeinsame „anthropologische und

173 Funke 1986, 5.

174 Wahle 1925b. Zum J. F. Lehmanns Verlag: Stark 1976, Thomann 1993.

175 Wahle/Scheidt 1925, 513.

176 Wahle 1925b, 563. 
archäologische Arbeit ermittelt die leibliche Beschaffenheit der Völker", so Wahle. Damit sei die Grundlage gewonnen, „um der Frage des Anteiles der einzelnen Rassen an der Ausbildung der einzelnen Kulturgüter und an dem Gange der Entwickelung überhaupt näber zu treten. " ${ }^{777}$ Obwohl der Verfasser schließlich zugeben muß, daß typologische Eigentümlichkeiten im Fundmaterial sich nicht mit Rasseeigentümlichkeiten erklären ließen, und daß die bisherigen Versuche einer „rassischen“ Deutung fehlgelaufen seien, forderte er, daß die Vorgeschichtsforscher auf breitester Grundlage an der Lösung der Aufgaben der „Rassenkunde“ arbeiten sollten. Zwar wurden hier methodische. Unzulänglichkeiten archäologischer "Rasseforschung“ benannt, Konsequenzen aus dieser Erkenntnis jedoch nicht gezogen. Es entsteht der Eindruck, Wahle habe gerade in der "Rassenkunde“ ein Potential für die künftige Aufwertung der Vorgeschichte erkannt.

Wahle war Mitherausgeber der Zeitschriften Volk und Rasse (1926-1933) und der Zeitscbrift für Rassenkunde (seit 1935). ${ }^{178}$ Volk und Rasse, 1926 begründet und ebenfalls im J. F. Lehmanns Verlag erschienen, hatte das Ziel, durch Interdisziplinarität den Zusammenhang zwischen der traditionellen Vorstellung von "Volk“ und der naturwissenschaftlichen Definition von "Rassen“ zu untersuchen. Eine höhere deutsche Volkskultur sollte durch die Herausstellung germanischer und die Aussonderung nicht-germanischer "Rasse“typen befördert werden. Die Zeitschrift hatte damit ein völkisches Programm und erreichte innerhalb von 3-4 Jahren eine Auflage von annähernd 3000 Exemplaren. ${ }^{179}$

Der „Rassenkundler“ Hans Friedrich Karl Günther ${ }^{180}$ wurde gerade durch seine in vielen Auflagen erschienenen "rassekundlichen" Publikationen bei J. F. Lehmann äußerst einflußreich und bekannt. Julius F. Lehmann (18641935) unterstützte mäzenatisch die „Rassenbewegung“ und gab Pseudowissenschaftlern wie Günther mit seinem auf „Rassenkunde“ und „Rassenhygiene“ ausgerichteten Verlag eine Plattform. Zwei Arbeiten Günthers wurden von Wahle rezensiert. In einer Besprechung der 10. Auflage vọn Rassenkunde des deutschen Volkes kritisierte er 1927 die Schlüsse des Autors. Trotz mangelhaf-

177 Wahle 1925b, $570 \mathrm{f}$.

178 Vgl. Pinn 1987; UBH Heid. Hs. 3989, 1,6, Egon von Eickstedt an Wahle (15.5.1934); Wahle arbeitete ferner für die Zeitschrift Deutsche Hefte für Volks- und Kulturbodenforschung, die von der Stiftung für deutsche Volks- und Kulturbodenforschung 1930-1934 in Leipzig herausgegeben wurde (vgl. hierzu: Fahlbusch 1994).

179 Stark 1976, 308; 312.

180 Zu Günther: Weisenburger 1997. 
ter wissenschaftlicher Grundlagen stelle Günther seine Schlußfolgerungen als gesichert hin. Dennoch seien flüssige Sprache, klare Gliederung und die Würdigung der "nordischen Rasse“ der Grund für den Erfolg des Buches, das „unendlich Vielen die Augen sowobl für die Beobachtung der Rasseneigenschaften wie für Rassefragen überbaupt geöffnet " habe. Zu hoffen sei daher, daß das Buch „nun auch die Fachwissenschaft zur Beleuchtung der aufgerollten Probleme anregt. " ${ }^{181} \mathrm{Zu}$ Günthers Veröffentlichung Herkunft und Rassegeschichte der Germanen schrieb Wahle 1935: „Das Buch vertieft die früberen Darstellungen des Verfassers und baut sie auf Grund neuen Stoffes wie auch einiger von der Gegenwart gebotener Anregungen nach verschiedenen Seiten bin aus. "182 Günthers Publikationen wurden damit von Wahle positiv aufgenommen.

Welche Bedeutung Wahle der „Rassenkunde“ nach 1933 in der Lehre einräumte, erfahren wir aus einem Aufsatz über die Lehrstätte für Frühgeschichte an der Universität Heidelberg, in dem es heißt: „Die gemeinsame Lektüre von Gobineau und Chamberlain lenkt den Blick auf ein anderes Bild gegenwartsnaber Vorgeschichtsarbeit, nämlich auf den Einsatz des Faches im Kampfe der Nationen. Die Studenten werden hier vor die Frage gestellt, welche Bedeutung die Vorgeschichte bei der Heranbildung des Nationalberw $3 t s e i n s$ und im politischen Leben baben kann, und wie dieser besondere Einsatz des Faches nun auch wieder die Einzelforschung zu beeinflussen vermag. " ${ }^{183}$ Gerade seit der Niederlage von 1918 sah Wahle für die deutsche Vorgeschichtsforschung nationalpolitische Aufgaben. Die „Beschäftigung mit den Problemen der Volks- und Kulturbodenforschung“, so schrieb er selbst 1945, „welche sich als ein Ergebnis von Krieg und Zusammenbruch bald nach 1918 zu formen beginnt, und in welcher die Präbistorie insofern auch vertreten ist, als die fremden Ansprüche auf den deutschen Volksboden vielfach mit Hinweisen auf tatsächliche oder vermeintliche Besitzverbältnisse in frübgeschichtlicher Zeit verfochten werden. Hier mitzuarbeiten, scheint dem Patrioten selbstverständlich. " 184

Eine solchermaßen völkische Legitimation der deutschen Vorgeschichte als Wissenschaft und eigenständiges universitäres Fach mit beamteten Hochschullehrern als Staatsdienern machte sich der badische Kultusminister Willy Hellpach nicht zu eigen. ${ }^{185} \mathrm{Wie}$ wir bereits gesehen haben, hatte Hellpach die Ein-

181 Wahle 1927, 48-49.

182 Wahle 1935b, 489.

183 Wahle 1939a, 67; unverändert abgedruckt in Kirchner (Hrsg.) 1964, 220-229, hier 227.

184 UBH Heid. Hs. 1,1, Selbstdarstellung 1945, 16.

185 Dennoch: wie Curtius galt auch Hellpach Ende der 1920er Jahre als Faschismussympathisant (vgl. Demm 1999, 187 ff.). 
richtung von Wahles beantragter Planstelle für deutsche Vorgeschichte an der Universität Heidelberg abgelehnt. Hellpach schrieb 1927, er hätte die Einrichtung neuer „Weltanschauungsprofessuren' für profane Fächer (wie Geschichte, Pbilosopbie u. dgl.)" während seiner Amtszeit von 1923-1925 abgewiesen. ${ }^{186}$ Entsprechend hatte man Hellpach 1925 von „deutschvölkischer" Seite "fanatische[n] Haß gegen jede Vaterlandsliebe, skrupellose Unterstützung des Internationalismus, des Pazifismus und anderer volksfremder und hochverräterischer Regungen" vorgeworfen, wohl auch unter dem Eindruck der Fürsprache Hellpachs für Emil Julius Gumbel. ${ }^{187}$ Wahle schrieb dementsprechend 1934, der „Staat von 1918“ hätte keine entschiedene Kulturpolitik getrieben und nicht auf die Konkurrenz zwischen deutscher Vorgeschichte einerseits und klassischer Altertumswissenschaft andererseits eingewirkt: „Den Wünschen der Präbistoriker kommt er [der Staat von 1918] nur zögernd und in geringem Umfang nach, wobl durch seine Ablebnung der völkischen Belange dazu veranlaßt. "188 Wahle konnte ja auf eigene Erfahrungen mit dem Ministerialreferenten Bartning im Karlsruher Kultusministerium zurückgreifen, der ihm im Februar 1922 bezüglich seiner Anstellung als Bodendenkmalpfleger gesagt hatte, der Staat habe kein Geld: „Der braucht sein Geld für viel wichtigere Dinge; Ibre Wissenschaft ist reiner Luxus. "189

Greifbar wird die Meinungsverschiedenheit über das nationale Erfordernis einer deutschen Vorgeschichte an der Einstellung Hellpachs zur völkischen Auffassung von „Blut“ und „Rasse“, Termini, die in der Diktion der Völkischen oft synonym gebraucht wurden. ${ }^{190}$ Wahle verwendete die Phrase von der "Stimme des Blutes" in seinem Buch Deutsche Vorzeit von 1932 (vgl. Tabelle 4, 125 bzw. 116-117; Tabelle 6, 203 bzw. 208). Später zitierte der Historiker Franz Petri Wahles Metapher von der „Stimme des Blutes" im Wortlaut in seinem eminent erfolgreichen Hauptwerk Germanisches Volkserbe in Wallonien und Nordfrankreich von 1937. ${ }^{191}$ Gelehrte wie Wahle und Petri verbanden den

186 Hellpach 1927, 463. Stattdessen seien Lehraufträge für Seelsorge und kirchliche Sozialethik geplant gewesen, um dem Studenten „die Möglichkeit zu geben, sich mit den ewigen Dingen in seiner Eigenart angemessenen Höbenlage von Vortrag, Kolloquium, Seminar zu befassen." Die badische Koalitionskrise von 1925 machte diese Pläne zunichte.

187 Zit. nach Gundlach 1989, 170.

188 Wahle 1934, 9.

189 UBH Heid. Hs. 3989, 2,8, Wahle an Schumacher (17.2.22), mit anliegendem Gesprächsprotokoll: Inbalt meiner Unterredung mit Herrn Bartning am 14. Februar 1922.

190 „... die besonders bäufig gebrauchte und meist umgedeutete (ältere) Wendung: ,der Stimme des Blutes folgen" (Seidel/Seidel-Slotty 1961, 81, ohne Nachweise).

191 Petri 1937, 997 mit Anm. 2; Schöttler 1999, 102 und 112, Anm. 67. 
Mythos vom eigenständigen Volk mit dem Mythos der eigenständigen Rasse. Die totalitäre Auffassung des Volksbegriffs im Gelehrtenmilieu spiegelt auch seine zentrale Stellung im verfassungsfeindlichen und antisemitischen Denken der „nationalen Opposition“ wider. ${ }^{192}$ Ohne den Rassenbegriff an sich abzulehnen, setzte Hellpach 1926 eigene Volkstumsvorstellungen gegen die radikalnationalistische völkische Ideologie: „Die Deutschen sind kein Rassevolk. Wer sie gewaltsam dazu machen, ibr Volkstum auf Rasse, ibr Nationalbewußtsein auf Rasseninstinkt gründen will, wird unausweichlich zum Zerstörer am Deutschtum. [...] Wer die Deutschen zu ,Germanen'stempelt und diesen Begriff im Sinne einer Rasse meint, mit bestimmten physischen Merkmalen: hochwüchsig, weißhäutig, langschädelig, blauäugig, blondhaarig etwa - der stößt Millionen und Abermillionen Deutscher aus dem deutschen Volkstum aus [... . ${ }^{193}$ Die ,Stimme des Blutes', wenn es überbaupt eine gibt, kann kein Hauptfundament deutschen Nationalbewußtseins sein; dazu wäre sie in Deutschland viel zu sebr Stimmengewirr. "194 Die gemeinsame Sprache und nicht die Rasse sei definierend für eine neuzeitliche Nation: „Es ist die wirkliche Stimme der Rede und nicht die metaphorische und stumme des Blutes, welche die Völker zu Nationen umgeschaffen hat und als Nationen zusammenbält und sondert, verbündet und verfeindet. " ${ }^{195}$ Allerdings ging auch Hellpach von der Existenz einer „Art, germanischen Volkstums “ aus, „an dem mit uns die Briten und Angelamerikaner, die Vlamen, Holländer, Dänen, Schweden und Norweger teilhaben. "196

Mit der Ernennung Wilhelm Grohs zum ersten Rektor der nationalsozialistischen Universität Heidelberg im Jahr 1933 endete - sowohl im Verständnis der NS-Wissenschaftler als auch ihrer politischen Widersacher - „die liberale Ära in der Geschichte der Heidelberger Universität" ${ }^{197}$ Einer erfolgreichen völkischen Legitimation der deutschen Vorgeschichte als Universitätsfach stand nun nichts mehr im Wege. Der von den Nationalsozialisten zum badischen Kultusminister ernannte Heidelberger Historiker Paul Schmitthenner forderte 1933, die Universität müsse „politisch sein [...] Sie muß ein deutsches Antlitz tragen [...] Die wissenschaftliche Erkenntnis [steht] in lebendigem Zusammenhang mit dem Volke. [Die Universität] muß als die vornebmste Stätte national-politischer Erziebung eine fübrende Ausleseschicht beranbilden [...] Diese Aufgabe ist

192 Sontheimer $1994^{4}, 250$.

193 Hellpach 1926, 113.

194 Hellpach 1926, 114.

195 Hellpach 1926, 116.

196 Hellpach 1926, 119.

197 Reichsstudentenführer Gustav Adolf Scheel 1933, zit. nach Wolgast 1987, 385, Anm. 120. 
ibre böchste Aufgabe schlechtbin. " 198 Die Freiheit von Forschung und Lehre wurde damit ganz den völkischen Zielen nationalsozialistischer Bildungpolitik geopfert, und neue Fächer, wie Vorgeschichte, Volkskunde und Kriegsgeschichte etabliert. ${ }^{199}$ Im Einklang mit Schmitthenners Programm stehen eine Reihe von Beiträgen, die Wahle ab 1934 für die Zeitschrift des NS-Lehrerbundes verfaßte.

\section{Deutsches und nationalsozialistisches Bildungswesen}

Mit der Unterstützung des Volkskundlers Eugen Fehrle hatte sich Wahle um die Einrichtung eines eigenen Instituts bemüht, um die „Ehe mit dem Altertum zu lösen", wie er noch 1980 schreibt, und sein Fach „als Teil der deutschkundlichen Wissenschaften binzustellen. "200 Fehrle zeigte die neuen Prioritäten, indem er die wertvollen Abgüsse des archäologischen Institutes zugunsten seiner volkskundlichen Sammlung in ein Kellermagazin verbannte. ${ }^{201} \mathrm{Die}$ Neueinrichtungen "deutschkundlicher" Institute in Heidelberg seit 1933, wie der Lebrstätte für Frühgeschichte (Wahle), des Kriegsgeschichtlichen Seminars (Schmitthenner), der Lehrstätte für Volkskunde (Fehrle), des Volks- und kulturpolitischen Instituts (Ernst Krieck) und des Instituts für Fränkisch-Pfälzische Landes- und Volksforschung (Fritz Ernst, Wolfgang Panzer, Fehrle), ${ }^{202}$ und ihre

198 Zitiert nach Jansen 1992a, 58.

199 Wolgast 1986, 157-158.

200 Wahle 1980, 100. Der Name Fehrles wird von Wahle nie genannt, doch ist seine Identität nach Wahles biographischen Angaben eindeutig; vgl. Drüll 1986, 68.

201 Wolgast 1986, 157.

202 Das Institut für Fränkisch-Pfälzische Landes- und Volksforschung, dessen Leitung sich zu Anfang der Geograph Wolfgang Panzer und der Historiker Fritz Ernst teilten, war erst 1938 nach dem Vorbild von Hermann Aubins Institut für geschichtliche Landeskunde der Rhein. lande in Bonn gegründet worden und eine Einrichtung der Westdeutschen Forschungsgemeinschaft (Quellen bei Dahlhaus 1992, 295 ff.; Miethke 1992, 109 und Schaab 1992, 189-194, ohne Darstellung des ideologischen Zusammenhangs mit der NS-„Westforschung“; diese umfassend bei Schöttler 1997b, 207 und Fahlbusch 1999, 376, passim). Fritz Ernst kam als Nachfolger von Günther Franz (zu „Bauern-Franz“ jüngst Behringer 1999) auf dem Lehrstuhl Karl Hampes und hatte mit der Institutsgründung die Pläne seines wegberufenen Vorgängers verwirklicht (Miethke 1992, $103 \mathrm{ff}$.). Fehrle forderte seine leitende Beteiligung am neuen Institut ein und konnte 1943 sie als Direktor der Abteilung Volkskunde des Instituts für Fränkisch-Pfälzische Landes- und Volksforschung gegen den Widerstand Panzers und Ernsts durchsetzen (vgl. Dahlhaus 1992, 301-303). Ausschlaggebend waren wohl seine besseren Kontakte zum Kultusminister Paul Schmitthenner, dem Heidelberger Ordinarius für Kriegsgeschichte. Ernst und Wolfgang Panzer versuchten daraufhin, die Frühgeschichte und damit 
gemeinsame Unterbringung im Deutschen Haus am Marsiliusplatz, einem kleineren, an das alte Seminarienhaus angeschlossenen Nebengebäude der Neuen Universität, waren ideologisch begründet. ${ }^{203} \mathrm{Daß}$ die von dem Danziger Architekten Karl Gruber entworfene Neue Universität mit seit 1928 fließenden amerikanischen Spendengeldern errichtet wurde, ist bei der späteren Besetzung des Deutschen Hauses mit Instituten, die doch gerade einem schädlichen „Internationalismus“ entgegenarbeiten sollten, besonders hervorzuheben. Seit dem Tod Stresemanns 1929 war die Finanzierung durch Spenden auch zunehmend auf deutschnationalen Widerspruch gestoßen. ${ }^{204}$ Zusammen mit dem ebenfalls deutschnational eingestellten Gruber, der übrigens Paul SchultzeNaumburg sehr schätzte, arbeitete Wahle den Plan der Raumaufteilung seiner Lehrstätte für Frühgeschichte aus. Die Räumlichkeiten im zweiten Stock des Deutschen Hauses bestanden aus einem studentischen Arbeitsraum, dem Zimmer des Direktors mit einem kleinem Nebenraum und dem Sammlungssaal. Eine Werkstatt für die „Belange der praktischen Denkmalpflege“ befand sich im Keller des Gebäudes. Ende April 1934 konnte der neue Bau bezogen werden. Auf Veranlassung des Hochschulreferenten Fehrle wurden der Lebrstätte die prähistorischen Sammlungen Max Verworn, Erich Kallius und Karl Sebastian Gutmann durch die Josefine und Leonhard von Portheim-Stiftung für Wissenschaft und Kunst als Lehrsammlung zu Verfügung gestellt. Diese Stiftung, deren Zweck besonders die Erhaltung und Erweiterung völkerkundlicher Sammlungen war, ${ }^{205}$ unterstützte die Einrichtung der Lehrstätte auch finanziell. ${ }^{206}$ „Als Wandschmuck stiftete Frau Geh. Hofrat Hoffmann, Ehrenbürger der Universität, ein Bild des Fübrers, das [Kultus]Ministerium einen Kunstdruck, C. D. Friedrichs, Hünengrab im Schnee' darstellend. Cand. phil. Jan Möhren-

Ernst Wahle als vierten Co-Direktor ins Spiel zu bringen. Fehrle konterte, es wären neben der Frühgeschichte auch andere, ebenso wichtige Fächer nicht beteiligt (Schaab 1992, 193). Wolfgang Panzer war als Referent für Geographie im Reichserziehungsministerium in Berlin für die Hetze gegen jüdische Geographen verantwortlich gewesen. Er war Reichsobmann für Geographie im NSLB und hatte 1935 den Lehrstuhl für Geographie in Heidelberg übernommen. Für die Volks- und kulturpolitische Forschungs- und Arbeitsgemeinschaft Heidelberg erhielt er 1938 von der Notgemeinschaft der deutschen Wissenschaft Fördermittel in Höhe von 18.000 RM (Fahlbusch 1999, 126, 137); 1940 war er vor Friedrich Metz interimistischer Leiter der Westdeutschen Forschungsgemeinschaft (Fahlbusch 1999, 359).

Wolgast 1987, 395; vgl. Wennemuth 1994, 368-370.

204 Vgl. hierzu: Romero 1990, $120 \mathrm{ff}$.

205 Verzeichnis der deutschen Stiftungen (Darmstadt 1997) 492.

206 UAH KE 8, Lehrstätte für Frühgeschichte 1933-1944, Stiftungskurator Alfred Otto Zintgraff an Hauptschriftleiter Bretz von der Volksgemeinschaft (2.8.1934). 
Köln, ein Mitglied der Lehrstätte, malte ein Bild, den ,Pfingstmorgen an der Queste' darstellend, sowie für den Arbeitsraum ein zweites, eines der Steingräber von Fallingbostel darstellendes Ölbild. ${ }^{\circledR 07}$

Ab 1933 waren die Veranstaltungen Wahles in den Vorlesungsverzeichnissen auch unter der Rubrik „Deutschkunde“ angekündigt worden. ${ }^{208}$ Auch wenn man berücksichtigt, daß diese Lehrveranstaltungen mit nun vordergründig nationalen oder völkischen Titeln zwar nicht unbedingt auf nationalsozialistische und rassistische Inhalte schließen lassen müssen, so weisen auch sie auf eine „auffallige Anpassungsbereitschaft an die nun berrschende Ideologie" hin. ${ }^{209}$ Und so wies Wahle in einem für das Sekretariat der Universität Heidelberg bestimmten Memorandum vom 19. April 1935 darauf hin, daß der „Errichtung einer selbständigen Lebrstätte [für Frühgeschichte] [...] das Interesse der nationalsozialistischen Bewegung für alle deutschkundlichen Fächer und dasjenige für Vorgeschichte im besonderen zugrunde" liege. ${ }^{210}$

Als fachlich immer angesehenerer Hochschullehrer verfaßte Wahle zwischen 1933 und 1936 insgesamt 33 Beiträge für das Organ des NS-Lehrerbundes, ${ }^{211}$ das Deutsche Bildungswesen. 1934, 1935 und 1936 erschien hier, zusammen mit kleineren Beiträgen vorgeschichtlichen Inhalts, auch eine Aufsatztrilogie mit den Titeln Deutsche Vorgeschichtsforschung und klassische Altertumswissenschaft, Die deutsche Vorgeschichtsforschung in der Gegenwart und Deutsche Vorgeschichte als gestaltende Kraft. Dem neuen Staat dankte Wahle die langerwartete Würdigung und Förderung seines Faches und so schrieb er im ersten Aufsatz von 1934: „So leuchtet mit dem Sieg der nationalsozialistischen Bewegung auch für die deutsche Vorgeschichtsforschung das Morgenrot der Freibeit. ${ }^{\text {"12 }}$ Auch die deutsche Vorgeschichte habe sich ihren Platz erst erobern müssen: „Insbesondere ist der vorgeschichtlichen Forschung die Forderung der Gegenwart nach kämpferischer Haltung und Einsatzbereitschaft nichts Neues;" so schrieb Wahle 1935, „denn sie bat sich gegenüber der Verständnislosigkeit bebaupten müssen und das Übelwollen der klassischen Altertumswissenschaft mit doppelter Willenskraft beantwortet. Und wenn das Erziebungsprogramm der

207 UAH KE 8, Lehrstätte für Frühgeschichte 1933-1944; Wahle an das Sekretariat der Universität (19.4.1935).

208 Vgl. den Anhang.

209 Jansen 1992a, 99, 333.

210 UAH KE 8, Lehrstätte für Frühgeschichte 1933-1944; Wahle an das Sekretariat der Universität (19.4.1935).

211 BAB (ehem. BDC) NSLB-Kartei, Mitgliedsnummer 285091.

212 Wahle 1934, 12. 
Gegenwart neben der Rassen- und der Volkskunde auch Vorgeschichte und wissenschaftliche Heimatkunde nennt, dann erkennt es neben dem sacblichen und - ideelen Wert dieser Fächer auch an, daß sie sich schon früb in den Dienst dieser geistigen Bewegung [dem NS] gestellt baben. So dürfen denn sowobl M.R. Gerstenbauer (Der völkische Gedanke in Vergangenbeit und Zukunft. Aus der Geschichte der völkischen Bewegung. 1933) wie auch K. Zimmermann (Die geistigen Grundlagen des Nationalsozialismus. 1933) unter den Wegbereitern des beutigen Denkens mit vollem Recht auch die durch $G$. Kossinna vertretene vorge-

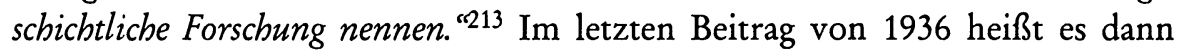
über das Erreichte: „So ist auch beute die Vorgeschichte ein Stück unseres nationalen Erziebungsprogramms, ist die Nationalgeschichte ein wichtiger Baustein zur Vertiefung und Verlebendigung des Nationalbewußtseins. "Dabei hätten sich besonders der in der Denkmalpflege tätige Forscherkreis „der weltanschaulichen Auswertung seines Stoffes noch nicht in demjenigen Umfang zugewandt, den man gerade heute von ibm verlangt. ${ }^{\text {"214 }}$ Über die 100-Jahrfeier des DAI 1929 schrieb Wahle rückblickend: „Hier triumphierte die Materie über den Geist, die Grabungs-,Technik' über die tiefere Sinngebung dieser Art von Quellenforschung; Vorträge über Warfen und Osebergschiff erschienen im Programm neben solchen über koreanische Altertümer und neue Synagogenforschung. " 215 Obwohl Kossinna und andere die Vorgeschichtsforschung im Gedankengut des Nationalsozialismus verankert hätten, würde diese Wissenschaft den Anforderungen der Gegenwart noch nicht gerecht: „Die Präbistorie stellt bei näberer Betrachtung keine solche Einbeit dar wie die Rassenbiologie, erscheint vielmebr nach sebr verscbiedenen Richtungen bin aufgespalten und auch nur teilweise von der völki. schen Gedankenwelt beseelt. "216 Die Gründe hierfür sah Wahle in Spannungen, die zwischen der "Zunft“ der Fachprähistoriker und den Laien, bestünden. Wahle unterschied dann zwischen beamteten Vorgeschichtsforschern in der Denkmalpflege, bei denen „das Stoffliche“ im Mittelpunkt stünde, Popularisierern und Dilettanten wie Herman Wirth und Wilhelm Teudt, die danach strebten "den sittlichen Gebalt der germanischen Frübzeit zu umreißen und in das völkische Leben der Gegenwart nutzbringend einzubauen", sowie den Kossinna-Anhängern, die in der deutschen Vorgeschichte eine „hervorragend nationale Wissenschaft" fänden. ${ }^{217}$ Der ersten Gruppe warf Wahle Versäumnis in

\footnotetext{
213 Wahle 1935a, 706.

214 Wahle 1936a, 168-169.

215 Wahle 1936a, 170.

216 Wahle 1935a, 706.

217 Wahle 1935a, 707-709.
} 
der Wahrnehmung nationaler Aufgaben vor, der zweiten Gruppe stand er als Wissenschaftler kritisch gegenüber, obgleich er die völkischen Verdienste und die populäre Breitenwirkung durchaus würdigte, und zur Gruppe der Kossinna-Anhänger zählte er sich selbst. Dieser Aufsatz Wahles wurde 1936 in die Nationalsozialistische Bibliographie aufgenommen und damit von der Partei zur Lektüre empfohlen. ${ }^{218}$ Die Anreicherung von „zeittypischem“ Schwulst und Militarismus ${ }^{219}$ scheint bei Wahle in dieser Unverblümtheit die Ausnahme geblieben zu sein. Doch mit seinen scharfen Angriffen auf die klassische Archäologie nach der eigenen Institutsgründung von 1934 bekannte sich Wahle offen zum Nationalsozialismus; seine Sprachhandlungen sind dabei möglicherweise auch psychologisch als eine persönliche Abrechnung mit dem Fach seines ehemaligen „Hausherrn“ Ludwig Curtius zu verstehen. 220

Die Zusammenarbeit Wahles mit der Redaktion des Deutschen Bildungswesen endete offenbar abrupt im Jahr 1936. Welcher Art der „Schlag“ war, der damals die Mitarbeit am Deutschen Bildungswesen beendete, verschweigt Wahle allerdings. ${ }^{221}$ Es fällt auf, daß die Zeitschrift Deutsches Bildungswesen 1936 in Nationalsozialistisches Bildungswesen umbenannt wurde. Der Hauptamtsleiter des Hauptamtes für Erzieher und Reichswalter des NSLB, Fritz Wächtler, teilte im Vorwort des ersten Heftes der umbenannten Zeitschrift markig den Abbruch sämtlicher Beziehungen zum Fichte-Verlag und den

218 Nationalsozialistische Bibliographie. Monatshefte der parteiamtlichen Prüfungskommission zum Schutze des NS-Schrifttums, Januar 1936, 1. Heft, 31.

219 Vgl. Seidel/Seidel-Slottky 1961, passim.

220 Die zunehmende Ablehnung der klassischen Altertumswissenschaft wurzelte bei Wahle aber tiefer. Nachdem Wahle 1928 das klassische Bildungsideal der humanistischen Gymnasien für die Verdrängung der deutschen Vorgeschichte aus dem „Bildungsgut der Nation“ verantwortlich gemacht hatte (Wahle 1928), so sah er später die Identitätskrise der Vorgeschichtswissenschaft um 1900 als ausschlaggebend dafür an, daß „die klassische Altertumswissenschaft von der Plattform der sogenannten römisch-germanischen Forschung ber versuchen konnte, die Präbistorie als einen Teil der Arcbäologie zu bebandeln." (UBH Heid. Hs. 3989 1,1, Selbstdar. stellung 1945, 20). Unter der Kapitelüberschrift Deutschtbum und Altertbum hatte schon der völkische Vordenker August Julius Langbehn in seinem 1890 anonym erschienenen Buch Rembrandt als Erzieher, von einem Deutschen, behauptet, die heutigen Deutschen stünden überwiegend unter dem Einfluß einer falschen Kultur ([Langbehn] 1890, 32; zu Langbehn: Behrendt 1996; Paul 1999). Wahle behandelte in seiner Vorlesung Die gegenwärtige Lage der deutschen Frühgeschichtswissenschaft von 1947 (vgl. weiter unten) rückblickend die „Geschichte der völkischen Bewegung" und ihre Bedeutung für die deutsche Vorgeschichte. In der „alldeutschen Auffassung der Vergangenbeit" so Wahle, „spielt nun die Frübzeit eine erbebliche Rol. le." Davor vermerkte er: „Wäre bier auch Langbehn, der Rembrandtdeutsche, zu nennen?" (UBH Heid. Hs. 3989 4,B5, S. 14).

221 Wahle 1980, 60. 
Wechsel zum „ältesten Verlag der Bewegung“, dem Deutschen Volksverlag in München, mit. ${ }^{222}$ Wahle schrieb rückblickend 1980, daß die Polizei in die Räume einer ihm „verbundenen Zeitschrift" eingedrungen sei und diese versiegelt habe. Es dürfte sich bei dieser Zeitschrift wohl um das beim Fichte-Verlag in München erscheinende Deutsche Bildungswesen gehandelt haben. ${ }^{223}$ Wahles bereits vorliegenden Beiträge, u. a. der programmatische Aufsatz Deutsche Vorgeschichte als gestaltende Kraft, wurden unter dem geänderten Zeitschriftentitel im Jahrgang 1936 noch gedruckt. Im neu verlegten Nationalsozialistischen Bildungswesen erschien danach nie wieder ein Beitrag aus seiner Feder. ${ }^{224}$

\section{Instrumentalisierung, Licht aus dem Osten und parteiamtliche Zensur}

Die ideologische Verwertbarkeit von Kossinnas Vorgeschichte würdigte Wahle nach 1933 ausdrücklich. Auch wenn er etwa im Jahr 1925 die „außerordentliche Einseitigkeit" von Kossinnas Buch Die deutsche Vorgeschichte, eine hervorragend nationale Wissenschaft in der Historischen Zeitschrift beanstandet hatte, so lehnte er doch das Programm Kossinnas - die völkische Vorgeschichtsforschung - nicht ab. „Man braucht das Buch von Kossinna nicht zu empfeblen, und man kann trotzdem der vorgeschichtlichen Forschung jede nur denkbare Förderung wünschen und hoffen, daß ibre Ergebnisse mannigfache Verbreitung und Verwertung in unserem Volke finden. Ja es ist leider nicht zuviel gesagt, daß man gerade von der Plattform dieser Auffassung aus dem Buche keine große Verbreitung wünscht, weil es eine Gefabr bedeutet. Wir kennen die deutsche Neigung, sich an den Taten der Vergangenheit zu berauschen, wir beob. achten auch mit Aufmerksamkeit, wie bestimmten Kreisen unseres Volkes gerade die Germanen eine Quelle der Begeisterung sind. Diese Kreise stellen die Mebrzabl der Leser des Buches von Kossinna. Ibnen liegt die historische Kritik ferne und sie finden in dem Buche gerade das, was sie ibrer ganzen Einstellung nach suchen. Aber damit entstebt in ibnen ein Phantasiegebäude [...]. Programmschriften sind

222 [Editorial] Nationalsozialistisches Bildungswesen. Einzige erziehungswissenschaftliche Zeitschrift der Bewegung 1936.

223 UAH PA 6215, Wahle, Ernst, Darstellung der Sacblage und Personalien (1945): „„... plötzlich von der Gestapo aufgeboben ..."

224 Auch Wahles Ausscheiden aus dem Herausgebergremium von Volk und Rasse 1933 erfolgte gleichzeitig mit der Umgestaltung der Herausgeberschaft unter dem Einfluß der SS (Heinrich Himmler und Richard W. Darré). 
nur zu leicht auf Kampf eingestellt. Auch bei dem Buche von Kossinna ist das der Fall. Es enthält eine Anzabl von Angriffen persönlicher Art, welche in sebr wenig schöner Form uns entgegentreten. Der Verfasser irrt, wenn er meint, damit seiner Wissenschaft zu nützen; er wird gerade das Gegenteil erreichen [Hervorhebungen von W.]. "225 Wahle kritisierte Kossinnas pseudowissenschaftliche Germanenverherrlichung und dessen Umgangsformen mit wissenschaftlich Andersdenkenden. Für seine apodiktischen Behauptungen zöge Kossinna keine Schriftquellen heran, sondern ginge nur anhand von Bodenfunden bis in prähistorische Zeit zurück. ${ }^{226}$

Unter der Überschrift Der südgermanische Lebensraum hatte Wahle im Deutschen Bildungswesen von 1935 die Expansion „germanischen Siedlungsraumes" in Mitteleuropa thematisiert und ein Verbreitungsgebiet kartiert, das sich von Belgien bis nach Rußland, von Dänemark bis nach Süddeutschland erstreckte; ${ }^{227}$ eine Darstellung, die methodisch in keinem Widerspruch $\mathrm{zu}$ Kossinna stand. ${ }^{228}$ Das starke Wachstum "germanischen Siedlungsraumes" begründete er mit einem "außerordentlichen Geburtenüberschuß", der wiederum „Ausdruck sebr starker Lebenskraft" sei. Diese schrittweise Ausdehnung des germanischen Siedlungsgebietes seit der Bronzezeit hatte Wahle in vergleichbarer Form schon 1932 in seinem Buch Deutsche Vorzeit auskartiert. Hier griff Wahle die Instrumentalisierung archäologischer Forschung als Folge des Ersten Weltkriegs an. Daß die Vorgeschichte stets in anderen Ländern und gegen Deutschland instrumentalisiert wird, verstand sich von selbst: „In dem Kampf um den Siedelungsraum, der sich aus Betonung des Nationalitätenprinzips ergibt, suchen die Parteien [d. h. die Staaten, D. H.] ibre Ansprüche aus den Zuständen der Vergangenheit zu begründen. Doch handelt es sich bier nicht um eine objektive Heranziebung geeigneter Tatbestände der Typologie und siedelungsgeschichtlicher Ergebnisse; zablreiche Befunde müssen es sich gefallen lassen, im Sinne politischer Thesen gedeutet und verwendet zu werden. "Zugleich pflegte Wahle ein unpolitisches Bild der deutschen Vorgeschichtsforschung: sie sähe sich nun - leider - gezwungen, dem internationalen Mißbrauch der Vorge-

225 Wahle 1925a, 114-116; mit ähnlichem, leicht verkürztem Wortlaut erschien diese Rezension auch in der Geographischen Zeitschrift 32, 1926, 157-158; Wahle dazu in einem maschr. Brief an Friedrich Drexel vom 24.1.25: „Den bervorragend nationalen $K$. babe ich gerade heute für die Geogr. Z. in einer für den Verf. nicht gerade erfreulichen Art besprochen." (ARGK Fasz. 1.268: Prof. Dr. Ernst Wahle, Heidelberg, 1918-42).

226 Wahle 1926, 554.

227 Wahle 1935a, 692.

228 Vgl. Kossinna 1911, Karte. 
schichte - gegen Deutschland - entgegenzutreten, müsse sich aber, unvorbereitet wie sie sei, erst einmal zur Gegenwehr rüsten. ${ }^{229}$

Wahle sah um 1930 aber auch eine „innenpolitische“ Instrumentalisierung der deutschen Vorgeschichte, denn diejenigen „Kreise, die einer germanischen Wiedergeburt das Wort reden, verlangen von ibr [der Prähistorie, D. H.] die Bestätigung ibrer Wunschbilder, welche ibnen ein Rüstzeng in ibrem kulturpolitischen Kampfe sein sollen. ${ }^{230}$ Wahles Kritik bezog sich hier stets auf die „Wunscbbilder" der Nationalsozialisten mit einer Vorgeschichte im Sinne Kossinnas und der "nordische[n] Herkunft der Kultur", was Wahles Forschungsergebnissen wie seinen eigenen „kulturpolitischen“ Bestrebungen zuwiderlief, denn „Deutschnationale“ und „Alldeutsche“ waren Anfang der 1930er Jahre mit den Nationalsozialisten zunehmend auch in eine ideologische Konkurrenz geraten. Obwohl Wahle nach eigenen Angaben schon 1925 aus dem Alldeutschen Verband und 1926 auch aus der DNVP ausgetreten war, ${ }^{231}$ fühlte er sich nach wie vor der radikalnationalistischen völkischen Bewegung des Kaiserreiches verpflichtet.

Seine Warnungen vor einer politischen Instrumentalisierung der Vorgeschichte erläuterte er im Februar 1945 in seiner Selbstdarstellung für die Leopoldinisch-Carolinisch Deutsche Akademie der Naturforscher in Halle, und daß diese persönliche Rechtfertigung kurz vor dem Zusammenbruch des „Dritten Reiches“ verfaßt wurde, ist sicherlich kein Zufall. So konnte Wahle schon kurz vor dem Zusammenbruch 1945 sinngemäß für sich in Anspruch nehmen, sowohl in der Weimarer Republik als auch in der Zeit des Nationalsozialismus einen „Sonderweg“ mit allen persönlichen Konsequenzen gegangen zu sein. Wahle ließ allerdings keinen Zweifel daran aufkommen, daß sein "Sonderweg“ politische Ziele einer ebenfalls völkischen deutschen Vorgeschichte verfolgt hatte. Einerseits habe er sich vor 1933, zur Zeit der Republik, gegen die Bevormundung der deutschen Vorgeschichte durch die klassische Altertumswissenschaft in Gestalt von DAI und RGK zur Wehr gesetzt. Diese Institutionen hätten die römische Antike "als eine für die Geschichte des Nordens ausschlaggebende Kraft bingestellt" und „bodenständige Faktoren" ganz vernachlässigt. ${ }^{232}$ Andererseits sei es ihm aber auch nicht möglich gewesen,

229 Wahle 1932, 24.

230 Wahle 1932, 24-25.

231 BAB R4901 (Reichsministerium für Erziehung, Wissenschaft und Volksbildung: Kartei aller Hochschullehrer; alt R 21)/10021.

232 UBH Heid. Hs. 3989, 1,1, Selbstdarstellung 1945, 26. 
„die von Kossinna eingeschlagene Richtung einer völkischen Frühgeschichts. schreibung fortzusetzen", jene "völkische Richtung" eben, die nach 1933 Bestandteil der NS-Geschichtsdoktrin geworden war. „Dies bängt nicht damit zusammen, daß sich meine persönlichen Beziebungen zu ibm [Kossinna, D. H.] gelockert hatten und schließlich von etwa 1923 an überbaupt aufbörten. Es erklärt sich auch nicht aus meiner langsamen Trennung von der alldeutschen Gedanken. welt, die in den Jahren gegen 1930 vor sich ging. Ich war älter geworden, hatte viel gesehen und vielerlei erlebt; so empfand ich manches als fragwürdig, was ich bis dabin als festen Besitz meiner politischen Gedankenwelt empfunden batte. Hierzu gebörte aber das Verbältnis des völkischen Staates zur Wissenschaft im allgemeinen, und im besonderen zu meinem Fach, das sowobl im Rabmen seiner Außenpolitik wie in seinem kulturpolitischen Wollen nur zu leicht bestimmte Aufträge zur Erledigung bekommt. Ich sah, daß die völkische Deutung der Frübzeit gerne bestimmte geschichtliche Tatbestände unberücksichtigt läßt, und daß sie mit dieser Einseitigkeit auf Kosten der wissenschaftlichen Objektivität einer romantischen Schau den Weg bereitet. Ich abnte eine sich daraus ergebende Gefabr, daß meine Wissenschaft nicht alle Wunschträume erfüllen würde, und fürchtete, daß sie auf die Dauer unter der politischen Belastung leide. In der im Spätjabr 1931 erschienenen, Deutschen Vorzeit' gebe ich diesen Bedenken gegenüber dem Einbau der Präbistorie in die Kulturpolitik der deutschvölkischen Bewegung in wenigen Sätzen, aber ganz offen, Raum. "233 Nach seiner "offenen“ Kritik an einer „völkischen Deutung der Frübzeit ist es", so räumte Wahle kurz vor Kriegsende ein, „natürlich auch für mich ein Erlebnis, zu seben, wie die deutsche Gegenwart [nach 1933, D. H.] das eigenste Arbeitsgebiet auf den Scbild hebt, wie sie ibm eine besondere Stellung in ibrem Bildungsideal zuerkennt und danach strebt, seine Ergebnisse für die Gestaltung der Zukunft nutzbringend zu verwerten. Wie weit ich mich in der Lage füble, dieser in ibrem akademischen Rang erböbten Präbistorie zu dienen, setze ich in den Jabren 1934 bis 1936 in drei eng zusammengehörenden Aufsätzen auseinander [...]. ${ }^{234}$ Die programmatischen Beiträge für das Deutsche Bildungswesen von 1934, 1935 und 1936 waren aber ein klares Bekenntnis zum neuen Regime mit seiner offiziellen Förderung einer spezifisch deutschen Vorgeschichtswissenschaft gewesen, und gleichzeitig ein Versuch Wahles, nach der Machtergreifung die eigenen völkischen Vorstellungen von deutscher Vorgeschichte nun an die Geschichtsdoktrin des „Dritten Reiches“ anzuschließen. Daß ihm dies letztendlich nicht gelang, zei-

233 UBH Heid. Hs. 3989, 1,1, Selbstdarstellung 1945, 27.

234 UBH Heid. Hs. 3989, 1,1, Selbstdarstellung 1945, 27-28. 
gen die Beanstandungen seiner wichtigsten Publikationen (vgl. weiter unten). Die Geschichtsbilder der zersplitterten „völkischen Bewegung“ waren aus der Sicht Wahles Grundlage für nationalsozialistische Geschichtsbilder gewesen, und so äußerte er in einer Vorlesung von 1947: „Die Geschichtsauffassung des 3. Reiches ist von der völkischen Bewegung, also z. T. schon vor dem 1. Weltkrieg, vorbereitet worden. Ibre Formulierung aber hat sie erst gegen 1933 bin erfabren, und erst in der Folgezeit ging man daran, die Präbistorie ibr dienstbar zu ma-

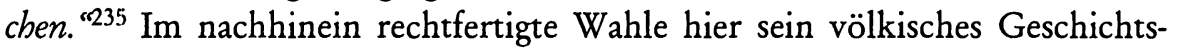
verständnis, weil es älter sei als das nationalsozialistische, bestätigte es auch als Basis der nationalsozialistischen Geschichtsdoktrin, führte aber die Instrumentalisierung der Vorgeschichtswissenschaft 1933-1945 allein auf den Nationalsozialismus zurück. Eine Verantwortung der deutschen Vorgeschichtswissenschaft für den Nationalsozialismus und seine Folgen bestand aus der Sicht Wahles ebensowenig, wie eine Verantwortung der „völkischen Bewegung", aus deren Reihen er kam.

Besonders in der Indogermanenfrage schieden sich die Geister der Völkischen. Entgegen der von Kossinna vertretenen Meinung hatte Wahle Ende der 1920er Jahre die Heimat der Indogermanen in den Steppengebieten des Ostens gesucht, wie schon einige Linguisten des 19. Jahrhunderts. Diese These war aus dem Gedankenaustausch mit den bereits erwähnten Kollegen Wahles in der Incalcata, Hermann Glockner und Hermann Güntert, um 1927/28 hervorgegangen, ${ }^{236}$ denn 1924 hatte Wahle noch keine Möglichkeit gesehen, die Heimat und archäologische Kultur des „indogermanischen Urvolkes“ zweifelsfrei zu identifizieren. ${ }^{237}$ Wahle führte die Ethnogenese der Germanen dann 1932 auf die „Auseinandersetzung und Durchdringung einer ansässigen Bevölkerung mit einem fremden Eroberervolk" im Neolithikum zurück. In der ansässigen Bevölkerung sah er neolithische Ackerbauern und Hirten im Ostseegebiet, die Erbauer der Megalithgräber. Die Kultur dieser „Riesenstubenleute“ hätte sich mit der Kultur einwandernder Indogermanen, der „Streitaxtleute“, vermischt. ${ }^{238} \mathrm{Im}$ Neolithikum seien also die Indogermanen aus dem Osten kommend als "Herrenvolk“ in das Gebiet "nordischer" Bauernvölker eingewandert und die Germanen dort durch die Mischung beider Völker ent-

235 UBH Heid. Hs. 3989, 4, B5, 10.

236 Wahle 1932, IX: „Die Auffassung, daß die Heimat der Indogermanen in den Steppen des Ostens liegt, erfubr durch Aussprachen mit dem biesigen Vertreter der vergleichenden Sprachwissenschaft, Herrn Prof. Güntert, mannigfache Förderung."

237 Wahle 1924, 58-60.

238 Glockner 1973, 164-165; vgl. Wahle 1932, 66-70. 
standen. ${ }^{239}$ Als Erzeuger der schnurverzierten Keramik und der charakteristischen geschliffenen Steinäxte (sog. „Streitaxtkultur“ bzw. „Schnurkeramik“) sah Wahle mithin die Indogermanen an.

Zur Stützung seiner These von der Ethnogenese der Indogermanen zog Wahle die Indogermanistik und die Forschungen seines Kollegen Hermann Güntert heran, die davon ausgehen, „daß die Sprachen der indogermanischen Einzelvölker nur durch den Einflu $\beta$ fremder Sprachen auf diejenigen des Urvolkes entstanden sein können [...] und daß die Heimat dieses Urvolkes im Osten zu su-

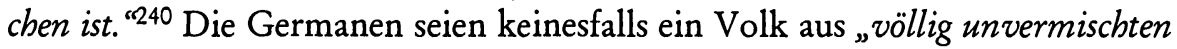
Indogermanen", ganz gleich, wo man ihre Urheimat auch suche. ${ }^{241}$ Die erste germanische Lautverschiebung sei auf die von Wahle postulierte Vermischung zurückzuführen, denn in „den lautlichen Tatsachen der germanischen Lautverschiebung und ibrer Durchfübrung spiegelt sich die Umbildung und Beeinflussung nordisch-germanischer Art durch den steinzeitlichen Megalith-Adel [...]. ${ }^{\text {"242 }}$ Eine „Mischung von kriegerischen und bäuerlichen Erbanlagen" schuf, so Güntert weiter, „die Art des, faustischen Menschen " bei den Germanen, die „germanische faustische Seele. "Dabei sei die Art des „faustischen Menschen“ nur den Germanen durch die "beinabe entgegengesetzten elterlichen Erbanlagen" eigentümlich, und nicht, wie Spengler behauptete, allen abendländischen Völkern. Ursache des Nieder- und Unterganges aller indogermanischen Stämme sei die „Entnordung der Fübrerschicht", denn "nicht schlechthin Reinrassigkeit, wobl aber Er. baltung der indogermanisch-nordischen Herrenschicht ist die wichtigste Voraussetzung zu indogermanischen Kulturleistungen!", so Güntert 1934. ${ }^{243}$ Politisch legitimierte Güntert seine These von der germanischen Ethnogenese mit Sätzen aus Hitlers "große[r] kulturpolitischer Rede“ vom September 1933: „Über die Entstebung des deutschen Volkes aber sagte der Fübrer: ,Das deutsche Volk ist nicht anders entstanden wie fast alle der uns bekannten wirklich schöpferischen Kulturvölker der Welt. Eine kleine organisationsfähige und kulturell schöpferisch begabte Rasse hat im Lauf vieler Jabrbunderte andere Völker überlagert und zum Teil aufgesaugt, zum Teil sich angepaßt. [...] Aus Siegern und Besiegten ist unterdes längst eine Gemeinschaft geworden. Es ist unser beutiges Volk. Und so wie es ist, lieben wir es und bängen an ibm. "'244 Andere NS-Sprachwissenschaftler

239 Wahle 1932, 69; vgl. auch Tabelle 3 .

240 Wahle 1932, 249, Anm. 61.

241 Güntert 1934, 71.

242 Güntert 1934, 84.

243 Güntert 1934, 132-133.

244 Güntert 1934, 182-183. 
lehnten Günterts These eines nichtindogermanischen "nordmegalithischen" Substrats im Germanischen ab. Zu Günterts Buch hieß es etwa: „Die leitenden Gedankengänge in dieser Arbeit sind wesentlich durch das Buch von E. Wable, Deutsche Vorzeit (Leipzig 1932) gelenkt worden. "245

Der bereits erwähnte Heidelberger Kulturphilosoph Hermann Glockner kam schließlich 1935 zur Synthese der kollegialen Forschungsergebnisse und führte die "deutsche Philosophie" auf "die Unausgeglichenbeit der deutschen Seele" und diese auf die prähistorische Völkermischung zurück: „Zwei Seelen wohnen ach! In unsrer Brust. Nämlich: eine Bauernseele und eine Soldatenseele. Mit unserer Bauernseele sind und bleiben wir der Erde und ibren Geheimnissen ebrfürchtig verbunden. Daher kommt das Lastende und das in die Tiefe ziehende der deutschen Philosophie; wir werden schwer über allem und alles wird schwer über uns [...]. Auch als Denker und Forscher bängen wir an unseren Abnen [...]." In einer Fußnote dazu wird angemerkt: „Hermann Güntert bat in seinem Buch ,Der Ursprung der Germanen' (1934) zu zeigen versucht, daß dieser Zwiespalt bereits germanisch ist und aus der Verschmelzung einer indogermanischen Herrenschicht mit dem Bauernadel der sogenannten Riesenstubenleute (megalithischer Bauernadel dalischer Rasse) erklärt werden kann [...]. Vgl. auch [...] Ernst Wables $z u$ den gleichen Ergebnissen fübrende ,Deutsche Vorzeit' (1932). ${ }^{\text {'46 }}$ Noch 1973 schrieb Glockner, das Buch Der Ursprung der Germanen von Hermann Güntert ginge „auf das zwiespältige bäuerlich-ritterliche Abnenerbe [!] der Germanen" ein. ${ }^{247}$ Anhand des „Faustischen“, des ständigen rastlosen Suchens nach tieferen "geistigen“ Erkenntnissen einerseits und des „Entschluß[es] und Wille[ns]" (Glockner) andererseits, die Oswald Spengler als typisch für das „deutsche Wesen" angesehen hatte, ${ }^{248}$ wurde durch Wahle, Güntert und Glockner eine abstammungsgeschichtliche Fiktion entwickelt, mit der die Entstehung der

245 Krause 1940/41, 27-28, 35 mit Anm. 32; vgl. UBH Heid. Hs. 3989, 1,6, [Karte Günterts an Wahle, 5.12.31]. Güntert dankt Wahle für die Übersendung seines Buches Deutsche Vorzeit: „Nun wird das Buch wäbrend der nächsten Monate kaum von meinem Schreibtisch verschwin. den; denn ich möchte meine Germanenarbeit [...] wieder aufnebmen und Ibre und meine These von der sprachgeschichtlichen Seite bestätigen und beweisen. Hoffentlich wird dann die Indogermanenfrage auf neuen, sichereren Grund gestellt [...] Ich wünsche nichts mebr, als daß Ibre Ansicht auch von Ibren Fachgenossen anerkannt wird und sich Babn bricht: alles Gute!" Glockner 1934, 15.

247 Glockner 1973, 165. Noch $1999^{6}$ (!) beginnt das Historische Lexikon der deutschen Länder von Gerhard Köbler mit dem Satz: „Die deutsche Geschichte ist zunächst und vor allem die Geschichte des deutschen Volkes, das sich allmäblich aus indogermanischer und germanischer Wurzel entwickelt bat."

248 von See 1994, 223 f. 
Germanen auf die „rassische Vermischung“ von Osten einwandernder Indogermanen und eines ansässigen „Megalithvolkes“ zurückgeführt wurde.

Die so Anfang der 1930er Jahre feststehende These Wahles von der Urheimat der Indogermanen im Osten stand der NS-Geschichtsdoktrin entgegen, nach der, wie von Kossinna behauptet, die Heimat der Indogermanen in Norddeutschland und in Skandinavien zu suchen sei. ${ }^{249}$ Wahle war sich dessen offenbar bereits früh bewußt, denn Glockner erwähnte eine Äußerung Wahles um 1928: „... wie aber werden sich die Rassefanatiker mit einer vergleichenden Sprachwissenschaft abfinden, die nun sogar im Fernen Osten noch Verwandtes aufspürt und z. B. allen Ernstes im Koreanischen einen indogermanischen Einschlag annehmen muß?" 250 Die „Rassefanatiker" reagierten tatsächlich, und die Deutsche Vorzeit brachte Wahle schon 1934 in Schwierigkeiten. In der Bücherkunde der Reichsstelle zur Förderung des Deutschen Schrifttums wurde vermerkt: „Das Buch kann nicht gefördert werden“. Moniert wurden die weitgehende Beschränkung des Verfassers auf die Geschichtsschreibung ohne Darstellung der Bodenfunde, die Vernachlässigung der Bronze- und Eisenzeit und seine Ansicht, die Urheimat der Indogermanen liege in den Steppengebieten des Ostens. „Scharfer Einspruch" wurde ferner erhoben gegen das Frontispiz, die Reproduktion eines romantischen Gemäldes von Karl Blechen aus dem Jahr 1828, das "fellbehangene und tierkopfgeschmückte germanische Krieger mit bunnischen Gesichtszügen" zeige und damit „ungewollt", so wird zwar entschuldigend vermerkt, „zur Verbreitung der falschen Vorstellung vom germanischen Barbarentum " beitrüge. ${ }^{251}$ Die Indizierung des Buches wirkte sich deutlich negativ auf seinen Absatz aus, der liegengebliebene Rest der Auflage verbrannte 1943 in Leipzig. ${ }^{252}$ Günterts Buch Der Ursprung der Germanen, das übrigens Eugen Fehrle gewidmet war, ereilte aus gleichen Gründen ein ähnliches Schicksal wie Wahles Deutsche Vorzeit. Der Verlag lehnte den Druck des bereits gesetzten Buches $a b,{ }^{253}$ und aus einer Verlagsanzeige ist ersichtlich, daß es ursprünglich bei J. F. Lehmann in München erscheinen sollte. ${ }^{254} \mathrm{Das}$ Buch kam schließlich 1934 bei Winter in Heidelberg heraus.

249 Vgl. hierzu auch Lutzhöft 1971, 114-123.

250 Glockner 1973, 165.

251 Vgl. Rave 1940, 225-227, Nr. 603. Das Gemälde mit dem Titel Das Semnonenlager zeigt Semnonen, die sich zum Aufbruch gegen die Römer rüsten.

252 Wahle 1980, 53.

253 Güntert 1934; vgl. Meid 1974, 520. Über die näheren Umstände, ob das Buch behördlich indiziert wurde oder nur der Verlag es ablehnte, war nichts in Erfahrung zu bringen.

254 Vgl. den Anzeigenteil in Darré 1930, unn. S. 5. 
Vermutlich 1933 war Wahle beauftragt worden, für das im Athenaion-Verlag in Berlin erscheinende Handbuch der deutschen Geschichte ${ }^{255}$ das Kapitel Von der Urzeit bis zum Ende des römischen Reiches zu schreiben. Auf Anregung Günterts trennte Wahle die „Indogermanisierung“ von den neolithischen Bauern. Die erste Lieferung mit dem Beitrag Wahles erschien 1935. ${ }^{256}$ Mehrfach kamen seit 1934 Änderungswünsche von Seiten des Verlages, und zwar auf Betreiben eines dem Verlag verbundenen Studienrates, „eines der ältesten Mitglieder der NSDAP in Potsdam mit einer ziemlich niedrigen Mitgliedsnummer". 1936 wurde Wahle schließlich mitgeteilt, seine Darstellung stünde im Widerspruch zu den Richtlinien des Ministers für Wissenschaft, Kunst und Volksbildung, nach welchen u. a. die "mitteleuropäische Heimat unseres Volkes" herausgestellt werden müsse. Der Verlag, so ließ man durchblicken, müsse auch an den Absatz seiner Publikationen denken. Wahle kam den Änderungswünschen nicht nach. Er ließ den Kontakt zum Verlag einschlafen, so daß dieser in der Neuauflage der ersten Lieferung $1938^{257}$ den Beitrag Wahles durch einen von Walter Frenzel (1892-1941) ersetzte - nicht ohne in einem Waschzettel darauf hinzuweisen, daß Wahles Darstellung überholt sei, den Absatz und das Ansehen des Werkes schädige. Der Standpunkt Wahles in der Indogermanenfrage werde von der Mehrzahl der Fachgenossen nicht geteilt. ${ }^{258}$ Frenzels Beitrag trug den Titel Älteste Geschichte der Germanen und Grundlagen deutscher Volkbeit. ${ }^{259}$

Im Erlaß des Reichsministers für Wissenschaft, Erziebung und Volksbildung vom 15.1.1935 ist zu lesen: „Die Weltgeschichte ist als Geschichte rassisch bestimmter Volkstümer darzustellen. An die Stelle der Lebre, ex oriente lux' tritt die Erkenntnis, daß mindestens alle abendländischen Kulturen das Werk vorwiegend nordisch bestimmter Völker sind [...]. ${ }^{\circ 60} \mathrm{Daß}$ die „Volkstümer rassisch be-

255 Herausgeber war, neben Otto Brandt und H. Ullmann, Arnold Oskar Meyer, dessen Geschichtsbild schon in den 1920er Jahren "mit völkisch-rassistischen, alldeutsch-nationalistischen und antisemitischen Versatzstücken angereichert" war (Wegeler 1996, 92).

256 Wahle 1935d.

257 Die Wahle zugegangenen Korrekturabzüge seines Beitrages befinden sich in UBH Heid. Hs. 3989, $2,5$.

258 Wahle 1980, 57-58.

259 Frenzel o. J [1938]. Dort heißt es unter Entstehungsgebiet des Urindogermanentums (30): „Nur das Negative kann als festebend angeseben werden: Die Charaktertiere und Pflanzen der asiatischen Steppen und Hocbländer haben keinen gemeinsamen indogermani. schen Sprachstam $m$, waren also in der Zeit des ungeteilten Gesamtvolkes diesem unbekannt (Esel, Maultier, Yak, Kamel und Katze). In deren Lebensbereich kann die Heimat der Indogerma. nen nicht gelegen haben. "[Hervorhebung von F.].

260 Zit. nach Hartung 1996, 37. 
stimmt" waren, daran gab es allerdings auch für Wahle und seine Kollegen keinen Zweifel. Durch seine schon vor 1933 vorgetragene individuelle Interpretation völkischer Vorgeschichte kam Wahle mit dem offiziellen völkischen Geschichtsverständnis schon unmittelbar nach der Machtergreifung in Konflikt. Im Gegensatz zu diesem sah Wahle seine völkische Vorgeschichte als wissenschaftlich fundiert an und vertrat sie deshalb entsprechend beharrlich gegen die NS-Ideologen. Das war seine „wissenschaftliche Opposition“ gegen ein Regime, dessen Kommen er im Hinblick auf seine Wissenschaft zwar begrüßt und von dem er mit der Einrichtung des Heidelberger Instituts profitiert hatte, dessen totalitäre Restriktion er aber jetzt zu spüren bekam, ohne jemals nur annähernd ein politisch Oppositioneller gewesen zu sein: Als völkischer Wissenschaftler war Wahle in einen Zwiespalt von wissenschaftlicher Opposition einerseits und politischem Opportunismus andererseits geraten.

Wie die Deutsche Vorzeit, so gab eine weitere kleine Schrift Wahles Grund zu „weltanschaulicher" Beanstandung, diesmal von Seiten der Badischen Historischen Kommission, die dem Kultusministerium in Karlsruhe unterstellt war. Wahle war beauftragt worden, einen Beitrag mit dem Titel Vorzeit am Oberrhein zu verfassen. Er erschien 1937 als Heft 19 der Neujabrsblätter der Badischen Historischen Kommission. Der Auftraggeber stieß sich nicht an Wahles These über die Urheimat der Indogermanen, die Wahle hier in gleichem oder ähnlichem Wortlaut vertritt wie 1932. In dieser Publikation wurde, so Wahle selbst, „versucht, die Darstellung in einen ethnischen Begriff der Gegenwart, nämlich den alemannischen Volksstamm, ausmünden zu lassen. ${ }^{\text {261 }}$ Für die Zensur war nach Wahles eigenen Angaben seine geographische Definition des Begriffes "Oberrbein" verantwortlich. Danach endete der Oberrhein schon vor Karlsruhe. Wahle selbst führte die verlangten Änderungen der staatlichen Badischen Historischen Kommission auf die Verteidigung der „Selbständigkeit des Gaues Baden und den Karlsruber Sitz seiner Verwaltung gegenüber gewissen Plänen der Reichsreform" zurück. Der Begriff Oberrhein liege noch nicht fest, umfasse aber mindestens das ganze Land Baden. Das einleitende Kapitel Das Land wurde letztendlich ganz gestrichen, ${ }^{262}$ Einleitung und der Schluß erheblich verändert und ein separates Vorwort der Badischen Historischen Kommission hinzugefügt (Tabelle 1). 
Tabelle 1. Textänderungen in Vorzeit am Oberrhein (Neujabrsblätter der Badischen Historischen Kommission, Heft 19). Heidelberg: Carl Winter's Universitätsverlag, 1937.

Verlagsnummer 2542

Verlagsnummer 2542a [zensiert]

(5) „Das Land“

[gestrichen]

(6) „Diejenige Kraft aber, welche diese so verschiedenartigen Landschaften in unserem Bilde vom Oberrheingebiet zusammenfügt, ist das Volkstum. Wir verstehen unter Oberrhein den alemannischen Rhein. [...] Über natürliche Grenzen hinweg hat hier ein Volkstum seine Kraft gespannt, und wenn auch die politischen Grenzen der späteren geschichtlichen Entwicklung den Alemannen die Einheitlichkeit der Staatsgesinnung genommen haben, so ist doch die Stammesart geblieben. Bewußt gefühlt von den einen, weniger empfunden von anderen und womöglich abgestritten von dritter Seite, äußert sie sich im Elsaß, in Baden und in der Schweiz dem aufmerksamen Beobachter in einer unverkennbaren Einheitlichkeit und Geschlossenheit."

(96) „Aus den diesseits der Sprachgrenze verbliebenen Südgermanen werden jetzt Deutsche, und auch über dem Oberrheingebiet, einem Lande der zähen Arbeit vieler Geschlechter, alter Kultur und mannigfacher Schicksale, steht jetzt das Kreuz!“

(96) „Indem aber hier die germanische Welt den neuen Glauben ihrer Art entsprechend aufnimmt und gestaltet, führt sie die Kultur des deutschen Mittelalters herauf."

Wahles nationalchauvinistische Haltungen sind kein Produkt der Zeit nach 1933. Bereits 1930 hatte er das Elsaß und Lothringen als deutschen, weil germanischen Siedlungsraum reklamiert und warf den Franzosen vor, die „These von den ebemaligen Wobnsitzen der Kelten auch am Rbein" erscheine ihnen geeignet, „politische Ansprüche der Gegenwart zu begründen. "Im Handbuch der Frankreichkunde hatte Wahle das einleitende Kapitel Die vor- und frübgeschichtlichen Grundlagen der französischen Geschichte verfaßt und darauf ausgerichtet, diesen Anspruch zu widerlegen. ${ }^{263}$ Zwar behaupte sich trotz des 
germanischen Einflusses in der Völkerwanderungszeit die vorrömische Bevölkerung in der Normandie, sei die germanische Oberschicht letztendlich in der romanischen Bevölkerung aufgegangen, doch heißt es abschließend: „Nur im Elsaß und in einem Teile von Lotbringen ist die Entwicklung anders; hier sind Alemannen und Franken zablreich genug, um die romanisierte Mischbevölkerung in sich aufzunehmen, und so liegen denn diese Gebiete östlich von der germanischromanischen Sprachgrenze. ${ }^{\text {264 }}$

1935 schrieb Wahle über den Oberrhein: „Wenn im Laufe einer mebrtausendjäbrigen frühgeschichtlichen Entwicklung der Rhein zur Grenze wird, dann geschiebt dies also nur auf Grund einer nicht an ibm bebeimateten ortsfremden Machtpolitik. Denn das Land, das man von den Randgebirgen her so bequem überschaut, gebört zusammen. Hier wie dort von germanischen Bauern bewobnt, tritt es ein in das deutsche Mittelalter. ${ }^{1265}$ Der Vorlesungstitel Kelten, Römer und Germanen im Kampf um den Rhein ${ }^{266}$ läßt vermuten, daß Wahle in dieser im WS 1936/37 angebotenen Lehrveranstaltung archäologische Forschung ähnlich politisch instrumentalisierte, wie in der gemaßregelten Veröffentlichung der Badischen Historischen Kommission von 1937.

Wahles Äußerungen lassen kaum vermuten, daß ihr Urheber den Vertrag von Locarno politisch gutgeheißen hatte, der doch Frankreich die Unverletzlichkeit seiner Ostgrenze - Wahles "alemannischen Rbein" - garantierte. Wahles eigene völkische Instrumentalisierung der Frühgeschichte war aber zum Zeitpunkt der Publikation offenbar noch nicht opportun. In Hitlers außenpolitischer Konzeption spielte das Elsaß eine - zumindest vordergründig untergeordnete Rolle: so wollte er „den ewigen Germanenzug nach Süden und Westen Europas" stoppen, zugunsten französischen Stillehaltens gegenüber der deutschen Ostpolitik - daher der öffentliche Verzicht auf Elsaß-Lothringen, der Revanchegedanken kaschierte und wiederholt als Beweis von Hitlers Friedenswillen gegenüber Frankreich diente. ${ }^{267}$ Die Zensur von Wahles Publikation Vorzeit am Oberrbein erfolgte zu einer Zeit, als Deutschland den Vertrag von Locarno zwar schon aufgekündigt hatte und damit die Garantie einer deutschen Westgrenze hinfällig geworden war (1936), man Frankreich aber keinesfalls mit revisionistischen Äußerungen in bezug auf Elsaß-Lothringen verstimmen wollte - um im Osten umso ungehinderter agieren zu kön-

264 Wahle $1930 \mathrm{a}, 13$.

265 Wahle $1935 \mathrm{e}, 13$.

266 Vgl. den Anhang.

267 Kettenacker 1973, 34-35. 
nen. ${ }^{268}$ Selbst nach der Kriegserklärung Frankreichs an Deutschland 1939 war man in der Formulierung von Ansprüchen auf Elsaß-Lothringen noch äußerst zurückhaltend. ${ }^{269}$ Daß die Badische Historische Kommission als Behörde des Kultusministeriums in Karlsruhe Wahle zurückpfiff, in einem ihrer Organe solche Gebietsansprüche historisch zu legitimieren, ist daher in Zusammenhang mit der nationalsozialistischen Außenpolitik zu sehen. Wahle stand mit seinem chauvinistischen Vorpreschen jedoch nicht allein: auch die in der Westdeutschen Forschungsgemeinschaft organisierten Wissenschaftler nahmen in der Frage Elsaß-Lothringen kein Blatt vor den Mund. ${ }^{270}$ So äußerte Franz Steinbach 1933 in aller Offenheit, die Ausführungen Hitlers zur Verständigung mit Frankreich nach Rückgabe des Saarlandes bedeuteten keinen Verzicht auf die alten „volksdeutschen Gebiete im Westen. Diese Ansprüche verjäh. ren nicht. ${ }^{271}$ Ein Kommilitone Wahles, der Geograph Friedrich Metz (18901969), ${ }^{272}$ leitete später in der Nachfolge von Wolfgang Panzer ab 1940 die Westdeutsche Forschungsgemeinschaft und hatte 1925 in seinem Buch Die Oberrbeinlande geäußert, die politischen Grenzen sollten mit den „Volkstumsgrenzen“ übereinstimmen. Nach Kriegsausbruch forderte er die „Einheit der Oberrbeinlande. ${ }^{273}$ Es ist hier noch anzufügen, daß der Verlag Winter in Heidelberg schon im Frühjahr 1946 „angewiesen“ wurde, die ursprüngliche Fassung (Verlagsnummer 2542, vgl. Tabelle 1) bei den noch am Lager befindlichen Exemplaren von Wahles Vorzeit am Oberrbein wiederherzustellen. Die Broschüren wurden zum Verkauf mit einer Banderole versehen: „Hiermit ist die Schrift, die kurz nach Erscheinen (1937) beanstandet wurde, in ibrer ursprüng. lichen Form wiederbergestellt. ${ }^{\text {"274 }}$

Die 1941 erschienene und vielbeachtete Veröffentlichung Ernst Wahles Zur ethnischen Deutung frühgeschichtlicher Kulturprovinzen gilt heute als fundamentaler Angriff auf Kossinnas siedlungsarchäologische Methode. Im Widerspruch zu Kossinna und den eigenen Schlüssen in seiner methodischen Ab-

268 Kettenacker 1973, 39.

269 Kettenacker 1973, 45.

270 Kettenacker 1973, 46-47; vgl. auch Fahlbusch 1999, 383-388.

271 Schöttler 1997b, 211.

272 Metz hatte 1913 wie Wahle bei Alfred Hettner promoviert (Fahlbusch 1999, 360, vgl. auch Wahle 1980, 57). „Er ist später mißverstanden und schlecht beurteilt worden, aber immer ein charaktervoller aufrechter Mann geblieben. Wir baben uns nach der Studienzeit nur gelegentlich und kurz gesehen, aber stets war er wie gestern, und so setze ich dem treuen Freunde hier gerne ein Denkmal. " (Wahle über Friedrich Metz, ebda., 121).

273 Kettenacker 1973, 46-47; Schöttler 1997b, 210.

274 Wahle 1980, 106. 
handlung in Scheidts Handbuch der Rassenkunde von 1925 schrieb ihr Verfasser nun, die Gleichsetzung von Kulturkreis und Volk dürfe nicht schematisch auf alle archäologischen Welten angewandt werden, denn die hinter keramischen Typen stehenden Menschen seien eben nicht zweifelsfrei zu fassen: ${ }^{275}$ „Natürlich hat diese Sprache der keramischen Typentafeln etwas Bestechendes; aber es fragt sich doch sebr, ob damit auch die binter ibnen stehenden Menschen so un. bedingt sicher gefaßt werden können, und ob nicht die an sich berechtigte Neigung der heutigen Präbistorie, mit einer bodengebundenen, Völkerbewegungen überdauernden Schicht von Menschen zu rechnen, bier in einer reichlich schematischen Form zum Ausdruck kommt. ${ }^{\text {"276 }}$

Anhand dreier Beispiele erörterte Wahle die Problematik und kam zu folgenden Schlüssen: 1.) es ist nicht möglich, die Sueben des Ariovist vor dem Hintergrund einer keltischen Urbevölkerung am Oberrhein archäologisch nachzuweisen; 2.) der Wechsel der Kunststile zwischen Hallstatt- und La Tène-Zeit ist nicht mit einem Bevölkerungswechsel verbunden; die Einheitlichkeit des Fundgutes könne nach Ausweis der Schriftquellen nicht mit einem Volk gleichgesetzt werden; und 3.) es ist methodisch ebenfalls nicht möglich, die Einwanderung der Germani cisrhenani Caesars archäologisch zu belegen: „Wenn dort, wo nach den Schriftquellen Germanen siedeln, eine Keramik erscheint, die man ibrem Stammbaum nach als sicher nicht-germanisch glaubt bezeichnen zu können, dann stebt man doch deutlich vor einer Unsicherbeit der archäologischen Methode. Entweder stimmen die Typenreiben nicht, oder sie verschleiern uns den tatsächlichen bevölkerungsgeschichtlichen Vorgang. ${ }^{277}$ Bei Kossinna sei der Vorgang einer germanischen Landnahme noch ganz einfach, eine Germanisierung der einheimischen Bevölkerung noch selbstverständlich. In der Zwischenzeit habe man aber auch gelernt, „mit Vorbevölkerung wie auch mit Unterschichten zu rechnen, die ibr Eigenleben wabren möchten. ${ }^{278}$ Sei dem Versuch, Fremdformen im archäologischen Formengut der Eisenzeit rechts des Rheines bis in das Saalegebiet als germanisch zu deuten, auch kein Erfolg beschieden, so weise „bier der allgemeine Inbalt der germanischen Frühzeit den Weg. Er lehrt uns nicht nur die fortgesetzte Ausweitung des [germanischen, D. H.] Siedelungsraumes, sondern auch das recht frühe Überschreiten des Niederrheines, auf welches die Schriftquellen binweisen [...] An dem

\footnotetext{
275 Wahle 1941, 28.

276 Wahle 1941, 39.

277 Wahle 1941, 44.

278 Wahle 1941, 45.
} 
vorgetragenen Beispiel zeigt es sich abermals, daß sich ein bevölkerungsgeschichtlicher Vorgang der formenkundlichen Erfassung zu entzieben vermag [...] Insbesondere aber steben wir vor der Erkenntnis, daß sich in den Funden doch nur ein bescheidener Teil des frühgeschichtlichen Lebens spiegelt. ${ }^{\text {279 }}$

Wahle gab in der Abhandlung einen kurzen forschungsgeschichtlichen Überblick zu Kossinnas siedlungsarchäologischer Methode. Sowenig wie sein Vordenker Oscar Montelius (1843-1921) bemühte sich auch Kossinna um die Begründung der Vorstellung, „daß der archäologisch greifbare Kulturkreis ein Volkstum anzeigt. "Beide gingen aufgrund der Typologie von einer Kontinuität sich „ganz allmäblich ablösender Kulturverbältnisse herab bis in die geschichtliche Zeit ${ }^{\mathrm{2} 80}$ aus und deuteten auch archäologische Funde aus prähistorischer Zeit ethnisch. Die zeitgenössische Forschung sei dem jedoch nur langsam gefolgt, weil diese Betrachtungsweise im "nordischen“ und besterforschten Raum gewonnen worden sei und damals auf die „Hallstattkultur“ oder andere weniger intensiv erforschte Fundprovinzen noch nicht habe angewandt werden können. „Dazu kommt, “ so Wahle weiter, „daß Kossinna selbst seine Methode vielfach nicht sonderlich glücklich anwendet und damit nicht gerade für sie wirbt. " Daß Kossinnas Methode dennoch an Boden gewonnen hätte, sei nur auf die Tatsache zurückzuführen, daß die Frage nach der Nationalität archäologischer Funde so alt sei wie die Forschung selbst. Dennoch sei die konsequente Verfolgung ethnographischer Ziele in der Prähistorie das eigentliche Verdienst Kossinnas und hätte ihre Entwicklung zu einer Geschichtswissenschaft unterstützt. ${ }^{281}$

Wahle hielt Kossinnas Diktum, die Verbreitung bestimmter Typen decke sich mit dem Siedlungsgebiet eines Volkes, in seiner Einseitigkeit offensichtlich für überholt, ohne aber die Methode der Siedlungsarchäologie an sich abzulehnen. Und er hatte auch eine Alternative anzubieten: wenn Kossinna versucht hätte, mit den Methoden und dem Blickwinkel seiner Generation die „historisch wirksamen Völker zu seben“, dann gälte es nun, „mit neuer Fragestellung an Funde wie Typentafeln beranzutreten, um der Präbistorie den Charakter einer Geschichtswissenschaft zu wabren. "282 Der „Fübrerpersönlichkeit" im archäologischen Fundmaterial, der „hervorragenden Einzelgestalt", die „den Gang der Ereignisse auf Grund ibrer besonderen Fäbigkeiten und der Zeitum-

\footnotetext{
279 Wahle 1941, 47.

280 Wahle 1941, 59-60.

281 Wahle 1941, 61.

282 Wahle 1941, 75.
} 
stände" bestimmt und dem Grad ihrer Wirksamkeit müsse die Forschung gelten: ${ }^{283}$ „Die hervorragende Persönlicbkeit ist also die Trägerin auch der frühgeschichtlichen Entwicklung; doch kann sie in dem archäologischen Stoff insgesamt mehr vermutet als wirklich nachgewiesen werden ". ${ }^{284}$ Daher bleibe die archäologische „Kulturprovinz“ das Subjekt der Prähistorie, doch gerate bei dem Für und Wider der ethnischen Deutung die wichtige Frage in den Hintergrund, „welche besonderen Lebensvorgänge denn jene Einheitlichkeit der Lebensführung hervorgerufen baben sollen [...]", die aus der Einheitlichkeit archäologischer Fundtypen erschlossen wird. ${ }^{285}$ Und weiter heißt es: „Daß binter einem geschlossenen, auch der Art seines Vorkommens nach einheitlichen Formenkreise ein nicht minder ausgeprägtes Volkstum steht, zeigen uns diejenigen Jabrbunderte, welche die Verkettung des archäologischen Stoffes mit der historischen Ethnographie gestatten. Man kann sogar sagen, daß hier überall, in welcher Zeit und welchem besonderen Raum man sich auch bewegen mag, die Eigenständigkeit der frübgeschichtlichen Nationalitäten durch das Vorbandensein entsprechender Fundprovinzen noch besonders unterstrichen wird. ${ }^{186}$ Mit seiner Kritik an Kossinna lehnte Wahle also keinesfalls die ethnische Deutung archäologischen Fundmaterials ab, sondern bestritt lediglich die Allgemeingültigkeit von Kossinnas siedlungsarchäologischer Methode. Vielmehr beabsichtigte Wahle, die historische Ethnographie im Sinne Kossinnas weiterzuentwickeln ${ }^{287}$ und die Frage zu erörtern, „wie weit die archäologischen Kulturprovinzen geschlossene Völker zu erkennen geben, und in welchem Umfang es der Präbistorie vergönnt ist, die hervorragende Einzelgestalt wenigstens in ibrer Wirksamkeit zu greifen. "288 Neben der Frage nach der archäologischen Nachweisbarkeit eines Volkstums ging er vom Vorhandensein von Fübrergestalten in der Frühgeschichte aus, wies aber auf die Probleme ihres archäologischen Nachweises hin. Reminiszenzen an ein völkisches Geschichtsbild und zeitgemäße faschi-

283 Wahle 1941, 75.

284 Wahle 1941, 96. In der Überzeugung, „daß der uniforme archäologische Stoff vielfach nur von der fübrenden Gesellschaftsschicht herrübrt", so Wahle im Vorwort zur 3. Auflage der Deutschen Vorzeit (Wahle 1962, XXI), hätte der Plan bestanden, der Darstellung Ethnische Deutung archäologischer Kulturprovinzen eine weitere unter dem Titel Herren und Hintersassen in archäologischer Greifbarkeit und bistorischer Bedeutung folgen zu lassen. Vgl. auch UBH Heid. Hs. 3989 1,1, Selbstdarstellung 1945, 31. Im SS 1952 bot Wahle auch eine Veranstaltung mit diesem Titel an (vgl. Anhang).

285 Wahle 1941, 97.

286 Wahle 1941, 100-101.

287 Vgl. UBH Heid. Hs. 3989 1,1, Selbstdarstellung 1945, 17.

288 UBH Heid. Hs. 3989 1,1, Selbstdarstellung 1945, 23. 
stische Führerparadigmen kann diese Publikation nicht verleugnen. Doch durch die offene Kritik an Kossinna galt Wahles Abhandlung nach dem Krieg als „mutige Tat" in der Zeit des Nationalsozialismus, weil sie gegen die NSGeschichtsdoktrin Reinerths und Rosenbergs verstieß. ${ }^{289}$ Die Abhandlung erlebte 1952 eine unveränderte Neuauflage.

Tatsächlich wurde auch diese Veröffentlichung Wahles parteiamtlich angegriffen. 1942 erschien in der Bücherkunde. Organ des Hauptamtes Schrifttumspflege bei dem Beauftragten des Fübrers für die Überwachung der gesamten geistigen und weltanschaulichen Schulung und Erziebung der NSDAP in der Rubrik Wir lebnen ab eine anonyme Rezension von Wahles AkademieAbhandlung. Wahles Auseinandersetzung mit Kossinnas Methode wurde hier - wie nach 1945 - als ihre Ablehnung bewertet. Der anonyme NS-Rezensent dreht sich beim Angriff auf Wahles Methodik und der Definition "geschlossener Funde" vielfach im Kreis, kann keine schlüssigen Argumente vorlegen, und seine Vorwürfe scheinen sich schließlich auf die Verletzung der Autorität Kossinnas als dem spiritus rector einer völkischen Vorgeschichtsforschung zu konzentrieren. Aber gerade Wahles Führerparadigma wird gewürdigt: die Leistung des einzelnen sei aber nur insofern für die Erfassung des „Volkstums" maßgeblich, wie sie „vom Volkstum als Ganzem, weil seiner Art entsprechend“, aufgenommen würde und sich die Leistung des einzelnen den Forderungen der Gesamtheit unterordne. Die Forschung nach dieser Gesamtheit, so zustimmend der Rezensent, liege „auch im Sinne einer nationalsozialistischen Geschichtsbetrachtung. "Wahles Angriff auf die Methode Kossinnas, so wird abschließend insinuiert, sei also wohl „nur von dem Wunsche getrieben“, „seine eigene Ansicht von der fast allgemein widerlegten, jedenfalls völlig abwegigen Behauptung von der Herkunft des Indogermanen aus Südrußland vor der Ablebnung zu retten". 290

Die drei ersten genannten Zensurfälle jedenfalls scheinen sonst für den Verfasser folgenlos geblieben zu sein, über Nachwirkungen des vierten ist nichts bekannt. In einem Schreiben des Gaustudentenführers Scherberger an den Gauschulungsleiter der NSDAP in Baden, Hartlieb, vom 11.1.1941, die Beurteilung der für die Wehrmachtsschulung vorgeschlagenen Dozenten betref-

289 Eggers 1986, 237, Bollmus 1970, 303, Anm. 11.

290 Bücherkunde. Organ des Hauptamtes Schriftumspflege bei dem Beauftragten des Führers für die Überwachung der gesamten geistigen und weltanschaulichen Schulung und Erziehung der NSDAP, 9. Jahrgang, Aug./Sept. 1942, Ausgabe D mit Gutachtenanzeiger (Bayreuth 1942) 270-271. 
fend, wird Wahle als „allgemein zuverlässig, obne besondere politische Betätigung oder Betonung" beurteilt. ${ }^{291}$

\section{Deutsche Vorzeit}

Das Buch Vorgeschichte des deutschen Volkes von 1924 war bald vergriffen und offenbar ein Erfolg. Aufgrund seiner theoretischen Ausrichtung und dem geographisch ausgerichteten Versuch, prähistorische Völker in ihren Siedlungsräumen als Teil der (Volks-)Geschichte darzustellen, wurde Wahle, wohl auch in seiner Eigenschaft als ehemaliger Kossinna-Schüler, von Kossinas Gegenspieler Carl Schuchhardt vorgeworfen, die materielle Kultur und damit die traditionelle Typologie zu wenig berücksichtigt zu haben. Das Buch solle besser den Titel Vorgeschichte des deutschen Bodens tragen, denn es werde dem Anspruch, eine Volksgeschichte zu sein, keinesfalls gerecht. ${ }^{292}$ Wahle ließ mit seinem Buch Deutsche Vorzeit von 1932 eine wesentlich erweiterte Überarbeitung folgen, die gegenüber ihrem Vorläufer vergleichsweise luxuriös ausgestattet war. Auch diese "historische Darstellung“ wurde in Fachkreisen zumindest zwiespältig aufgenommen. Der zu dieser Zeit am Römisch-Germanischen Zentralmuseum in Mainz angestellte Prähistoriker Ernst Sprockhoff kritisierte, daß Wahle zunächst nach wirtschaftsgeschichtlichen und soziologischen Gesichtspunkten in Urkultur, die Zeit der höheren Sammler und die Bauern des Neolithikums gliedere, für die folgenden Epochen dann aber eine historische Einteilung anwende. Keine Darstellung der reichen deutschen Vorzeit biete Wahle in seinem Buch, sondern eine Wirtschaftsgeschichte Mitteleuropas, die zudem noch unter dem Einfluß Vorderasiens gesehen werde. Dieser „Darstellung unter dem Titel,Deutsche Vorzeit" konnte Sprockhoff nicht zustimmen, denn das Bodenständige sei zugunsten eines Ex oriente lux stark vernachlässigt. Die archäologischen Funde als Quellenmaterial des Prähistorikers hätten wichtigere Aussagen $\mathrm{zu}$ machen als die Soziologie für das Paläolithikum und die "dürftigen schriftlichen Urkunden" für das Frühmittelalter: „Wable aber hat gerade die Sachgüter als Hilfmittel ungenügend herangezogen und damit die Vorgeschichtswissenschaft in ibrem ureigensten Gebiete vom Thron gestoßen und zum Aschenbrödel erniedrigt. ${ }^{\mathrm{N} 293}$

291 UAH PA 3690 Fritz Ernst, abgedruckt in Ernst [1996] 1959, 98.

292 Schuchhardt 1924.

293 Sprockhoff 1932, 318. 
Nach dem Krieg erschien 1950 eine zweite, „durchgearbeitete Auflage" der Deutschen Vorzeit bei der Wissenschaftlichen Buchgemeinschaft in Tübingen. Ein Teil der Auflage erschien auch bei dem Verlag Benno Schwabe in Basel, ${ }^{294}$ zehn Jahre später folgte noch eine dritte Auflage als unveränderter Nachdruck, der lediglich mit einem neuen Vorwort versehen wurde. ${ }^{295}$ Eine weitere Auflage hatte Wahle nicht vorgesehen, da er durch eine Kurzfassung des Themas, die bis 1999 mehrere Auflagen erlebte, keinen Bedarf mehr dafür sah. ${ }^{296}$ Die Wissenschaftliche Buchgemeinschaft hatte von Wahle zuvor den Nachweis einer ausreichenden Anzahl von Subskribenten verlangt, worauf dieser eine Umfrage bei den Geschichtsvereinen veranlaßte, ob an einer Neuauflage seines Buches überhaupt Interesse bestünde. ${ }^{297}$ Dies war der Fall. Die Wissenschaftliche Buchgemeinschaft, später in Darmstadt unter Wissenschaftliche Buchgesellschaft (WBG) firmierend, war 1949 von Ernst Anrich gegründet worden, dem auch Wahle im Vorwort zu DV ${ }^{2}$ dankt. ${ }^{298}$ Der Historiker Anrich, ein schillernder Nationalsozialist, war in enger Zusammenarbeit mit dem SS-Abnenerbe maßgeblich an der Gründung der Reichsuniversität Straßburg beteiligt gewesen. ${ }^{299}$ Anrich legte nach dem Krieg in der WBG einer Reihe wissenschaftlicher Aufsätze und Monographien wieder neu auf, die in den zwanziger und dreißiger Jahren entstanden und deren Autoren Denker der „Konservativen Revolution“ oder namhafte Wissenschaftler im „Dritten Reich" gewesen waren. ${ }^{300}$

Wahles Hauptwerke Vorgeschichte des deutschen Volkes von 1924 (VDV) und Deutsche Vorzeit in den Auflagen von 1932 (DV) und $1950^{2}\left(\mathrm{DV}^{2}\right)$ bieten sich zur Untersuchung von Kontinuität oder Wandel der Schriftsprache, Diktion und Inhalte an. Da diese Bücher schon vor bzw. erst nach der Zeit des "Dritten Reiches“ erschienen, sind aufgezwungene, angepaßte Diktion oder ideologische Lippenbekenntnisse auszuschließen. Die Synopse vergleichbarer Textstellen soll ansatzweise schriftsprachliche Übereinstimmungen - und damit Kontinuität - oder ihre Veränderungen sichtbar machen, auch wenn die

\footnotetext{
294 Wahle 1980, 63.

295 Wahle $1962^{3}$.

296 Wahle $1999^{9}$.

297 Wahle 1980, 62.

298 Wahle $1950^{2}$, IX.

299 Zur Person Anrichs: Kettenacker 1968; Heiber 1991, 417-421.

300 Kater 1974, 437, Anm. 206. Auf die anachronistischen Neuauflagen hat jüngst Wolfgang Behringer (1998) am Beispiel von Wilhelm Groenbechs Kultur und Religion der Germanen mit dem Vorwort des NS-Ideologen Otto Höfler hingewiesen.
} 
Textstellen dabei aus ihrem Zusammenhang gerissen werden. Während sich Textstellen der Auflagen von DV und $\mathrm{DV}^{2}$ durch die weitgehend unveränderte Gliederung im Textkorpus einfach vergleichen lassen, sind sich Passagen aus VDV kaum mit solchen aus DV und $\mathrm{DV}^{2}$ zu parallelisieren. Anhand einer Textstelle ist jedoch der inhaltliche und sprachstilistische Zusammenhang von VDV, DV und $\mathrm{DV}^{2}$ zu zeigen (Tabelle 2).

Tabelle 2. Veränderung und Kontinuität von Schriftsprache und Inhalten. Schlüsselbegriffe sind hervorgehoben.

Vorgeschichte des deutschen Deutsche Vorzeit (1932) Deutsche Vorzeit $\left(1950^{2}\right)$ Volkes (1924)

(39) „Beträchtlich ist der Arbeitsaufwand, den die Erbauung dieser Anlagen erfordert hat. Bei Erbauung der Befestigung von Urmitz unweit Koblenz sind rund $40000 \mathrm{cbm}$ Erde bewältigt worden, und zwar mit den einfachen Geräten jener Zeit! [...] Nur durch das einheitliche Zusammenwirken zahlreicher Kräfte können diese Werke geschaffen worden sein. Wir haben hier die Möglichkeit des Einblikkes in die straffe politische Organisation großer dörflicher Gemeinwesen, und es bleibt nur die Frage offen, ob dieser jeden einzelnen beherrschende Wille der Ausdruck einer aristokratischen oder einer demokratischen Gesellschaftsordnung war. Den gleichen Schluß für dieselbe Zeit gestatten uns die manchen Pfahlbaudörfern des Alpenvorlandes auf der Seeseite vorgelagerten Wellenbrecher."
(76-77) „Mögen die Pfahlreihen, welche gelegentlich die Seeseite der Pfahlbauten und Moorsiedelungen begleiten, von einer Befestigung herrühren oder als Wellenbrecher gedacht sein, - ihre Errichtung ist nur möglich, weil das Gefühl der Zusammengehörigkeit alle Kräfte vereinigt. So kann man auch um die Siedelungen herum schützende Gräben ausheben und Palisadenzäune anlegen, die von besonders erdachten Toranlagen unterbrochen sind. Gelegentlich entsteht auch einmal eine als Zuflucht für die Bewohner eines Gaues bestimmte Fliehburg. Eine Vorstellung von dem Arbeitsaufwand, der hierbei nötig ist, gibt die Tatsache, daß bei der Errichtung der großen Anlage von Urmitz unweit Koblenz allein etwa $40000 \mathrm{cbm}$ Erde bewegt worden sind."
(70) „In diese Richtung verweisen uns die Moorbrücken genau so wie die Einfriedigungen von Landund Moorsiedlungen sowie von den sog. Pfahlbauten, mögen sie nun als Schutz vor Menschen, Raubtieren oder Wellenschlag zu deuten sein. In jedem dieser Fälle ist ihre Herstellung nur möglich, weil das Gefühl der Zusammengehörigkeit viele Kräfte vereinigt. Bei der Errichtung der großen Anlage von Urmitz haben etwa $40000 \mathrm{cbm}$ Erde bewegt werden müssen, und für die Beschaffung des Holzes [...] war ein entsprechender Arbeitsaufwand nötig.“ 
Wahle schrieb im Vorwort zu DV² 1950: „Als [das Buch] 1932 erschien, waren etliche politisch orientierte Thesen im Begriff, die deutsche Präbistorie ibren Zwekken dienstbar zu machen. Das Buch hat damals aus der Abneigung gegenüber diesen Bestrebungen kein Hebl gemacht und somit jetzt nicht einer, Bereinigung' bedurft. " ${ }^{301} \mathrm{Im}$ wesentlichen dürfte hier das Postulat Wahles, die Indogermanen seien im Osten beheimatet gewesen, gemeint sein, das mit der "nordischen“ Herkunft, wie sie die NSDAP für die "nordische Rasse“ vorsah, unvereinbar war und letztlich zur Indizierung von Wahles Buch führte (vgl. oben). Die aus „Wunschbildern und kulturpolitischen Bestrebungen erwachsene, zum Teil recht umfangreiche Literatur" - so wird im Vorwort von DV ${ }^{2}$ die NS-Literatur zum "Germanentum" umschrieben. Es hätte sich die Frage gestellt, so Wahle, inwieweit diese in der Neuauflage zu berücksichtigen sei, „mu $\beta$ doch damit gerechnet werden, daß manche der damals weit verbreiteten und fortgesetzt wiederbolten Ansichten den Heutigen noch geläufig sind, und daß nur der Fachmann weiß, wie wenig tragfähig ibr Boden in Wirklichkeit ist. " Der Auseinandersetzung mit "diesen angedeuteten, zweckbestimmten Gedankengängen" sei jedoch nur in wenigen Fällen etwas Sachdienliches zu entnehmen. ${ }^{302}$

Die Bezeichnung „Vorgeschichte“ wurde nach 1945 als politisch belastet empfunden und deshalb vermieden. Auch Wahle sah den Begriff „Vorgeschichte“ nach 1945 als überholt an. ${ }^{303} \mathrm{DV}^{2}$ wird auf dem Titelblatt ${ }_{\text {}}$ durchgearbeitet" genannt, und in der Tat gibt es wesentliche Änderungen mit der Streichung oder Neuabfassung ganzer Textblöcke in III. Die Bauern der jüngeren Steinzeit und ibre Indogermanisierung. Die Streichungen betreffen "rassenkundliche“ und völkisch gefärbte Textstellen oder sind rein sachliche Änderungen (Tabelle 3, 54-55). Bis auf diese Streichungen sind die meisten „rassenkundlichen“ Äußerungen offenbar unverändert in $\mathrm{DV}^{2}$ übernommen worden, ja es gibt selbst neu hinzugefügte Verweise auf „rassenkundliche“ Publikationen Wahles, die nach 1932 erschienen waren. ${ }^{304}$ Ein verschleierndes „semantische[s] Wechselspiel zwischen Rassenkunde und Antbropologie“ nach 1945, wie es etwa bei Franz Petri zu beobachten ist, gibt es in den Nachkriegspublikationen Wahles nicht. ${ }^{305}$ Die typische und unverwechselbare Ter-

\footnotetext{
301 Wahle $1950^{2}$, VII.

302 Wahle $1950^{2}$, VII.

303 Wahle 1950², IX; vgl. Narr 1990, 279.

304 Wahle 1950², 287, Anm. 369: „E. Wable, Fremdes Blut im germ. Adel der geschichtlichen Früh. zeit (Z. f. Rassenkunde 4, 1936, 201-203)."

305 Schöttler 1999, 103.

306 Vgl. zu diesen Termini ganz umfassend Seidel/Seidel-Slotty 1961, 77-83.
} 
minologie von „Blut und Boden“ ist in der Neuauflage DV ${ }^{2}$ nach wie vor unverändert vertreten. ${ }^{306}$

Tabelle 3. Veränderung und Kontinuität von Schriftsprache und Inhalten am Beispiel ausgewählter Textstellen aus der ersten und zweiten Auflage des Buches Deutsche Vorzeit von 1932 bzw. $1950^{2}$. Schlüsselbegriffe sind hervorgehoben.

Deutsche Vorzeit (1932)

(DV)

(24) "So hat die römisch-germanische Forschung ein doppeltes Gesicht; einerseits soll sie ein Stück der antiken Welt, anderseits einen Abschnitt der deutschen Geschichte behandeln. Wie mit dem zweiten Teil dieser Aufgabe ihr Verhältnis zur Vorgeschichte bestimmt wird, so mit dem erstgenannten die geschichtliche Einstellung der süd- und westdeutschen Prähistorie.

Durch den Krieg und die nachfolgende Revolution werden geistige Strömungen stark gefördert, die vorher schon in Entwickelung begriffen sind. Man sucht in Natur und Geschichte der Heimat Kräfte zu finden, welche der Erstarkung des eigenen Volkstums dienen können; man sucht das Wesen der eigenen Art zu ergründen und ihr aus dem angestammten Boden neue Kräfte zuzuführen."

(50) „Damit aber gewinnen alle diese Denkmale für uns ein unmittelbares, ein persönliches Interesse; denn das Blut derer, die sie errichteten, lebt noch in uns."

(54) „Während aber die Träger des Michelsberger und Pfahlbautenkreises sowohl wie der Bauernadel der großen Steingräber in leiblicher Hinsicht vorwiegend langschädelig sind, begegnet in den Gräbern der Glockenbecherleute zumeist die Form des Kurzkopfes."

(54) „[Die dritte Bewegung verdient] Beachtung wegen der damit verbundenen Zufuhr fremden Blutes; der mit einem Kurzschädel ausgestattete anthropologische Typus erfährt durch sie einen bemerkenswerten Zuzug."
Deutsche Vorzeit $\left(1950^{2}\right)$

$\left(\mathrm{DV}^{2}\right)$

(26) „So hat diese sogenannte römischgermanische Forschung ein doppeltes Gesicht; einerseits soll sie ein Stück der antiken Welt, andererseits einen Abschnitt der deutschen Geschichte behandeln.

In den auf den ersten Weltkrieg folgenden Jahrzehnten nimmt die Menge der neuen, nach Bearbeitung verlangenden Funde ständig zu."

(51) „Damit aber gewinnen alle diese Denkmale für uns ein unmittelbares, ein persönliches Interesse; denn das Blut derer, die sie errichteten, lebt noch in uns." 
(55) „Eher muß man sich vorstellen, daß schon damals der in den großen

Erbbegräbnissen bestattende Bauernadel seine Rechte an die von Osten hereingebrochenen Indogermanen abgetreten hatte. In der Tat findet ein Zweig der Glockenbecherleute, welcher den Niederrhein überschreitet, im heutigen Holland dieses Herrenvolk, das die Entwickelung der Folgezeit bestimmt, bereits vor."

(55) [unter „b) Der nordische Kreis"] „Die Ankömmlinge sind stark genug, um in ihrem neuen Siedlungslande die Herrenschicht zu bilden. Sie bringen den Ackerbau und einige Nutztiere aus ihrer westeuropäischen Heimat mit, Kulturgüter, welche ihnen die wirtschaftliche Überlegenheit über die bodenständige Bevölkerung verleihen."

(58) „Ist der Rössener Stil nur der Ausdruck einer Kulturwelle, welche die band-

keramische Bevölkerung in Mitteldeutschland durchzieht, so lehrt der Vorstoß der Walternienburger und der aus ihr entstehenden Bernburger Kultur, daß die Bauern des bandkeramischen Kreises doch nicht in der Lage sind, das Flußgebiet der Saale auf die Dauer gegenüber dem Andrängen der nordischen Scharen zu halten. Aber nicht nur hier, sondern auch in den inneren Teilen von Böhmen weichen sie vor diesem

Tochterstamm des nordischen Volkes zurück [...]. Es scheint, als ob nicht nur in Böhmen, sondern auch an der Saale die Reste des bandkeramischen Volkes die Selbständigkeit zum mindesten ihrer Kultur noch längere Zeit behaupten.

Donaukultur und westeuropäische Einstrahlung hindern also das nordische Volk an einer stärkeren Ausbreitung nach Südwesten und Süden. Nicht minder bezeichnend als diese Tatsache ist es nun, daß sich die ganze Ausdehnungskraft des Nordens gegen den Osten und Südosten wendet. Die Auswanderer aus dem nordischen Kreise begegnen hier zunächst in Hinterpommern, Posen und Polen. Gelangen sie nach Ostpreußen nur in wenigen Ausläufern, so ist ihr Vorstoß längs Weichsel und Bug um so stärker; kommen sie doch auf diesem Wege bis nach Wolhynien und dem östlichen Galizien. Getragen wird diese mächtige Ausbreitung
(57) [unter „c) Der nordische Kreis"] „Sie sind stark genug, um in ihrem neuen Siedlungslande die Herrenschicht zu bilden. Sie bringen den Ackerbau und einige Nutztiere aus ihrer westeuropäischen Heimat mit, Kulturgüter, welche ihnen die wirtschaftliche Überlegenheit über die bodenständige Bevölkerung verleihen."

(59) „Da dieser [der Rössener Stil D. H.], einer Welle vergleichbar, große Teile der bandkeramischen Fundprovinz erfaßt, so hat man ihm gerne eine besondere Stellung eingeräumt. Doch ist diese Bewegung offenbar nur mehr äußerlicher Natur, denn sie ändert nichts an dem Wesen des Donaukreises, wenn auch dieser ihr gegenüber sehr aufnahmebereit erscheint. Die Berührung geht in dem Gebiete der mittleren Elbe vor sich, also in demjenigen Raum um Magdeburg, in welchem sich auch einige kleine Stuben finden. Ungleich nachhaltiger aber als diese Erscheinung sind diejenigen vorwiegend nordsüdlichen Bewegungen, welche nach den Fundorten Baalberge und Salzmünde, Walternienburg, Bernburg und Schönfeld, als Kugelflaschen- und Havelländische Gruppe benannt werden. Die Gliederung dieser vielfach eng verzahnten Typenkreise zeigt nicht nur ein zeitliches Nacheinander, sondern zugleich eine räumliche Verschachtelung der Fundgruppen, so daß die Neigung, jeden archäologischen Stil einem eigenen Volk oder Stamm zuzuschreiben, kaum durchführbar ist. Doch gibt der Stoff zu erkennen, daß die Donaukultur einschließlich der Rössener Schicht zugunsten der nordisch bestimmten Wellen im Laufe der Zeit verschwindet. Dies ist sowohl in SachsenThüringen der Fall wie, zumindest weitgehend, in Böhmen. Selbst dann, wenn man hier mit einer nennenswerten Menge von 
der nordischen Kultur von Leuten nordischer Art. Sie ziehen in diese Gebiete, wo bis dahin die Nachkommen frühneolithischer Sammlervölker, verstärkt vielleicht durch Zuzug aus dem Osten, fast unbeschränkte Herren sind. Doch ist die Schar dieser Auswanderer nicht genügend groß, um diese weiten Landschaften in ganzem Umfange zu besetzen; es scheint vielmehr, daß sie hier nur eine dünne Herrenschicht bilden, welche ihre wirtschaftliche Kultur langsam den Eingesessenen mitteilt. Wie sich im einzelnen die Beziehungen zwischen den diesen beiden Schichten der Bevölkerung gestalten, wissen wir noch nicht." [...]

(59) „Es ist aber sehr bezeichnend, daß dieser ansehnliche Gebietszuwachs nur mit der Aufgabe einer ganzen Anzahl von Eigentümlichkeiten des nordischen Kulturkreises erkauft wird. Deutlich sagen uns die Funde, daß dort, wo in den weiten Ebenen des Ostens die Nachkommen der frühneolithischen Sammler hausen, die nordische Kultur die überlegene ist, daß sie sich überall durchsetzt und nur in verhälnismäßig geringem Umfange Beeinflussungen von seiten der bodenständigen Bevölkerung zeigt."

[...]

"Wie in diesen Neuländern überall das Kulturgut der Auswanderer eine gewisse Veränderung erlebt, so muß auch mit einem (60) langsamen Wandel ihrer leiblichen Art gerechnet werden. Denn je weiter das nordische Volk die Kreise seiner Macht zieht, um so mehr Fremdblütige nimmt es in seinen Körper auf."

(63) [unter "c) Die Donaukultur"] "Der hier entstehende Rössener Typus ist das Zeugnis einer starken Durchtränkung der sächsischthüringischen Bandkeramik mit nordischen Elementen. Die Bedeutung dieser Fühlungnahme liegt darin, daß sich dieser Rössener Kreis als eine Kulturwelle der Mehrzehl der mitteleuropäischen Verbreitungsgebiete der Bandkeramik mitteilt.“

[...]

"Ja, längs des Alpenrandes überschreitet diese Bewegung sogar die Grenze der alten Stammesgemeinschaft und dringt in den Pfahlbautenkreis ein; auch hier sind die
Zuwanderern aus dem Norden rechnet, bleibt doch der Eindruck einer sehr starken bodenständigen Kraft, welche den verschiedenen Fundprovinzen ein eigenes, vielfach nicht-nordisches Gepräge verleiht. [...] Nicht minder bezeichnend aber ist es, daß sich die in den genannten Erscheinungen bekundende Ausdehnungskraft des Nordens im wesentlichen nach (60) Osten und Südosten wendet. Sie geht über Hinterpommern nach Ostpreußen, sowie Oder, Warthe und Weichsel aufwärts bis an den Fuß der Karpaten; erst im östlichen Galizien kommt sie zum Erliegen. Auch hier bleibt es wieder unentschieden, wo die Grenze zwischen einer Abwanderung der nordischen Jungmannschaft und einer Kulturwelle gezogen werden kann. Vorwiegend ergießt sich diese Bewegung über einen Raum, in welchem die bäuerliche Zivilisation bis dahin nur in Ausläufern vertreten war; hier zwischen der Nordgrenze des Lösses und der Ostsee siedeln die Nachfahren mesolithischer Sammlervölker, und es gilt zu überlegen, wie sich ihre Beeinflussung durch die überlegene Wirtschaftsform in demjenigen archäologischen Bilde spiegelt, welches von ihrem Gebiet jetzt Besitz ergreift. Schon die Größe des Raumes weist darauf hin, daß hier nur die Zivilisation gewandert sein dürfte; in der Tat deuten sich in dem keramischen Gut etlicher Siedlungen manche Züge an, die man für bodenständig erklären möchte. [...] Jedenfalls gibt sich eine außerordentliche Dynamik des nordischen Kreises zu erkennen, hinter welcher diejenige des Westens weit zurücksteht."

(53) [unter „a) Die Donaukultur"] „Sodann geht über große Teile des Gebietes die nach dem Fundort Rössen bei Merseburg benannte keramische Stilwelle hinweg, welche offenbar ein Zeugnis dafür ist, daß der Donaukreis jetzt die nordisch-megalithische Fundprovinz zum Nachbarn hat und daß von dieser her eine Wirkung auf ihn ausgeübt wird. Neue keramische Stilgruppen von geringerer Verbreitung sind der Gradmesser des Zerfalles der alten Einheit." 
keramischen Stilgruppen von kleiner

Verbreitung der Gradmesser des Zerfalls der alten Volkseinheit."

(69) [unter „e) Die Indogermanen und ihre Teilvölker“] „Aus denjenigen Indogermanen, welche in dem Gebiete der großen nordischen Steingräber heimisch werden, gehen die Germanen hervor. Wie der dortige Bauernadel seine Stellung an die neuen Herren des Landes abtreten muß, so gehören jetzt auch seine Erbbegräbnisse der Vergangenheit an."

(69) „Neben einigen Völkerstämmen westeuropäischer Herkunft sind insbesondere die Träger der Bandkeramik an der Entstehung der Kelten mitbeteiligt. [...] Im Vorlande der Alpen, insbesondere in seinem schweizerischen Anteil, stauen sich die Trupps der Indogermanen, die hier im Gebiete der der spätsteinzeitlichen Pfahlbauten eine verhältnismäßig dichte Besiedelung vorfinden. Nicht minder deutlich als anderwärts zeigt sich auch hier sofort das Kulturgut der neuen Herren, abenso aber die Bedeutung der bodenständigen Bevölkerung. Aus der Verschmelzung dieser Pfahlbautenleute mit den Indogermanen erwächst ein Volk, daß sich von dem in seinem Norden wohnenden Nachbarn unterscheidet."

[...]

„Stärker als sonstwo auf mitteleuropäischem Boden zeigt sich hier die ganze innere $\mathrm{Kraft}$ der neuen Herren, welche über Gebirge und Waldgebiete hinweg eine Reihe von sehr ungleichartigen Völkern und Stämmen zu einem Ganzen zusammenschweißen."
(62) [unter „d) Die Indogermanen und ihre Teilvölker"] „Aus demjenigen Zweig der Streitaxtleute, welcher von dem Gebiet der großen Steingräber Besitz ergreift, geht die Fundprovinz der nordischen Bronzezeit hervor. Die Sitte des megalithischen Familiengrabes gehört jetzt der Vergangenheit an."

(62) „An der Herausbildung dieser neuen ethnischen Welt sind offenbar auch die Träger der Bandkeramik mitbeteiligt."

(63) „Stärker als anderwärts zeigt sich hier die Kraft der neuen Herren, welche über Gebirge und Waldgebiete hinweg einer recht wenig einheitlichen Bevölkerung doch ein ganz bestimmtes Gepräge gibt.“

Der darwinistische Topos vom „Kampf ums Dasein“ bestimmte Wahles Vorstellungen von neolithischen „Völkerbewegungen“: ein hochwertiges Volk setzt sich stets im Kampf gegenüber einem minderwertigeren durch. So dringe im Neolithikum ein westeuropäisches „Megalithvolk“ nach Südskandinavien vor und später in Norddeutschland ein, überlagere in wirtschaftlicher Überlegenheit als „Herrenschicht" die mesolithischen "Sammlervölker“, die den Ackerbau nach und nach übernähmen. So bilde sich das "nordische Volk“, 
das sehr expansiv sei, sich überall gegenüber den „Sammlervölkern“ durchsetze und in Mitteldeutschland auf die „Bandkeramik“ („Donaukultur“) stoße, sich aber auch weit nach Ost- und Westeuropa ausbreite. Stets sind es Einwanderer, die eine höherstehende „Kultur“ (,bäuerliche Gesittung") einer niedererstehenden „bodenständigen Bevölkerung" weitergeben. ${ }^{307}$ Die Bauern „verwurzeln im Laufe der jüngeren Steinzeit fest mit ibrer Scholle", überstünden aufgrund dieser Bodenständigkeit die Einwanderung der aus Westeuropa kommenden „Glockenbecherleute“, um diese „binnen ganz weniger Geschlechter aufzusaugen." Irgendwann im Spätneolithikum kämen die Indogermanen als „Eroberervolk" von Osten, sähen in „diesen seßhaften Ackerbauern willkommene Knechte, welche ibnen gerade die Feldarbeit abnebmen, die ibnen ibrer ganzen inneren Einstellung nach nicht liegt [...] und treten hier als die neuen Herren auf." Pferd und Streitwagen hätten den Indogermanen die Unterwerfung der seßhaften Bauern ermöglicht. Aus Indogermanen und dem „Bauernadel“ im Gebiet der „großen nordischen Steingräber" entstünden schließlich die Germanen (vgl. auch Tabelle 4, 99). ${ }^{308}$

Die Vorstellungen von einwandernden „Herrenschichten " und einer unterworfenen „bodenständigen“ Bevölkerung als Faktoren prähistorischer Ethnogenese hatte Wahle um 1927 u. a. mit dem Bonner Historiker Fritz Kern diskutiert, der glaubte, zwischen der „Streitaxtkultur“ bzw. „Schnurkeramik“ und den indogermanischen Völkern "nordeurasischer Rasse" bestünde ein geschichtlicher Zusammenhang. ${ }^{309}$ Kern unterschied zwischen seßhaften „Pflanzer-" und wandernden „Bewegungsrassen", wobei die seßhaften stets als „Bauern“, die wandernden stets als „Herren“ anzusehen seien. ${ }^{310}$ Der „eurasische Typus“ sei eine typische „Bewegungsrasse“, die zu den „Herren“ und nicht zu den „Bauern“ gehöre, und dementsprechend zeige das indogermanische Wanderhirtentum „aristokratische Züge " ${ }^{311}$ Der spätere Reichslandwirtschaftsminister Richard W. Darré sah in Kerns Rassentheorien eine Geringschätzung des Bauernstandes zugunsten des Nomadentums. Der Bauer wurde im Nationalsozialismus mit der „Reinerhaltung des Blutes und der Rasse" verbunden und galt nach völkischem Verständnis zunächst als der Träger der Kultur eines

307 Wahle 1932, $55 \mathrm{ff}$.

308 Wahle 1932, $66 \mathrm{ff}$.

309 Kern 1927, VII, 171 ff.; vgl. Wahle 1932, 248, Anm. 61: „Kern sieht die spätsteinzeitlichen Streitaxtleute und ibre archäologischen Verwandten als die Keimzelle der Indogermanen an."

310 Kern 1927, $149 \mathrm{ff}$.

311 Vgl. Lutzhöft 1975, 117 ff.; Kern 1927, 197. 
Volkes. Derartige Vorstellungen hatten ihre Wurzeln in der zweiten Hälfte des 19. Jahrhunderts und begegnen schon bei Wilhelm Heinrich Riehl und Friedrich Ratzel. ${ }^{312}$ Doch eine „Herrenschicht nordischer Rasse [die] über einer nichtnordischen Bevölkerung [...] Adel ist" findet sich auch bei Darré, ${ }^{313}$ und der von Wahle so zustimmend rezensierte Hans F. K. Günther hatte 1926 geschrieben, die germanischen Bauern der vorgeschichtlichen Zeit „- und hier zeigt sich das Wesen der nordischen Rasse - diese Bauern waren "Adelbauern": Freibeitslust, Abnenstolz, Herrentum - [sic] machten ibr Wesen aus. " ${ }^{114}$ Wahles ethnogenetische Vorstellungen scheinen sowohl auf den Ansichten Kerns zu beruhen, als auch die verworrenen Vorstellungen Darrés und Günthers zu spiegeln, indem sie einerseits einwandernde Indogermanen als „Herrenschicht" darstellen, andererseits eine ansässige bäuerliche Bevölkerung als Bewohner von „Erbhöfen“ bzw. „Erbbegräbnissen“ und damit als „rassisch“ hochwertig annehmen. Der "völkischen" Aufwertung des doch von einem Einwanderervolk unterworfenen „Bauernvolkes“ kam Wahle entgegen, indem er einen neolithischen „Bauernadel“ als Erbauer der Megalithgräber propagierte, der wiederum selbst aus Westeuropa eingewandert sei. ${ }^{315}$ Sein „nordischer Kreis“ war mithin ebenfalls Kerns „Bewegungsrassen“ zuzuordnen und dementsprechend ließ Wahle das Siedlungsgebiet des "nordischen Kreises“ expandieren.

Sowohl „Bauer“ als auch „Adel“' sind Begriffe, die von Wahle und Kern einer „archetypischen Stilisierung " unterworfen wurden. In dieser für den Konservatismus nach 1918 typischen Tendenz wurden „gesellschaftliche Relikte der vergangenen politischen Ordnung zu orientierungsstiftenden Vor- und Urbildern eines unpolitischen gesellschaftlichen Daseins" umgedeutet. Nicht nur auf die gerade Geschichte gewordene Zeit des Kaiserreiches ließ sich diese archetypische Stilisierung anwenden, sondern ganz besonders auf die weit entfernte Urgeschichte. Auch der neolithische Pseudo-Adel und der neolithische PseudoBauernstand waren gesellschaftlich vordemokratische Strukturen, aus ihnen ließ sich ein „unpolitisches Idyll" herstellen, eine vordemokratische Welt, in der Politik nichts zählt und allein die Naturgewalt, die natürliche Auslese - darwinistisch gedacht - als Maßstab gilt. ${ }^{316}$ Urgeschichte kann hier als „ $\mathrm{Al}$ ternative zur modernen Welt" gelten, Vorgeschichtswissenschaft als dezidiert

312 Smith 1991, 129 f.; vgl. Schmitz-Berning 1998, s. v. Bauer, 85-86.

313 Darré 1930, 14.

314 Günther 1926, 20.

315 Wahle 1932, 55.

316 von dem Bussche 1998, 253, 257. 
konservative, antimoderne Disziplin, die in den 1920er und 1930er Jahren nicht zu einer Geschichtspflege, sondern zur Geschichtsverfälschung beitrug: die archetypische Stilisierung in der Vorgeschichtswissenschaft sollte ein Gegenbild der unliebsamen politischen Gegenwart liefern, ein „Wunschbild von Tradition". 317

Der Begriff „Bauernadel“ ist damit ein geeigneter Indikator für eine konservative, völkische Geschichtsauffassung. Wahle verwendete sie 1932 mehrfach in DV, strich sie aber 1950 in DV $^{2}$ ersatzlos. In DV taucht sie mehrfach in Verbindung mit dem Neolithikum und der produzierenden Wirtschaftsweise auf. Die „bäuerliche Megalithkultur“, so Wahle, sei ihrer archäologischen Erscheinung nach „einem Bauernadel vergleichbar, der einerseits als Herr auftritt, andererseits sebr eng mit seiner Scholle verwächst. "318 Trübners deutsches Wörterbuch in der Ausgabe von 1939 weiß hierzu ergänzend: „Als Walter Darré 1930, zugleich mit der Romantrilogie, Bauernadel' von H. E. Busse, die Schöpfung eines ,Neuadels aus Blut und Boden ${ }^{319}$ forderte, beseitigte er alle Abstraktionen, griff zurück auf die alte völkische Wurzel und stellte den Anschluß an die germanische Überlieferung her. Adal, der ,Erbhof', ist wieder in sein uraltes Recht eingesetzt. "320 „Bauernadel“ ist nach völkischer Auffassung eine Oberschicht, die, Kennzeichen des „deutschen“ oder „germanischen Adels“, für die „erbliche Weiterreichung der erprobten Fübrerbegabung" sorgt - nur so wird sie zu einer „Fübrerschicht“ ${ }^{321}$ Entsprechend ist auch bei Wahle von den Megalithgräbern als „Erbbegräbnissen“ des neolithischen „Bauernadels" die Rede (Tabelle 3, DV 55, 69). Es ist bemerkenswert, daß auch das Parteiprogramm der NSDAP die Abschaffung des Bodenzinses forderte, damit „aus Blut und Boden ein neuer Bauernadel entstehe. ${ }^{\text {"322 }}$ „Blut und Boden“ ist in der völkischen Terminologie Gerstenhauers - dessen Buch Der völkische Gedanke in Vergangenbeit und Zukunft Wahle 1935 zitierte ${ }^{323}$ - gleichbedeutend mit "Rasse und Landbesitz". ${ }^{324}$ „Blut", „Volksboden", „bodenständige Kraft", „Herren“, „Herrenvolk" und „Herrenschicht" sind weitere von Wahle verwendete völkische Termini, die in DV und praktisch unverändert auch in $\mathrm{DV}^{2}$ auftauchen.

317 Vgl. von dem Bussche 1998, 258.

318 Wahle 1932, 80.

319 Darré 1930.

320 Zit. nach Seidel/Seidel-Slotty 1961, 131. Vgl. ergänzend Schmitz-Berning 1998, 10-11.

321 Darré 1930, 10-11.

322 Zit. nach Seidel/Seidel-Slotty 1961, 132.

323 Wahle 1935a, 706.

324 Gerstenhauer 1933, 5. 
Konservative Gelehrte wie Wahle und Güntert hatten ihre Auffassung von einem einheimischen "Bauernadel" und einer eingewanderten indogermanischen „Herrenschicht" als Ausgangspunkt der germanischen Ethnogenese im völkischen Sinne entwickelt und rassistische Begrifflichkeiten wie Ideen der zeitgenössischen völkischen und radikalnationalistischen Diskussion entnommen. Auffallend ist die Kontinuität des Führerparadigmas und des „nordischen" Gedankens in DV ${ }^{2}$ (Tabelle 4). Die wiederholte Verwendung des Begriffs "Jungmannschaft" im Sinne einer jungen, agilen, kraftstrotzenden und daher expandierenden Bevölkerungsschicht in $\mathrm{DV}^{2}$ dagegen ist neu. Namengebende Fundplätze oder archäologische „Keramikstile“ wurden stets mit diffusen völkischen Begriffen wie „Leute" oder „Träger" verbunden („Michelsberger Leute", „Träger der Bandkeramik").

Tabelle 4. Veränderung und Kontinuität von Schriftsprache und Inhalten am Beispiel ausgewählter Textstellen aus der ersten und zweiten Auflage des Buches Deutsche Vorzeit von 1932 bzw. $1950^{2}$. Schlüsselbegriffe sind hervorgehoben.

Deutsche Vorzeit (1932)

(DV)

(81) „Wohl aber lehrt der Fundstoff, daß zu allen Zeiten die Führernaturen Gelegenheit haben, sich über den Durchschnitt zu erheben und ihn zu lenken. Die Befestigungen, welche die Träger der Michelsberger Kultur zum Schutze vor dem bandkeramischen Kreise um ihre Dörfer legen, sind uns Zeugnisse eines lebendigen Gemeinschaftsgefühls. Aber die Annahme, daß hier eine demokratische Ordnung das Verhältnis des Einzelnen zur Gesamtheit bestimmt und ihn zur Teilnahme an der gemeinsamen Arbeit zwingt, wird kaum richtig sein. Viel eher wird man sich vorstellen dürfen, daß die Stunde der Gefahr es dem Tüchtigen ermöglicht, rasch eine Führerstellung zu gewinnen und in entscheidenden Befehlen das Schicksal einer Dorfgemeinde oder eines ganzen Gaues zu lenken. Wie aber eine derartige einflußreiche Stellung rasch erreicht werden kann, so ist sie mit der Befriedung der Zustände binnen ebenso kurzer Zeit zur Bedeutungslosigkeit verurteilt. Und wie hier im Michelsberger Kreise das Vertrauen der Allgemeinheit der tatkräftigen Einzelpersön-
Deutsche Vorzeit $\left(1950^{2}\right)$

$\left(D^{2}\right)$

(72) „Gerade hier hat der Tüchtige die Möglichkeit, rasch eine Führerstellung zu gewinnen und mit seinen entscheidenden Anweisungen das Schicksal einer kleinen Gemeinde oder eines ganzen Gaues zu lenken. Ohne derartige Gestalten ist auch die Abwanderung der Jungmannschaft nicht denkbar, ganz einerlei, wo sie stattfindet." 
lichkeit die Gelegenheit zur Entfaltung gibt, so hat auch der nordische Bauernadel seine Führer, wenn er sie braucht. Ohne sie ist die Vergrößerung seines Kulturgebietes, sind auch die Abwanderungen der überzähligen Mannschaft nicht denkbar."

(82) „Die indogermanische Herrenschicht gelangt allem Anscheine nach als eine nach außen hin verhältnismäßig stark abgeschlossene Gesellschaft zu uns. Nur so kann man ihre anthropologische Einheitlichkeit erklären; in den Gräbern der Streitaxtleute fällt die Gleichartigkeit der Langschädel auf. Die Einheitlichkeit der körperlichen Erscheinungsform ist hier größer als anderswo innerhalb der Herrenschichten; so zeigt z. B. der Bauernadel des nordischen Kreises ungleich stärkere Verschiedenheiten in der Schädelbildung."

(99) „Die Germanen haben dort ihre Heimat, wo ein Zweig des indogermanischen

Urvolkes den nordischen Bauernadel unter seine Botmäßigkeit zwingt. Dieser nordische Kulturkreis des Neolithikums nimmt im Rahmen der gleichzeitigen Erscheinungen Mitteleuropas eine besondere Stellung ein; wie er eine stärkere gesellschaftliche Gliederung zeigt, als wir sie sonst feststellen können, dehnt er auch am meisten unter allen Kreisen sein Machtgebiet aus. Es ist, als ob er noch einmal in jener frühen Blüte in Erscheinung tritt, welche das Germanentum während der älteren Bronzezeit erlebt, und für die weder Kelten noch Illyrier etwas Entsprechendes aufzuweisen haben. Vielleicht war hier die gegenseitige Befruchtung der Indogermanen und der Bodenständigen glücklicher als anderwärts. Jedenfalls lebt in den Germanen der ganze Inhalt des mitteleuropäischen Neolithikums, die Überschichtung des seßhaften Bauerntums durch die Halbnomaden, am deutlichsten, längsten und geschichtlich wirksamsten fort."

(125) „Der Tatsache, daß sie [die linksrheinischen Germanen, D. H.] langsam der Keltisierung verfallen und zu Beginn der Römerzeit nur noch wenig Germanisches an sich haben, steht die Überlegung gegenüber, daß der Germanisierung ihres Gebietes in der
(74) „Die indogermanische Herrenschicht gelangt allem Anscheine nach als eine nach außen hin verhältnismäßig stark abgeschlossene Gesellschaft zu uns. Nur so kann man ihre anthropologische Einheitlichkeit erklären; in den Gräbern der Streitaxtleute fällt die Gleichartigkeit der Langschädel auf. Die Einheitlichkeit der körperlichen Erscheinungsform ist hier größer als anderswo; auch die Träger des nordischen Kreises zeigen ungleich stärkere Verschiedenheiten in der Schädelbildung."

(92-93) „Die Germanen haben dort ihre Heimat, wo ein Zweig des indogermanischen Urvolkes den nordischen Kreis unter seine Botmäßigkeit zwingt. Dieses nordische Neolithikum nimmt im Rahmen der gleichzeitigen Erscheinungen Mitteleuropas eine eigene Stellung ein. Es hat eine besondere Lebenskraft und sendet sowohl etliche Kulturwellen wie auch Scharen von Jungmannschaften aus. Es ist, als ob diese Vitalität sich in die Bronzezeit hinein fortsetzt, welche hier ein Niveau zeigt, wie es von den anderen Kulturprovinzen nicht erreicht wird. Vielleicht war in diesem Raum die gegenseitige Befruchtung der Indogermanen und der Bodenständigen glücklicher als anderwärts. Jedenfalls lebt in den Trägern der nordischen Bronzezeit der ganze Inhalt des mitteleuropäischen Neolithikums, die Überschichtung des seßhaften Bauerntums durch die Halbnomaden, am deutlichsten, längsten und geschichtlich wirksamsten weiter."

(116-117) „Der Tatsache, daß sie [die linksrheinischen Germanen, D. H.] langsam der Keltisierung verfallen und zu Beginn der Römerzeit nur noch wenig Germanisches an sich haben, steht die Überlegung gegenüber, daß der Germanisierung ihres Gebietes in der 
nachrömischen Zeit ein bleibender Erfolg beschieden war. Vielleicht hat eine unhörbare Stimme des Blutes die romanisierten Nachkommen der Belgen für die fränkische Art so empfänglich gemacht, daß sie sich ihr leichter zuwandten, als es sonst in den Gebieten der germanischen Landnahme der Fall war."

(147) „Wie diese Heer- und Wanderführer von dem Vertrauen ihrer Stammesgenossen auf den Schild gehoben werden, so haben sie die Hoffnungen, welche man auf ihre Führung setzt, durch den Erfolg zu rechtfertigen; darüber hinaus aber will man sie als erhabenes Beispiel der hervorragendsten Mannestugenden vor sich sehen, welches dem Ideal des Führers möglichst nahe kommt." nachrömischen Zeit ein bleibender Erfolg beschieden war. Vielleicht hat eine unhörbare Stimme des Blutes die romanisierten Nachkommen der Belgen für die fränkische Art so empfänglich gemacht, daß sie sich ihr leichter zuwandten, als es sonst in den Gebieten der germanischen Landnahme der Fall war."

(142) „Wie diese Heer- und Wanderführer von dem Vertrauen ihrer Stammesgenossen auf den Schild gehoben werden, so haben sie die Hoffnungen, welche man auf ihre Führung setzt, durch den Erfolg zu rechtfertigen; darüber hinaus will man sie als erhabenes Beispiel der hervorragendsten Mannestugenden vor sich sehen, welches dem Ideal des Führers möglichst nahe kommt."

Der angehängte Kartenteil von $\mathrm{DV}^{2}$ wurde überarbeitet und zwei Karten weggelassen. So ist in $\mathrm{DV}^{2}$ die Karte 1 („Die vorindogermanischen Bauern der jüngeren Steinzeit") gegenüber der entsprechenden Karte 2 in DV stark vereinfacht worden. Hinzugefügt wurde jedoch die Kartierung einer „Ausweitung des nordisch-neolitbischen Kreises" im Gebiet Mitteldeutschlands und Polens. Auch die Kartentitel wurden verändert (Tabelle 5).

Tabelle 5. Die Kartentitel der Auflagen von Deutsche Vorzeit.

Deutsche Vorzeit (1932)

Deutsche Vorzeit $\left(1950^{2}\right)$

(DV)

$\left(\mathrm{DV}^{2}\right)$

„Karte 1. Das mitteleuropäische Siedelungsgebiet in der Diluvialzeit und die paläolithischen Funde"

„Karte 2. Die vorindogermanischen Bauernvölker der jüngeren Steinzeit“

„Karte 3. Die Herausbildung der Siedelungsräume während des 2 . Jahrtausends v. Chr."

Karte 4. Die Siedelungsräume während der ersten Hälfte des letzten Jahrtausends v. Chr.
„Karte 1 Die vorindogermanischen Bauern der jüngeren Steinzeit ${ }^{\text {“ }}$

„Karte 2 Die Herausbildung der indogermanischen Teilvölker bis zum Ende des 2. Jahrtausends v. Chr." 
„Karte 5. Die Siedelungsräume um die Mitte des letzten Jahrtausends v. Chr.“

„Karte 6. Die Siedelungsgebiete kurz vor Beginn unserer Zeitrechnung“

„Karte 7. Die Verlagerung des germanischen Siedelungsgebietes und die Westwärtsbewegung der Ostvölker“
„Karte 3 Die Lebensgemeinschaften um die Mitte des letzten Jahrtausends v. Chr.“

„Karte 4 Die Siedlungsgebiete kurz vor Beginn unserer Zeitrechnung“

„Karte 5 Die Verlagerung des germanischen Siedlungsgebietes und die Westwärtsbewegung der Ostvölker"

$\mathrm{DV}^{2}$ aktualisierte Wahle durch Arbeiten von Fachwissenschaftlern, die in den zwei Jahrzehnten seit der Publikation von DV erschienen waren. Dazu gehörten auch während des „Dritten Reiches“ veröffentlichte Arbeiten von Franz Petri, Hermann Aubin und Franz Steinbach, der späteren sog. „Bonner Schule“. ${ }^{325}$ Diese hatten versucht, deutsches "Volkstum" auf dem Territorium Frankreichs historisch nachzuweisen und damit Gebiets- und Herrschaftsansprüche während des 2. Weltkrieges im Rahmen der NS-, Westforschung“ zu legitimieren. Methoden und Fragestellungen bestanden nach 1945 unverändert fort. ${ }^{326}$ Wie wir bereits gesehen haben, war Wahle einigen Protagonisten der späteren NS-„Westforschung“, wie Friedrich Metz, Friedrich und Wolfgang Panzer, freundschaftlich und kollegial verbunden, wie er ja auch bei der Vorgängerorganisation der „Westforschung“, der Stiftung für deutsche Volksund Kulturbodenforschung (1930-1934), mitarbeitete. Einige Textstellen in DV thematisieren Inhalte der späteren NS-,,Westforschung“, wie den "Grenzkampf", und blieben völlig unverändert in $\mathrm{DV}^{2}$ stehen (Tabelle 6). Die Abschnitte IV. Die Entwickelung des Bildes der frühgeschichtlichen Zeit (in DV ${ }^{2}$ geändert in: IV. Die Entwicklung des Bildes zur Zeit des Tacitus) sowie V. Vom Werden von Volk und Staat des Mittelalters scheinen für $\mathrm{DV}^{2}$ fast gar nicht überarbeitet worden zu sein (Vgl. Tabelle 4, 147 bzw. 142 und Tabelle 6). Selbst anachronistische Begriffe, wie „reichsdeutsches Moselgebiet", „DeutschLothringen " und „Deutsches Reich" sind hier stehengeblieben. ${ }^{327}$ Einige sachliche, aber nicht schriftsprachliche Änderungen wurden dennoch sorgfältig vorgenommen. ${ }^{328}$

325 Wahle 1950², 301, Anm. 570-571. Vgl. Schöttler 1999, hier 95 ff.

326 Vgl. hierzu den Beitrag von Hubert Fehr, in diesem Band, sowie Schöttler 1997a und ders. 1999.

327 Wahle 1950², 205 und 233; vgl. Wahle 1932, 200, und 222.

328 Wahle 1950², 236-238 (Änderungen und Ergänzungen), vgl. Wahle 1932, $225 \mathrm{ff}$. 
Tabelle 6. Veränderung und Kontinuität von Schriftsprache und Inhalten am Beispiel ausgewählter Textstellen aus der ersten und zweiten Auflage des Buches Deutsche Vorzeit von 1932 bzw. $1950^{2}$. Schlüsselbegriffe sind hervorgehoben.

Deutsche Vorzeit (1932)

(DV)

(202) „Außerhalb des deutschen Volksbodens liegen diejenigen Gebiete, in welchen die Germanen im Laufe der Zeit romanisiert werden."

(205) „Doch nicht nur auf diesem Wege gelangen während der Merowingerzeit Angehörige einer fremden Rasse nach Mitteleuropa; vom fünften Jahrhundert an sehen wir, wie die Juden in größerem Umfang in das Wirtschaftsleben der Städte eindringen und sich in besonderen Vierteln ansiedeln."

(203) "Ja, vielleicht spricht hier in diesen Grenzgebieten noch eine Stimme des Blutes mit, die seit der Überschreitung des

Niederrheines durch die Germani cisrhenani in den Bewohnern der Provinzen Germanien und Niedergermanien schlummert, und die trotz aller provinzial-römischen Tünche noch so lebendig ist, daß sich diese durch die Art der einwandernden Germanen angezogen fühlen und sich deshalb jetzt nach Jahrhunderten wieder ihrer alten Art zuwenden. [...] Was in diese letzteren, von Romanen dicht besiedelten Räume während der Völkerwanderung hineingelangte, verfiel der

Romanisierung; dagegen vermochte der germanische Zustrom dort seine volkliche Eigenart zu bewahren und durchzusetzen, wo er weniger dicht bewohnte Landstriche vorfand, und so gehören denn diese letzteren Gegenden noch heute zum germanischen Sprachgebiet. Die heutige Linie, welche Deutsche und Romanen scheidet, ist also das Ergebnis eines längeren Kampfes."

(222-223) „Germanen sowohl wie Nichtgermanen müssen dem deutschen Volkstum einverleibt werden. Damit aber sind die Deutschen von Anfang an in erheblichem
Deutsche Vorzeit $\left(1950^{2}\right)$

$\left(\mathrm{DV}^{2}\right)$

(207) „Außerhalb des deutschen Volksbodens liegen diejenigen Gebiete, in welchen die Germanen im Laufe der Zeit romanisiert werden."

(210) „Doch nicht nur auf diesem Wege gelangen während der Merowingerzeit Angehörige einer fremden Rasse nach Mitteleuropa; vom fünften Jahrhundert an sehen wir, wie die Juden in größerem Umfang in das Wirtschaftsleben der Städte eindringen und sich in besonderen Vierteln ansiedeln."

(208) „Ja, vielleicht spricht hier in diesen Grenzgebieten noch eine Stimme des Blutes mit, die seit der Überschreitung des Niederrheines durch die Germani cisrhenani in den Bewohnern der Provinzen Germanien und Niedergermanien schlummert und die trotz aller provinzialrömischen Tünche noch so lebendig ist, daß sich diese durch die Art der einwandernden Germanen angezogen fühlen und sich deshalb jetzt nach Jahrhunderten wieder ihrer alten Art zuwenden [...]. Was in diese letzteren, von Romanen dicht besiedelten Räume während der Völkerwanderung hineingelangte, verfiel der

Romanisierung; dagegen vermochte der germanische Zustrom dort seine volkliche Eigenart zu bewahren und durchzusetzen, wo er weniger dicht bewohnte Landstriche vorfand, und so gehören denn diese letzteren Gegenden noch heute zum germanischen Sprachgebiet."

(233-234) „Germanen sowohl wie Nichtgermanen müssen dem deutschen Volkstum einverleibt werden. Damit aber sind die Deutschen von Anfang an in erheblichem 
Nachteil gegenüber ihrem Nachbarn im Westen, dessen Heranbildung zu einer geschlossenen Nation viel rascher vor sich geht."

(224) „Je später die Eindeutschung der úmrissenen Gebiete erfolgt, um so länger verharren sie in den einfachen Zuständen von vorgeschichtlicher Art. Das Licht der schriftlichen Überlieferung fällt erst zu einer Zeit auf sie, da andere Teile des deutschen Volksbodens schon eine lange Geschichte hinter sich haben."
Nachteil gegenüber ihrem Nachbarn im Westen, dessen Heranbildung zu einer geschlossenen Nation viel rascher vor sich geht."

(234-235) „Je später die Eindeutschung der umrissenen Gebiete erfolgt, um so länger verharren sie in den einfachen Zuständen von älterer Art. Das Licht der schriftlichen Überlieferung fällt erst zu einer Zeit auf sie, $\mathrm{da}$ andere Teile des deutschen Volksbodens schon eine lange Geschichte hinter sich haben."

Diktion und Vokabular Wahles zeigen oft eine militärische Konnotation urgeschichtlicher Ereignisse, wie auch der darwinistische Topos vom „Kampf ums Dasein“ Wahles Bild von prähistorischen Gesellschaften bestimmte. Ein Hin- und Herwogen sich unter ihren Führern gegenseitig bekriegender und unterjochender Völkerscharen wird aus der Verbreitung archäologischer Typen, im wesentlichen Keramik, durchaus phantasievoll herausgelesen und sprachstilistisch entsprechend dargeboten. Wiederholt begegnen bei Wahle lebensphilosophische Topoi, die Apotheose der Tat und das Leistungsprinzip: ${ }^{329}$ „besonderes Können “ 330 „absolute Leistung“, „schöpferische Kraft", 331 „, hervorragende" und „originale Leistung", 332 „ein großes, ernstes Werk", 333 und „Lebenskraft ${ }^{\times 334}$ in der Vorgeschichte gipfeln in der Behauptung, daß der archäologische Befund überhaupt „Niederschlag einer besonderen volklichen Kraft" sei. ${ }^{335}$ Solche Merkmale, wie sie für den Sprachwandel des „Dritten Reiches" herausgearbeitet wurden, sind bereits bei völkischen Gelehrten der Weimarer Republik präsent und bleiben kontinuierlich nach 1945 in der gedruckten Schriftsprache in Gebrauch: „Den militanten Charakter manifestieren die vielen kategorischen Erklärungen dort, wo man sie am wenigsten erwartet, z. B. in der Wissenschaft. " ${ }^{\text {"36 }}$ Angesichts der Kontinuität im Gebrauch dieser

329 Vgl. auch: Wahle 1936 b.
330 Wahle 1941, 90.
331 Wahle 1941, 91.
332 Wahle 1941, 82, 86.
333 Wahle 1932, 142.
334 Wahle 1941, 130.
335 Wahle 1941, 104.
336 Seidel/Seidel-Slotty 1961, VII-VIII und passim. 
Schriftsprache konstatierten Sprachwissenschaftler, die nach 1945 die Sprache des "Dritten Reiches“ durch die Forschung über sie entfremden wollten, schon früh ein Scheitern ihrer „Entfremdungsbemühungen“. 337

Sowohl in Wahles Buch Deutsche Vorzeit von 1932 als auch in der Akademie-Abhandlung Zur etbnischen Deutung frühgeschichtlicher Kulturprovinzen von 1941 finden wir die Idee von der Bedeutung der „Fübrergestalt" in der Vorgeschichte ausgearbeitet. ${ }^{338}$ Besonders ausgestattete oder erbaute „Fürstengräber" wurden mit „Führernaturen“ in Zusammenhang gebracht, und auch bei den Indogermanen sah Wahle das Führerprinzip präsent. Neolithische und bronzezeitliche Fürstengräber - als Beispiele werden hier u. a. die frühbronzezeitlichen Hügelgräber von Leubingen und Helmsdorf genannt - veranschaulichten „das urindogermanische Fübrertum. "339

Neben der Würdigung der hervorragenden Leistungsfähigkeit der nationalen Vorfahren trug auch Wahle zur Konstruktion eines Germanen-Mythos aus bäuerlicher Bodenständigkeit und Landnahme einerseits und einer kriegerischen Volksnatur andererseits bei. Ein völkisches Verständnis der Vorgeschichte und seine Kontinuität nach 1945 ist aus den Publikationen Ernst Wahles weder durch Diktion noch durch Inhalte zu widerlegen.

\section{Die ungestörte Prähistorie}

Gemäß Erlaß der amerikanischen Militärregierung war Wahle am 19. November 1945 aus dem Hochschuldienst entlassen worden. ${ }^{340}$ Seine Schüler traten am 15.1.1946 mit einer Eingabe an die amerikanische Militärregierung, ${ }^{341}$ Wahle wurde entlastet und am 22. November 1946 als planmäßiger außerordentlicher Professor wiedereingesetzt. ${ }^{342}$

In einer Vorlesung setzte sich Wahle 1947 fast ebenso früh wie Joachim

337 Ehlich 1997.

338 Wahle 1932, 147; Wahle 1941, 78-79.

339 Wahle 1932, 254, Anm. 120.

340 Drüll 1986, 282; vgl. dagegen UBH Heid. Hs. 3989 1,2; [maschinenschriftliche akademische Laufbahn auf einem Umschlag (nach 1957)]: „24.11.1945 auf Befebl der feindlichen Besatzung und obne Angabe von Gründen aus dem Dienst entlassen".

341 UAH PA 6215 Gesuch für die Wiedereinsetzung von Herrn Professor Dr. Ernst Wable, Professor der Frühgeschichte an der Universität Heidelberg, vorgelegt von Studenten der Universität Heidelberg, 15.1.1946; vgl. auch Wahle 1980, 122.

342 „Der Betroffene ist entlastet." (UAH PA 6213 Spruch der Berufungskammer Heidelberg, Az. 59/4/4507, 2736 vom 15.1.1947); Drüll 1986, 282. 
Werner ${ }^{343}$ unter dem Eindruck der Katastrophe 1945 mit der jüngsten Vergangenheit seines Faches und den ideologischen Hintergründen auseinander. Wahle ging bis zum Ende des 19. Jahrhunderts zurück, zeigte besonders den Einfluß der „völkischen Bewegung" auf die Vorgeschichtswissenschaft und gliederte die Wissenschaftsgeschichte seines Faches in der Weimarer Republik und im „Dritten Reich“:

Die gegenwärtige Lage der deutschen Frühgeschichtswissenschaft

Einleitung: Rechtfertigung und Umreissung des Themas; Gliederung

\section{Die Voraussetzung der Politisierung}

1. Das politische Wunschbild

2. seine Förderung:

a) infolge einer besonderen deutschen Neigung zum Mystischen

b) durch das Aufgreifen wissenschaftlicher Probleme

c) begünstigt durch die allgemeine Situation der deutschen Prähistorie um 1900 (u. des dt. Bildungs. lebens)

3. seine Verwicklung in den Schriften der Dilettanten

a) Tatbestände

b) krit. Würdigung

II. Im Dritten Reich

1. der utopische Dilettantismus

a) Aufkommen und Höhepunkt

b) der Sieg der Wiss. über ibn

2. Die Maßnabmen von Staat und Partei

a) die Prähistorie Rosenbergs

b) das "Abnenerbe“

3. das Ergebnis der Politisierung

III. Der Weg in die Zukunft

1. die Voraussetzungen der deutschen Weiterarbeit (Gliederung)

a) der Zustand des Stoffes und die tecbnische Möglichkeit seiner Verarbeitung

b) die Füblung über die polit. Grenzen hinaus

c) die geistige Bereitschaft

2. das europ. Interesse an der deutschen Präbist. (Gliederung)

a) der europ. Stoff als Aufgabe einer internationalen Prähistorie

b) die kleinen mitteleuropäischen Staaten und die deutsche Frühgeschicbtswissenschaft

3. nationale und internationale Präbistorie

a) die Aufgabe

b) die nationale Gebundenheit ibrer Lösung

Schlußwort: Uberwindung der Reste des biolog. Materialismus durch die Frage nach dem Menschen ${ }^{344}$

343 Vgl. hierzu den Beitrag von Hubert Fehr, in diesem Band.

344 UBH Heid. Hs. 3989 4,B5. 
Für die Instrumentalisierung der Vorgeschichte zu politischen Zwecken, insbesondere für die historische Legitimation von Territorialansprüchen nach 1918, machte Wahle in dieser Vorlesung - wie schon mit fast gleichen Worten in seinem Buch Deutsche Vorzeit von 1932 - Deutschlands Kriegsgegner verantwortlich: „... der Zugriff auf den dt. Volksboden, der im Anschluß an die dt. Revolution von 1918 damals sofort aus allen 4 Himmelsrichtungen erfolgte, [wurde] gerne mit dem Hinweis auf die frühgeschichtliche Verteilung der Nationalitäten bemäntelt [...]." Schon vor dem 1. Weltkrieg hätten danach Polen und Ostbalten ihre vom fremden deutschen Einfluß überdeckte Urkultur hervorgehoben und den deutschen Anteil an ihrer Geschichte ins Negative zu verkleinern versucht. In den zwei letzten Jahren sei, so Wahle 1947, „der polnische Anspruch auf die Neiße-Oder-Linie damit unterbaut worden, daß es [sich] bei Hinterpommern, Niederschlesien usw. um urpolnische und altslawische Siedelungsgebiete handele. ${ }^{345}$ Außerdem sei die politische Inanspruchnahme der Prähistorie nunmehr schon fast 100 Jahre alt, auch nicht zuerst von deutscher Seite, sondern von einem Dänen unternommen worden, ${ }^{346}$ und damit keinesfalls nur auf Deutschland und das „Dritte Reich“ beschränkt. Das „Streben, die nationale Frübzeit zu nutzen" sei eben eine allgemeinere Erscheinung und Ergebnis der nationalstaatlichen Entwicklung. Diese Tatsache löse das Thema aus der gegenwärtigen „von Scbuld und Sübne bestimmten Atmospbäre." Einer ausführlichen Darstellung der Frühgeschichtsforschung im „Dritten Reich“ will Wahle 1947 jedoch nicht vorgreifen, „weil wir noch keinen genügenden zeitlichen Abstand von dieser jüngsten Vergangenheit baben, mit ibr noch zu eng verknüpft sind. "347

Die Zeitgeschichte und seine behinderte Karriere beschäftigten Wahle bis ins hohe Alter. In einem zweiteiligen Vortrag, den Wahle 1966 unter dem Titel Vorgeschichtsforschung und Nationalsozialismus I, II im Rahmen des Studium Generale in der Vortragsreihe Wissenschaft und Nationalsozialismus der Universität Heidelberg hielt, hatte er seine Positionen zur jüngeren Geschichte seines Faches nochmals zusammengefaßt. ${ }^{348}$ Der Vortrag blieb unveröffentlicht, doch war Wahle Anfang der 1970er Jahre gebeten worden, eine überarbeitete Fassung 1975 in der Jabresschrift für mitteldeutsche Vorgeschichte (59) in

345 UBH Heid. Hs. 3989 4, B5, 9-10.

346 Vgl. Worsaae 1848.

347 UBH Heid. Hs. 3989 4, B5, 11.

348 Ruprecht-Karl-Universität Heidelberg, Studium Generale Winter-Semester 1965/66 (Heidelberg 1965); vgl. Bollmus 1970, 303, Anm. 5. 
Halle zu veröffentlichen. Aus politischen Gründen kam es in der DDR nicht zu einer Veröffentlichung, und Wahle zog das Manuskript zurück, um den Herausgeber nicht in Schwierigkeiten zu bringen. ${ }^{349}$

Rückblickend sah Wahle 1981 sein Fach im „Dritten Reich“ als mißbrauchte Wissenschaft und zog sich in eine Opferrolle zurück: „Bei Pressefreibeit konnte sich natürlich eine Diskussion entwickeln; wenn aber in einem autoritären System bestimmte wissenschaftliche Stoffgebiete gepflegt werden, dann sind Abweicher nicht geduldet. Dies hat die Präbistorie 1933-1945 erleben müssen und einer der von ibm Verfolgten war der Schreiber dieses. "350 Seine Herleitung der Indogermanen aus dem Osten, seine Warnungen vor einer Politisierung und Instrumentalisierung der Vorgeschichtswissenschaft durch die Germanophantasten in seinem indizierten Buch Deutsche Vorzeit von 1932, kurzum seine Ablehnung der nationalsozialistischen Parteidoktrin in Sachen Vorgeschichte in den 1930er Jahren seien für Rektor und Ministerium ausschlaggebend gewesen, ihm das Ordinariat zu verweigern. Die Beanstandung von Wahles Publikationen in der Zeit des Nationalsozialismus war in der Tat relevant für seine Entlastung 1946. ${ }^{351}$ In seiner Opferrolle fand sich Wahle auch durch Dritte bestätigt. ${ }^{352}$ Der als NS-Hochschulreferent so einflußreich gewesene Heidelberger Volkskundler Eugen Fehrle, der als "belastet“ eingestuft von 1946-1948 eine Lagerhaft über sich ergehen lassen mußte, ${ }^{353}$ hatte nach Wahles eigenem Bekunden später wiederholt betont, ihn vor dem Amt Rosenberg geschützt zu haben, das ihn um seine Stellung habe bringen wollen. ${ }^{354}$

349 UBH Heid. Hs. 3989, 3,10.

350 Wahle 1980, 56.

351 UAH PA 6213, Spruch der Berufungskammer Heidelberg, Az. 59/4/4507, 2736 vom 15.1.1947.

352 Wahle 1980, 116. Wahle beruft sich auf eine entsprechende „Erklärung“ des Heidelberger Historikers und damaligen Prorektors Fritz Ernst vom 30.6.1946, die der Universität Heidelberg zugegangen war (UAH PA 6213; Kopie in UBH Heid. Hs. 3989 2,5; Diethard Aschoff über Fritz Ernst in: Ernst [1996] 1959). Ernst, der Wahle offenbar auch persönlich verbunden gewesen war (vgl. Schaab 1992, 196), schrieb 1960: „...jeder hatte in seinem Fach oder in seinem Bekanntenkreis Kollegen, die der radikalen Absetzungspolitik des Anfangs zum Opfer gefallen waren und für die er sich einsetzen mußte, wenn er vor seinem Gewissen bestehen wollte." (Ernst [1985] 1960, 385, dort auch detailiert zum Vorgang der Entnazifizierung an der Universität Heidelberg). Zur Rolle von Wahle und Ernst bei der Gründung des Instituts für Fränkisch-Pfälzische Landes- und Volksforschung vgl. Anm. 202.

353 Assion 1985, $242 \mathrm{f}$.

354 Wahle 1980, 100. Dem erneuten Antrag der Fakultät vom 29.3.1935, Wahle zum persönlichen Ordinarius zu ernennen, wurde nach Fehrles Angaben deshalb nicht stattgegeben, „um Herrn Professor Wable vor einer möglichen Gegnerschaft zu scbützen. " (UAH PA 6212, 233, 
Letztendlich gab es für Wahle nach dem Zusammenbruch des „Dritten Reiches“ aber keinen Zweifel daran, daß sein Fach von 12 Jahren nationalsozialistischer Herrschaft profitiert hatte. An die erzielten Forschungsfortschritte gelte es anzuknüpfen: „In konsequenter Weiterentwicklung dieses Suchens nach den lebendigen Kräften wird sich das Interesse an der allgemeinen Kulturgeschichte auch bei uns neu beleben [...] und es stebt zu boffen, daß die allgemeine Kulturgeschichte zu einer vergleichenden wird [...]. Trügen nicht alle Anzeichen, dann ist in der beutigen Präbistorie die Tradition der deutschen Wissenschaft noch lebendig genug, um ibre erfolgreiche Mitarbeit an dieser Aufgabe erboffen zu lassen [...]. Dem Auslande würde sie zu erkennen geben, daß unsere deutsche Prähistorie in den vergangenen 12 Jahren, aller politischen Beanspruchung zum Trotz, in ibrer inneren Entwicklung nicht nennenswert gestört worden ist. ${ }^{\text {"3555 }}$ Ähnlich äußerte sich Wahle im Vorwort zur Neuauflage seines Buches Deutsche Vorzeit von 1950. Trotz aller politischen Beanspruchung habe die Prähistorie „genügend Substanz bewabrt, um ibre Stellung im Rabmen der internationalen Forschung bebaupten zu können." Die Neuauflage ergänzte er durch Publikationen aus eigener und fremder Feder, die in der Zeit des Nationalsozialismus erschienen waren. ${ }^{356}$

Die innere Emigration als "unpolitischer" Wissenschaftler mit dem Verzicht auf Teilnahme, die nach 1945 auch Wahle sinngemäß für sich in Anspruch nahm, war dabei durchaus nicht mit dem Verzicht auf Teilhabe verbunden, ${ }^{357}$ denn schließlich hatte auch er nur der NS-Wissenschaftspolitik das eigene Institut und wirtschaftliche Absicherung $\mathrm{zu}$ verdanken. „Man siebt:", so Wahle 1980, „stille planmäßige Arbeit in verschiedenen Teilen des Gesamtgebietes konnte, trotz Diktatur, auch ibre Früchte tragen. Aber nun liegt das Jabr der ,Befreiung; 1945, bereits einige Zeit zurück; aber es ist eine gewisse Ordnung eingekehrt [...] Man schüttelt sich die Hände wie einst [...]. ${ }^{\mathrm{M} 58}$

Neben der Deutschen Vorzeit erlebte auch die beanstandete Akademie-Abhandlung Zur ethnischen Deutung frühgeschichtlicher Kulturprovinzen aus dem Jahr 1941 eine Neuauflage. ${ }^{359}$ In einem von Wahles Assistent Horst Kirchner

Dekan Richard Kienast an den Rektor, 26.6.1941). Fehrle gab bei seiner Entnazifizierung an, er habe zu den Ansichten Rosenbergs in scharfem Gegensatz gestanden, und dies wahrscheinlich unter dem Vorwand parteiinterner Querelen um Rosenbergs Arbeitsgemeinschaft für Deutsche Volkskunde (Assion 1985, 242 f.).

355 Wahle 1947.

356 Wahle $1950^{2}$, VII-VIII.

357 Funke 1986, 14.

358 Wahle 1980, 62.

359 2. Auflage 1952. 
anläßlich von Wahles 75. Geburtstag 1964 herausgegebenen Sammelband wurden Aufsätze der 1920er und 1930er Jahre wiederabgedruckt; neben der wissenschaftsgeschichtlichen Abhandlung über Karl Wilhelmi (1786-1857), dem Gründer der Sinsheimer Gesellschaft zur Erforschung der vaterländischen Denkmable der Vorzeit aus dem Jahr 1933, auch der Aufsatz Die frübgeschichtliche Vergangenbeit in der nationalen Willensbildung von 1939.360

Den Göttinger Altertumskundler und DNVP-Politiker Ulrich Kahrstedt (1888-1966), ${ }^{361}$ der 1919 in seiner Denkschrift Irredenta an Kuno Graf Westarp die erfundene „Schändung lieblicher deutscher Mädchen durch Neger und Polen" als Agitationsmittel zur Aufstachelung des Hasses empfohlen ${ }^{362}$ und der 1933 der internationalen Wissenschaft und Gelehrtenrepublik öffentlich abgesagt hatte, ${ }^{363}$ finden wir unter den Autoren der Wahle-Festschrift von 1950 mit dem Beitrag Grundsätzliches und archäologisches zu bistorischen Grenzen. „Die fetten Jabre, " so heißt es da traurig, „wo dem Freund der Frübgeschich. te fast täglich neues Material zuströmte, sind - nicht nur in Deutschland - mageren gewichen, wo es mit Ausgrabungen und neu erschlossener Kunde traurig bestellt ist. Ein Anlaß, den Gedanken nachzugeben, die auch schon in besseren Tagen bier und da auftauchten... ${ }^{\text {"364 }}$

\section{Epilog}

Daß der Radikalnationalist Kahrstedt Gedanken aus „besseren Tagen“ nachhing, war nicht neu, hatte er doch auch nach Versailles in der nationalen Sammlungspartei DNVP die konservativen Werte des Kaiserreiches erneuern wollen. Viele Gelehrte aus der unterlegenen und gedemütigten „Frontgeneration" hatten den $\mathrm{Haß}$ gegen Frankreich, Polen und die Republik von Weimar geschürt und sich verpflichtet gefühlt, ihre Wissenschaft nun in den Dienst der „Volksnation“ und gegen das internationalistische „System“ zu stellen. In diesem "nationalen“ Wissenschaftsverständnis leitete auch Ernst Wahle die Legitimation seiner "deutschen Vorgeschichtswissenschaft" von der "vaterländischen Altertumskunde“ ab, obwohl der völkische Nationalismus

360 Kirchner (Hrsg.) 1964, vgl. Wahle 1939b.

361 Vgl. Wegeler 1996, 89-98.

362 Thimme 1969, 48-49.

363 Wegeler 1996, 89-91, $155 \mathrm{f}$.

364 Kahrstedt 1950, 61. 
des Kaiserreiches und der 1920er Jahre etwas ganz anderes war, als der patriotisch-liberale Nationalismus, der hinter der „vaterländischen Altertumskunde“ des frühen 19. Jahrhunderts stand. Mit seiner „Verwurzelung in der wilhelminischen Welt", seiner Prägung durch den wilhelminischen Militarismus, stand Wahle, der aus einem „deutschgesinnten“ evangelischen Elternhaus kam und einen diesbezüglich politisch aktiven Vater hatte, nicht allein. ${ }^{365}$ Zur Zeit der Weimarer Republik war er der „nationalen Opposition“ konservativer und verfassungsfeindlicher Hochschullehrer zuzurechnen, die meist bildungsbürgerlicher Herkunft waren. ${ }^{366}$ Sein Name ist zwar unter keiner politischen Erklärung oder Resolution zu lesen. Seine "nationale Opposition“ wird aber in den völkischen Inhalten seiner Publikationen deutlich, seine politische Einstellung durch die Mitgliedschaft in "nationalen Verbänden“ nach der Auswertung von Selbstzeugnissen und Akten ersichtlich. Wie bei anderen Intellektuellen der Zeit zeigt sich auch Wahles Teilnahme am nationalen „Identitätsdiskurs“ und an der Konstruktion nationaler Identität - mit seinen Versuchen, während der Weimarer Republik ein "nationales Fach“ an der Universität zu etablieren und sich selbst wirtschaftlich abzusichern - deutlich von seiner sozialen Lage und seinen praktischen Problemen nach 1918 bestimmt: ${ }^{367}$ dem gestörten Selbstverständnis einer deklassierten Bildungselite, der materiellen wie sozialen Existenzangst und wissenschaftlichen Minderwertigkeitsgefühlen durch die bildungspolitische Zurückhaltung der Republik gegenüber seinem unetablierten, politisch konservativen Fach. Im Vergleich, etwa zu den namhaften Heidelberger Soziologen des Instituts für Sozial- und Staatswissenschaften, war Wahle ein wenig exponierter Wissenschaftler, der über die Fachgrenzen hinaus bedeutungslos geblieben ist, innerhalb seines Faches jedoch durchaus Wirkung hatte. Solche weitgehend anonym gebliebenen, politisch wie wissenschaftlich kaum in Erscheinung getretenen weniger prominenten Gelehrten wurden bisher in ihrer Wirkung unterschätzt und, etwa durch biographische Studien, nur selten untersucht. ${ }^{368}$ Wahle gehörte zu den zahlreichen Hochschullehrern, die eine völkische Geisteswissenschaft publiziert und unterrichtet haben. Mit seinem Hauptwerk Deutsche Vorzeit von 1932, das aus "„einer in sich rubenden Vaterlandsliebe heraus" enstanden sei, stellte sich Wahle in die nationalbewußte Tradition der skandinavischen

365 Vgl. Lennartz 1997, 651.

366 Vgl. Jansen 1992a, 246-249.

367 Vgl. Giesen et al. 1994, 346.

368 Ringer 1987, 200; vgl. auch Jansen 1992a, 13. 
Archäologen Jens Jacob Assmussen Worsaae (1821-1885), Hans Hildebrand (1842-1913) und Sophus Müller (1846-1934). ${ }^{369}$

Im Gegensatz zu den Gelehrten der „jungen Frontgeneration“ Wahles und Kahrstedts, die noch lange dem "alten“ Nationalismus des Kaiserreichs anhingen und sentimental ihrem 1918 untergegangenen bildungsbürgerlich-elitären Selbstverständnis nachtrauerten, gaben sich in den 1920er Jahren jüngere ebenfalls völkisch eingestellte Studenten vernunftbetont kühl, sachlich, diszipliniert und antibürgerlich. Zwar fehlte ihnen das prägende Kriegserlebnis, doch standen Kindheit und Jugend der „Kriegsjugendgeneration“ ganz unter dem Eindruck der sozialen und politischen Verwerfungen des Ersten Weltkrieges. ${ }^{370}$ Diese zielstrebigen Jungwissenschaftler verfochten in den 1920er und 1930er Jahren rücksichtslos den „neuen Nationalismus“ der radikal völkischen nationalsozialistischen Rechten, der an Langzeitelemente des etablierten kaiserzeitlichen Nationalismus anknüpfen konnte und sich eine „völkische Wiedergeburt“ Deutschlands erhoffte (Hans-Ulrich Wehler). Aus der „Kriegsjugendgeneration" kamen, neben vielen der überzeugtesten NS-Täter, auch prominente NS-Prähistoriker, wie etwa die Archäologen Herbert Jankuhn (1905-1990) und Hans Reinerth (1900-1990), ${ }^{371}$ die später beide aus pragmatischer wie ideologischer Motivation steile Karrieren in den konkurrierenden NS-Organisationen des SS-Abnenerbes bzw. des „Amts Rosenberg“ begannen.

Mit dem generationellen Unterschied zwischen Wahles „Frontgeneration“ und diesen jüngeren Prähistorikern der „Kriegsjugendgeneration“ war damit auch ein ideologischer verbunden. Wenn „generationelle Typisierungen“ hier überhaupt greifen, dann könnten die beiden komplementären generationell bzw. ideologisch bestimmten Faktoren bei Wahle plausibel erklären, warum er nach 1933 keine Karriere in den NS-Eliten machte, sein akademisches Fort-

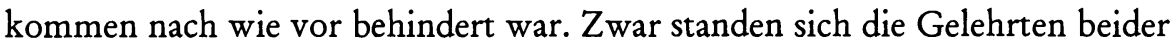
"Generationen“ im radikalen völkischen Denken in nichts nach, ${ }^{372}$ doch wurden die älteren „Alldeutschen“ und „Völkischen" von den jüngeren Nationalsozialisten nach 1933 zunehmend als hinderlich oder gar konkurrierend empfunden. Dieser Umstand ermöglichte es nach 1945, aus potentiellen Wegbereitern des Nationalsozialismus Ausgegrenzte oder sogar Opfer zu machen.

Doch Wahle verdankte dem neuen Regime und den ihm gewogenen Natio-

369 UBH Heid. Hs. 3989, 1,1, Selbstdarstellung 1945, 29.

370 Vgl. hierzu: Herbert 1996, 42-45.

$371 \mathrm{Zu}$ Reinerth jüngst Strobel 1999, hier 67, $81 \mathrm{f}$.

372 Herbert 1996, bes. $57 \mathrm{ff}$. 
nalsozialisten Fehrle und Groh seine 1934 geschaffene Planstelle. Mit dieser gesicherten Stellung begann auch Wahles politisch motivierte Publikationstätigkeit im Deutschen Bildungswesen. Trotz seiner völkischen, deutsch-nationalen Grundeinstellung blieb Wahle aber ein unbequemer und unangepaßter Außenseiter. Durch seine eigene und kompromißlose Auffassung völkischer Vorgeschichtswissenschaft offenbarte er nach 1933 in Fragen nicht parteikonform zu sein, die von den in der Vorgeschichte dilettierenden Parteiideologen oder den ihnen verbundenen Fachwissenschaftlern gerade als Schlüsselfragen angesehen wurden. Im Machtkampf der Wissenschaftsinstitutionen und NS-„Intellektuellen“ des „Dritten Reiches“ spiegelt sich eben auch die Heterogenität und die Ambivalenz verschiedener völkischer Geschichtsbilder wider. „Weltanschauliche" und politische Gründe wurden im Interesse der eigenen Karriere schonungslos als Waffen gegen den wissenschaftlich Andersdenkenden oder den Konkurrenten eingesetzt. Die Beiträge Wahles im Deutschen Bildungswesen zeigen, daß auch er über die nationalsozialistische Dumpfheit und den Terror hinwegsah und zu denjenigen gehörte, die im neuen Staat - wohl zumindest anfänglich - auch eine „Offenbarung einer neuen Gestalt völkisch-geschichtlichen Werdens" sahen und sich vom Nationalsozialismus die endgültige Revision des Versailler Vertrages versprachen. Nach der Einschätzung von Martin Broszat können aber dennoch solche „intellektuellen Repräsentanten eines vernunftwidrigen Mythos von Volk und Volksgemeinschaft nicht direkt als Väter des Nationalsozialismus" betrachtet werden. ${ }^{373}$ Wahles parteipolitisches Engagement seit 1919, sein völkischer Sonderweg seit etwa 1936 - gekennzeichnet durch die Zensur seiner wichtigsten Schriften -, seine wiederholten und extrem widersprüchlichen Warnungen vor der politischen Instrumentalisierung der Vorgeschichtswissenschaft und sein kritisches Denken stellen ihn in die Reihe genau dieser Repräsentanten. Mit teilweise großem Selbstbewußtsein vertrat Wahle eigene völkische Thesen, ohne sich von den drohenden Konsequenzen schrecken zu lassen. Er war davon überzeugt, daß seine Thesen wissenschaftlich begründet, die der offiziellen Ideologie dagegen wissenschaftlich unhaltbar waren. Insofern reklamierte er für sich eine Freiheit der Wissenschaft, deren Existenz er in Zeiten der Demokratie als Verfassungsfeind gar nicht wahrgenommen hatte. Intellektuelle Fähigkeiten und besonders die „subjektive Redlichkeit ibrer Überzeugung“, die gerade in den Selbstzeugnissen Ernst Wahles zum Ausdruck kommt, un- 
terschieden einige solcher völkischen Gelehrten von den machtbesessenen nationalsozialistischen. Einfluß und Leitbilder der völkischen Gelehrten wirkten jedoch verheerend: Ihre Irrationalität lief einem kritischen Denken, wie es Wahle doch selbst gefordert hatte, zuwider. Völkische Rasse- und Volkstumsvorstellungen waren schon vor 1933 Bestandteil in dem heterogenen Gemenge von Wahnideen, aus denen sich die NS-Ideologie zusammensetzte. Völkische Intellektuelle konnten sich damit zunächst ohne weiteres mit dieser Ideologie identifizieren. Wenn diese antirepublikanischen „unpolitischen“ Gelehrten schon nicht als die „Väter des Nationalsozialismus“ bezeichnet werden können, so waren sie doch mit der Pflege seiner ideologischen Vorformen seine intellektuellen Wegbereiter. ${ }^{374}$ Völkische Wissenschaftsdiskurse haben zur Radikalisierung des "neuen Nationalismus“ in den 1920er und 1930er Jahren maßgeblich beigetragen.

Gegenüber rasseanthropologischen und wissenschaftspolitischen Fragen nahm Wahle eine ambivalente Haltung ein. Einerseits kritisierte er das Wirken der Rassefanatiker und das "politische Wunschdenken“ der Anhänger Kossinnas, andererseits sah er in der Rassenanthropologie auch ein legitimes Arbeitsmittel. Von der in seinen Augen unwissenschaftlichen Vorgeschichte nationalsozialistischer Dilettanten distanzierte er sich, um seine eigene völkische Vorgeschichtswissenschaft zu praktizieren, aber dennoch von den Segnungen der offiziellen nationalsozialistischen Wissenschaftspolitik zu profitieren. Wahle selbst sah sich als "unpolitischen“ Intellektuellen und verstand seine Forschung als völkischen Sonderweg, der von den parteiamtlichen Richtlinien, wie Geschichte nationalsozialistisch zu sehen und zu vermitteln war, abwich: „Scbließlich ist derjenige, der seinen eigenen Weg gehen will," so Wahle 1947 über die Zeit des „Dritten Reiches“, „genötigt; dies in der Stille zu tun. So verschwinden etliche Namen im Laufe der Jahre aus der Öffentlichkeit. Der Kreis derer, die ibren alten Weg nicht aufgeben wollen, bält sich zurück und wartet des Kommenden. ${ }^{~} 375$ Die nationalsozialistische Restriktion dieses völkischen Sonderwegs brachten ihm nach 1945 den Ruf ein, im „Dritten Reich“ ein Oppositioneller, ein unpolitisch forschender Wissenschaftler in der inneren Emigration gewesen zu sein. Seine Äußerungen nach 1945 zeigen, daß diese Einschätzung anderer auch seiner eigenen entsprach.

Die Vorgeschichtswissenschaft Ernst Wahles zeigt, wie viele Facetten völki-

374 Broszat 1958, $67 \mathrm{f}$.

375 UBH Heid. Hs. 3989 4,B5, S. 122. 
schen Geschichtsverständnisses es in der Weimarer Republik gegeben hat. Alle haben die Grundlage für die Rolle dieses jungen Faches im „Dritten Reich" mitgelegt. Im Machtkampf völkischer Ideologien setzten sich die Thesen Kossinnas bei den NS-Ideologen durch, so daß anders völkisch denkende Gelehrte wie Wahle an den Rand gedrängt wurden. So kann man zu dem - für die hier interessierende Fragestellung nur marginalen - Schluß kommen, daß Ernst Wahle trotz Parteizugehörigkeit kein überzeugter Nationalsozialist war, sondern dem völkischen Gedankengut des Kaiserreiches und der frühen 1920er Jahre verhaftet blieb. Die politische Restauration der 1950er und 1960er Jahre profitierte aber von der Kontinuität völkischen Gedankengutes gerade bei solchen Gelehrten. In Nachdrucken ihrer vor 1945 erschienenen Werke fand es unter dem Publikum der jungen Bundesrepublik Verbreitung. Dennoch konnte Wahle 1962 einen „Mangel des philologischen Interesses an der germanischen Stammeskunde" beklagen und stellte fest, in Mitteleuropa würde es „gerne vermieden, von Germanen und Kelten zu reden", ferner bestünde „gegenüber den Fragen der Völkergeschichte eine ausgesprochene Zurückbaltung, um nicht zu sagen Unsicherbeit oder gar Scheu. "Dies sei aber verständlich, da in der jüngeren Vergangenheit darüber zu viel und zu einseitig gehandelt worden sei und sich „auch etliche nicht dazu Berufene" diesen Fragen gewidmet hätten. ${ }^{376}$

Ernst Wahles völkische Vorgeschichte kann letzten Endes als Quelle bis heute gängiger Indogermanenklischees - von Pferd und Wagen bis hin zu den passionierten Viehzüchtern - gelten. Auf die völkische Typisierung der „Indogermanen“ als aggressive Reiterkrieger, als „Herrenvolk“ und deren Rezeption ist bereits von anderer Seite hingewiesen worden. ${ }^{377}$ Die Verbindung der „Indogermanen“ mit den typologischen Konstrukten der sog. "Schnurkeramik“ bzw. „Streitaxtkultur" wurde nachhaltig über die Publikationen Wahles und ihre Neuauflagen bis in die Gegenwart tradiert. ${ }^{378} \mathrm{Die}$ völkischen Ideen von „Blut und Boden“, „Volk und Rasse“ spielten latent auch nach 1945 in seiner Forschung eine Rolle, denn der Prähistoriker Ernst Wahle war, wie viele seiner Generation, nach wie vor davon überzeugt, „daß geschichtlicher Wandel sich im Werdegang der Völker vollziehe. ${ }^{\text {(379 }}$

376 Wahle $1962^{3}$, XXI.

377 Häusler 1995, 215-216; ders. 1996, 76.

378 Wahle $1999^{9}$.

379 Kossack 1981, 224. 


\section{Primärliteratur}

\section{Curtius 1934}

Ludwig Curtius, Mussolini und das antike Rom. Veröffentlichungen des Petrarca-Hauses, zweite Reihe: Vorträge, 4 (Köln 1934).

\section{Curtius 1950}

Ludwig Curtius, Deutsche und antike Welt. Lebenserinnerungen (Stuttgart 1950).

\section{Darré 1930}

Richard Walther Darré, Neuadel aus Blut und Boden (München 1930).

\section{Ernst [1985] 1960}

Fritz Ernst, Die Wiedereröffnung der Universität Heidelberg 1945-1946, in: Gunther G. Wolf, (Hrsg.), Fritz Ernst. Gesammelte Schriften (Heidelberg 1985) 375-402.

\section{Ernst [1996] 1959}

Fritz Ernst, Im Schatten des Diktators. Rückblick eines Heidelberger Historikers auf die NSZeit. Hrsg. von Diethard Aschoff (Heidelberg 1996).

Frenzel o. J. [1938]

Walter Frenzel, Älteste Geschichte der Germanen und Grundlagen deutscher Volkheit, in: Otto Brandt/Arnold Oskar Meyer (Hrsg.), Handbuch der Deutschen Geschichte, Band 1. Deutsche Geschichte bis zum Ausgang des Mittelalters (Potsdam o. J. [1938]) 20-61.

Gerstenhauer 1933

Max Robert Gerstenhauer, Der völkische Gedanke in Vergangenheit und Zukunft: Aus der Geschichte der völkischen Bewegung (Leipzig 1933).

Glockner 1934

„Deutsche Philosophie“, in: Zeitschrift für Deutsche Kulturphilosophie 1, 1935 (1934), 3-39.

Glockner 1973

Hermann Glockner, Freunde in Heidelberg. Erinnerungen an Hermann Güntert, in: Heidelberger Jahrbücher 17, 1973, 157-175.

\section{Güntert 1934}

Hermann Güntert, Der Ursprung der Germanen (Heidelberg 1934).

Günther 1926

Hans F. K. Günther, Adel und Rasse (München 1926).

Gummel 1938

Hans Gummel, Forschungsgeschichte in Deutschland. Die Urgeschichtsforschung und ihre historische Entwicklung in den Kulturstaaten der Erde, 1 (Berlin 1938).

Hellpach 1926

Willy Hellpach, Rasse und Stämme im deutschen Volkstum, in: Die Neue Rundschau 1, 1926, 113-138. 
Kahrstedt 1950

Ulrich Kahrstedt, Grundsätzliches zu historischen und archäologischen Grenzen, in: Horst Kirchner (Hrsg.), Ur- und Frühgeschichte als historische Wissenschaft. Festschrift zum 60. Geburtstag von Ernst Wahle (Heidelberg 1950) 60-62.

\section{Kern 1927}

Fritz Kern, Stammbaum und Artbild der Deutschen. Eine kultur- und rassengeschichtlicher Versuch (München 1927).

\section{Kirchner 1938}

Horst Kirchner, Das germanische Altertum in der deutschen Geschichtsschreibung des 18. Jahrhunderts (Berlin 1938).

Kirchner (Hrsg.) 1964

Horst Kirchner (Hrsg.), Ernst Wahle. Tradition und Auftrag prähistorischer Forschung. Ausgewählte Abhandlungen als Festgabe zum 75. Geburtstag am 25. Mai 1964 (Berlin 1964).

\section{Kossinna 1896}

Gustaf Kossinna, Die vorgeschichtliche Ausbreitung der Germanen in Deutschland, in: Zeitschrift des Vereins für Volkskunde 6, 1896, 1-14.

\section{Kossinna 1911}

Gustaf Kossinna, Die Herkunft der Germanen. Zur Methode der Siedlungsarchäologie. Mannus-Bibliothek, 6 (Würzburg 1911).

Kossinna 1912

Gustaf Kossinna, Die deutsche Vorgeschichte eine hervorragend nationale Wissenschaft. Mannus-Bibliothek, 9 (Würzburg 1912).

\section{Kossinna 1913}

Gustaf Kossinna, Altgermanische Kulturhöhe, in: Deutscher Volkswart 1, Heft 1, 1913, 1-11.

\section{Krause 1940/41}

Wolfgang Krause, Die Herkunft der Germanen, in: Jahrbuch der Akademie der Wissenschaften in Göttingen für das Geschäftsjahr 1940/41, 18-36.

[Langbehn] 1890

[Julius Langbehn] Rembrandt als Erzieher, von einem Deutschen (Leipzig 1890).

\section{Petri 1937}

Franz Petri, Germanisches Volkserbe in Wallonien und Nordfrankreich (Bonn 1937).

Rothacker 1963

Erich Rothacker, Heitere Erinnerungen (Frankfurt/M. 1963).

\section{Scheidter 1944}

Hannelore Scheidter, Die frühgeschichtliche Zeit im Geschichtsbild des Landeshistorikers J. Chr. Beckmann (1641-1717). Ungedr. Diss. (Heidelberg 1944).

\section{Schuchhardt 1924}

Carl Schuchhardt, [Rezension von:] Ernst Wahle: Vorgeschichte des deutschen Volkes. Ein Grundriß. Curt Kabitzsch, Leipzig 1923 [sic], in: Prähistorische Zeitschrift 15, 146-149. 
Sprockhoff 1932

Ernst Sprockhoff, [Rezension von:] Ernst Wahle, Deutsche Vorzeit, Leipzig 1932 [...], in: Germania 16, 1932, 317-320.

Stemmermann 1934

Paul Hans Stemmermann, Die Anfänge der deutschen Vorgeschichtsforschung. Deutschlands Bodenaltertümer in der Anschauung des 16. und 17. Jahrhunderts (Quakenbrück 1934).

Wahle 1913/14a

Ernst Wahle, [Rezension von:] Gustaf Kossinna, Der germanische Goldreichtum in der Bronzezeit I. Der Goldfund von [sic] Messingwerk bei Eberswalde und die goldenen Kultgefäße der Germanen (Mannus-Bibliothek Nr. 12) Würzburg 1913, in: Deutscher Volkswart 1, 1913/1914, 158-159.

Wahle 1913/14b

Wahle, Ernst. [Rezension von:] Hungerland, Heinz. Deutsche Stamm-, Sprach-, und Literaturgeschichte in den Grundzügen. Stockholm 1913, in: Deutscher Volkswart 1, 1913/1914, 279-280.

Wahle 1918a

Ernst Wahle, Der moderne Krieg - ein Minderer der vor- und frühgeschichtlichen Bodenfunde, in: Mannus 10, 1918, 117-120.

Wahle $1918 \mathrm{~b}$

Ernst Wahle, Gustaf Kossinna, in: Neues Leben. Monatsschrift für Deutsche Wiedergeburt 13, 4. Heft, Gilbhard 1918, 66-67.

Wahle 1921

Ernst Wahle, Die Besiedelung Südwestdeutschlands in vorrömischer Zeit nach ihren natürlichen Grundlagen, in: Berichte der Römisch-Germanischen Kommission 12, 1920 (1921), 1-75.

Wahle 1924

Ernst Wahle, Vorgeschichte des deutschen Volkes (Leipzig 1924).

Wahle 1925a

Ernst Wahle, [Rezension von:] Kossinna, Gustaf. Die deutsche Vorgeschichte, eine hervorragend nationale Wissenschaft. 4. Vermehrte und verb. Aufl. Leipzig, C. Kabitsch, 1925 (Mannus-Bibliothek, herausg. v. G. Kossinna Nr. 9), in: Historische Zeitschrift 132, 1925, 114-116.

Wahle $1925 b$

Ernst Wahle, Die rassenkundliche Auswertung vorgeschichtlicher Forschungsergebnisse, in: Walter Scheidt, Allgemeine Rassenkunde als Einführung in das Studium der Menschenrassen. Rassenkunde, 1 (München 1925) 548-572.

Wahle/Scheidt 1925

Ernst Wahle/Walter Scheidt, Anhang. Die Arbeitsweise der Rassenforschung, in: Walter Scheidt, Allgemeine Rassenkunde als Einführung in das Studium der Menschenrassen. Rassenkunde, 1 (München 1925) 512-513.

Wahle 1926

Ernst Wahle, [Rezension von:] Kossinna, Gustaf. Die Indogermanen. Ein Abriß. I. Das indogermanische Urvolk, 1921 (Mannus-Bibliothek Nr. 26), in: Historische Zeitschrift 134, 1926, 554. 
Wahle 1927

Ernst Wahle, [Rezension von:] H. F. K. Günther, Rassenkunde des deutschen Volkes. 10. Aufl. München, Lehmann 1926, in: Geographische Zeitschrift 33, 1927, 48-49.

Wahle 1928

Ernst Wahle, Die vorgeschichtliche Forschung am Anfang des 19. und am Anfang des 20. Jahrhunderts, in: Forschungen und Fortschritte. Korrespondenzblatt der deutschen Wissenschaft und Technik 4, 1928, 138.

Wahle 1930a

Die vor- und frühgeschichtlichen Grundlagen der französischen Geschichte, in: Handbücher der Auslandskunde, 4, Handbuch der Frankreichkunde, zweiter Teil (Frankfurt/M. 1930) 1-14.

Wahle $1930 \mathrm{~b}$

Die Vertretung der vorgeschichtlichen Forschung an der Universität Heidelberg, in: Nachrichtenblatt für deutsche Vorzeit 6, 1930, 225-228.

Wahle 1932

Ernst Wahle, Deutsche Vorzeit (Leipzig 1932).

Wahle 1933

Ernst Wahle, Karl Wilhelmi als Begründer der Altertumsforschung in Südwestdeutschland, in: Neue Heidelberger Jahrbücher, 1933, 1-88.

Wahle 1934

Ernst Wahle, Deutsche Vorgeschichtsforschung und klassische Altertumswissenschaft, in: Deutsches Bildungswesen. Erziehungswissenschaftliche Monatsschrift des N.S. Lehrerbundes für das gesamte Reichsgebiet, 10. 1934, 1-12.

Wahle 1935a

Ernst Wahle, Die deutsche Vorgeschichtsforschung in der Gegenwart, in: Deutsches Bildungswesen. Erziehungswissenschaftliche Monatsschrift des N.S. Lehrerbundes für das gesamte Reichsgebiet, 3, 1935, 705-715.

Wahle $1935 \mathrm{~b}$

Ernst Wahle, [Rezension von:] H. F. K. Günther, Herkunft und Rassegeschichte der Germanen (1935), in: Geographische Zeitschrift 41, 1935, 489-490.

Wahle 1935 c

Ernst Wahle, [Rezension von:] Banse, Ewald. Rassenkarte von Europa. 2. neubearbeitete Aufl. 1:5000 000. Mit 3 S. Einführungstext. Braunschweig, Georg Westermann, 1934, in: Geographische Zeitschrift 41, 1935, 35.

Wahle 1935d

Ernst Wahle, Von der Urzeit bis zum Ende des Römischen Reiches, in: O. Brandt, A. O. Meyer und H. Ullmann (Hrsg.), Handbuch der Deutschen Geschichte, 1, 1. Lieferung (Berlin 1935) 20-61.

Wahle 1935e

Ernst Wahle, Oberrheinische Bevölkerungsgeschichte in frühgeschichtlicher Zeit, in: ElsaßLothringisches Jahrbuch 14, 1935, 1-13. 
Wahle 1936a

Ernst Wahle, Deutsche Vorgeschichte als gestaltende Kraft, in: Nationalsozialistisches Bildungswesen. Einzige erziehungswissenschaftliche Zeitschrift der Bewegung, 1, 1936, 168-179.

Wahle 1936b

Ernst Wahle, Zur deutschen Vor- und Frühgeschichte. Die germanische Körpererziehung, in: Deutsches Bildungswesen. Erziehungswissenschaftliche Monatsschrift des N.S. Lehrerbundes für das gesamte Reichsgebiet, 4, 1936, 354-359.

Wahle 1939a

Ernst Wahle, Die Lehrstätte für Frühgeschichte an der Universität Heidelberg, in: Volk und Vorzeit 1939, 61-68 (wiederabgedruckt in Kirchner (Hrsg.) 1964, 220-229).

Wahle $1939 \mathrm{~b}$

Ernst Wahle, Die frühgeschichtliche Vergangenheit in der nationalen Willensbildung, in: Mitteilungsblätter des historischen Vereins für Hessen 1, 1939, 244-248 (wiederabgedruckt in Kirchner (Hrsg.) 1964, 236-246).

Wahle 1940

Ernst Wahle, [Rezension von:] Hans Gummel, Forschungsgeschichte in Deutschland. Erster Band von „Die Urgeschichtsforschung und ihre historische Entwicklung in den Kulturstaaten der Erde“. Herausgegeben von Karl Hermann Jacob-Friesen. Berlin, de Gruyter 1938 [...], in: Historische Zeitschrift 161, 1940, 409-410.

Wahle 1941

Ernst Wahle, Zur ethnischen Deutung frühgeschichtlicher Kulturprovinzen. Grenzen der frühgeschichtlichen Erkenntnis I [mehr nicht erschienen]. Sitzungsberichte der Heidelberger Akademie der Wissenschaften, Philosophisch-Historische Klasse, Jahrgang 1940/41, 2 (Heidelberg 1941).

Wahle 1947

Ernst Wahle, Frühgeschichte weiter gefragt? Zur Situation einer belasteten Wissenschaft, in: Die Zeit 1947, 2. Jg., Nr. 34, 3.

\section{Wahle $1950^{2}$}

Ernst Wahle, Deutsche Vorzeit. Zweite durchgearbeitete Auflage (Tübingen 1950).

Wahle 1950/51

Ernst Wahle, Geschichte der prähistorischen Forschung, in: Anthropos. Internationale Zeitschrift für Völker- und Sprachenkunde 45, 1950, 497-538; 46, 1951, 49-112.

Wahle $1962^{3}$

Ernst Wahle, Deutsche Vorzeit. Dritte Auflage. Unveränderter, mit einem besonderen Vorwort versehener Nachdruck der zweiten durchgearbeiteten Auflage von 1952 (Homburg v. d. H. $\left.1962^{3}\right)$.

Wahle 1980

Ernst Wahle, Und es ging mit ihm seinen Weg (Heidelberg 1980).

Wahle $1999^{9}$

Ernst Wahle, Ur- und Frühgeschichte im mitteleuropäischen Raum, in: Bruno Gebhardt/ Herbert Grundmann (Hrsg.), Handbuch der deutschen Geschichte, 1 (München 1999). 
Worsaae 1848

Jens Jakob Asmussen Worsaae, Danevirke, der alte Gränzwall Daenemarks gegen Süden: ein geschichtlicher Beitrag zur wahren Auffassung der Schleswigschen Frage von J. J. A. Worsaae. Aus dem Dänischen übersetzt von A. Courländer. Antischleswigholsteinische Fragmente, Heft 2 (Kopenhagen 1848).

\section{Sekundärliteratur}

\section{Assion 1985}

Peter Assion, „Was Mythos unseres Volkes ist“. Zum Werden und Wirken des NS-Volkskundlers Eugen Fehrle, in: Zeitschrift für Volkskunde 81, 1985, 220-244.

\section{Behrendt 1999}

Bernd Behrendt, August Julius Langbehn, der ,Rembrandtdeutsche', in: Uwe Puschner/Walter Schmitz/Justus H. Ulbricht (Hrsg.), Handbuch zur „Völkischen Bewegung“ 1871-1918 (München 1996) 94-113.

\section{Behringer 1998}

Wolfgang Behringer, Das Ahnenerbe der Buchgesellschaft. Zum Neudruck einer GermanenEdition des NS-Ideologen Otto Höfler, in: Sozialwissenschaftliche Informationen 27, 1998, Heft 4, 283-289 (gekürzt in der Frankfurter Allgemeinen Zeitung, Nr. 82 vom 9.4.97, Seite N6).

\section{Behringer 1999}

Wolfgang Behringer, Von Krieg zu Krieg. Neue Perspektiven auf das Buch von Günther Franz Der Dreißigjährige Krieg und das deutsche Volk (1940) ${ }^{2}$, in: Benigna von Krusenstjern/Hans Medick (Hrsg.), Zwischen Alltag und Katastrophe. Der Dreißigjährige Krieg aus der Nähe. Veröffentlichungen des Max-Planck-Instituts für Geschichte, 148 (Göttingen 1999) 543-591.

\section{Berg (Hrsg.) 1991}

Christa Berg (Hrsg.), Handbuch der deutschen Bildungsgeschichte, 4. 1870-1914 Von der Reichsgründung bis zum Ende des Weltkriegs (München 1991).

Bollmus 1970.

Reinhard Bollmus, Das Amt Rosenberg und seine Gegner. Zum Machtkampf im Nationalsozialistischen Herrschaftssystem (Stuttgart 1970).

\section{Broszat 1958}

Martin Broszat, Die völkische Ideologie und der Nationalsozialismus, in: Deutsche Rundschau $84,1958,53-68$.

von dem Bussche 1998

Raimund von dem Bussche, Konservatismus in der Weimarer Republik. Die Politisierung des Unpolitischen (Heidelberg 1998).

\section{Dahlhaus 1992}

Joachim Dahlhaus, Geschichte in Heidelberg - Aktenstücke und Statistiken, in: Jürgen Miethke (Hrsg.), Geschichte in Heidelberg. 100 Jahre historisches Seminar. 50 Jahre Institut für Fränkisch-Pfälzische Geschichte und Landeskunde (Berlin/Heidelberg/New York 1992) 263-319. 
Dauber 1983

Albrecht Dauber, Zur Geschichte der archäologischen Denkmalpflege in Baden, in: Denkmalpflege in Baden-Württemberg 12, 1983, 47-51.

\section{Demm 1999}

Eberhard Demm, Von der Weimarer Republik zur Bundesrepublik. Der politische Weg Alfred Webers 1920-1958. Schriften des Bundesarchivs, 51 (Düsseldorf 1999).

Drüll 1986

Dagmar Drüll, Heidelberger Gelehrtenlexikon 1803-1932 (Berlin/Heidelberg/New York 1986).

\section{Eggers $1986^{3}$}

Hans Jürgen Eggers, Einführung in die Vorgeschichte. Serie Piper, 93 (München 1986).

\section{Ehlich 1997}

Konrad Ehlich, „..., LTI, LQI,...“- Von der Unschuld der Sprache und der Schuld der Sprechenden, in: Heidrun Kämper/Hartmut Schmidt (Hrsg.), Das 20. Jahrhundert. Sprachgeschichte - Zeitgeschichte. Institut für deutsche Sprache, Jahrbuch 1997 (Berlin/New York 1998) 280-282.

\section{Faber 1995}

Richard Faber, Humanistische und faschistische Welt. Über Ludwig Curtius (1874-1954), in: Hephaistos. Kritische Zeitschrift zu Theorie und Praxis der Archäologie und angrenzender Gebiete 13, 1995, 137-186.

\section{Fahlbusch 1994}

Michael Fahlbusch, „Wo der deutsche ... ist, ist Deutschland!“: die Stiftung für Deutsche Volks- und Kulturbodenforschung in Leipzig; 1920-1933. Abhandlungen zur Geschichte der Geowissenschaften und Religion-Umwelt-Forschung, Beiheft 6 (Bochum 1994).

\section{Fahlbusch 1999}

Michael Fahlbusch, Wissenschaft im Dienst der nationalsozialistischen Politik? Die „Volksdeutschen Forschungsgemeinschaften" von 1931-1945 (Baden-Baden 1999).

\section{Fricke 1996}

Dieter Fricke, Der „Deutschbund“, in: Uwe Puschner/Walter Schmitz/Justus H. Ulbricht (Hrsg.), Handbuch zur „Völkischen Bewegung“ 1871-1918 (München 1996) 328-340.

\section{Funke 1986}

Manfred Funke, Universität und Zeitgeist im Dritten Reich. Eine Betrachtung zum politischen Verhalten von Gelehrten, in: Aus Politik und Zeitgeschichte 12, 1986, 3-14.

Giesen et al. (1994)

Bernhard Giesen/Kay Junge/Christian Kritschgau, Vom Patriotismus zum völkischen Denken: Intellektuelle als Konstrukteure der deutschen Identität, in: Helmut Berding (Hrsg.), Nationales Bewußtsein und kollektive Identität. Studien zur Entwicklung des kollektiven Bewußtseins in der Neuzeit, 2 (Frankfurt/M. 1994) 345-393.

\section{Gropengießer 1966}

Erich Gropengießer, Bibliographie Ernst Wahle, in: Jahrbuch des Römisch-Germanischen Zentralmuseums Mainz 11, 1964, 217-254. 


\section{Gropengießer 1982}

Erich Gropengießer, Ernst Wahle †. 25. Mai 1889 - 21. Januar 1981, in: Zeitschrift für die Geschichte des Oberrheins 130, N.F. 91, 1982, 357-361.

\section{Gundlach 1985}

Horst Gundlach, Willy Hellpach; Attributionen, in: Carl F. Graumann (Hrsg.), Psychologie im Nationalsozialismus (Berlin 1985) 165-195.

\section{Häusler 1995}

Alexander Häusler, Über Archäologie und Ursprung der Indogermanen, in: Martin Kuna/ Natalie Venclová (Hrsg.), Whither Archaeology? Papers in Honour of Evzen Neustupný (Praha 1995) 211-229.

\section{Häusler 1996}

Alexander Häusler, Invasionen aus den nordpontischen Steppen nach Mitteleuropa im Neolithikum und in der Bronzezeit: Realität oder Phantasieprodukt?, in: Archäologische Informationen 19, 1996, 75-88.

\section{Hartung 1996}

Günter Hartung, Völkische Ideologie, in: Uwe Puschner/Walter Schmitz/Justus H. Ulbricht (Hrsg.), Handbuch zur „Völkischen Bewegung“ 1871-1918 (München 1996) 22-41.

\section{Heiber 1991}

Helmut Heiber, Universität unterm Hakenkreuz, 1: Der Professor im Dritten Reich. Bilder aus der akademischen Provinz (München 1991).

\section{Herbert 1996}

Ulrich Herbert, Best. Biographische Studien über Radikalismus, Weltanschauung und Vernunft 1903-1989 (Bonn 1996).

\section{Jansen 1991}

Christian Jansen, Emil Julius Gumbel. Portrait eines Zivilisten (Heidelberg 1991).

\section{Jansen 1992a}

Christian Jansen, Professoren und Politik: politisches Denken und Handeln der Heidelberger Hochschullehrer 1914-1935 (Göttingen 1992).

\section{Jansen $1992 b$}

Christian Jansen, Vom Gelehrten zum Beamten: Karriereverläufe und soziale Lage der Heidelberger Hochschullehrer 1914-1933; mit einem personalbibliografischen Anhang und den Wohnsitzen der 1886-1936 Lehrenden (Heidelberg 1992).

\section{Jansen 1993}

Christian Jansen, „Deutsches Wesen“, „deutsche Seele“, „Deutscher Geist“. Der Volkscharakter als nationales Identifikationsmuster im Gelehrtenmilieu, in: Reinhard Blomert/Helmut Kuzmics/Annette Treibel (Hrsg.), Transformationen des Wir-Gefühls. Studien zum nationalen Habitus (Frankfurt/M. 1993) 199-278.

\section{Jansen 1997}

Christian Jansen, Das Institut der Außenseiter. Inneruniversitäre Spannungen und Öffentlichkeit, in: Reinhard Blomert/Hans Ulrich Eßlinger/Norbert Giovannini (Hrsg.), Heidelberger Sozial- und Staatswissenschaften: das Institut für Sozial- und Staatswissenschaften zwischen 1918 und 1958 (Marburg 1997) 25-54. 
Jansen 2000

Christian Jansen, Antiliberalismus und Antiparlamentarismus in der bürgerlich-demokratischen Elite der Republik. Willy Hellpachs Publizistik der Jahre 1925-1933 (unveröff. Manuskript).

Junker 1997

Klaus Junker, Das Deutsche Archäologische Institut des Deutschen Reiches zwischen Forschung und Politik. Die Jahre 1929 bis 1945 (Mainz 1997).

\section{Kater 1974}

Michael H. Kater, Das „Ahnenerbe“ der SS 1935-1945: ein Beitrag zur Kulturpolitik des Dritten Reiches (Stuttgart 1974).

\section{Kettenacker 1968}

Lothar Kettenacker, Kontinuität im Denken Ernst Anrichs. Ein Beitrag zum Verständnis gleichbleibender Anschauungen des Rechtsradikalismus in Deutschland, in: Dieter W. Rebentisch (Hrsg.), Paul Kluke zum 60. Geburtstag (Frankfurt/M. 1968) 140-152.

\section{Kettenacker 1973}

Lothar Kettenacker, Nationalsozialistische Volkstumspolitik im Elsaß (Stuttgart 1973).

Kirchner 1972

Horst Kirchner, Des churbrandenburgischen Hof- und Kammergerichtsraths M. F. Seidel (1621-1693) Thesaurus Orcivus Marchius. Aus den Anfängen der Vorgeschichtsforschung in der Mark Brandenburg. Berliner Beiträge zur Vor- und Frühgeschichte, 14 (Berlin 1972).

\section{Kossack 1981}

Georg Kossack, Ernst Wahle 25.5.1889 - 21.1.1981, in: Bayerische Akademie der Wissenschaften, Jahrbuch 1981, 223-234.

\section{Lankenau 1986}

Klaus Lankenau, Willy Hellpach - Ein Leben zwischen Politik und Wissenschaft, in: Zeitschrift für die Geschichte des Oberrheins 134, 1986, 359-375.

\section{Lennartz 1997}

Ulrike Lennartz, Ein badischer "Preuße“. Paul Schmitthenner, Badischer Staatsminister, in: Michael Kißener/Joachim Scholtyseck (Hrsg.), Die Führer der Provinz. NS-Biographien aus Baden und Württemberg (Konstanz 1997) 623-653.

\section{Lutzhöft 1971}

Hans-Jürgen Lutzhöft, Der Nordische Gedanke in Deutschland 1920-1940. Kieler historische Studien, 14 (Stuttgart 1971).

\section{Meid 1974}

Wolfgang Meid, Hermann Güntert: Leben und Werk, in: Manfred Mayrhofer/Wolfgang Meid/Bernfried Schlerath/Rüdiger Schmitt (Hrsg.), Antiquitates Indogermanicae. Studien zur indogermanischen Altertumskunde und zur Sprach- und Kulturgeschichte der indogermanischen Völker. Gedenkschrift für Hermann Güntert (Innsbruck 1974) 517-520.

\section{Miethke 1992}

Jürgen Miethke, Die Mediävistik in Heidelberg seit 1933, in: Jürgen Miethke (Hrsg.), Geschichte in Heidelberg. 100 Jahre historisches Seminar. 50 Jahre Institut für Fränkisch-Pfälzische Geschichte und Landeskunde (Berlin/Heidelberg/New York 1992) 93-126. 
Möller 1997

Horst Möller, Bürgertum und bürgerlich-liberale Bewegung nach 1918, in: Lothar Gall (Hrsg.), Bürgertum und bürgerlich-liberale Bewegung in Mitteleuropa seit dem 18. Jahrhundert. Historische Zeitschrift, Sonderheft 17 (München 1997) 293-342.

\section{Narr 1990}

Karl J. Narr, Nach der nationalen Vorgeschichte, in: Wolfgang Prinz/Peter Weingart (Hrsg.), Die sogenannten Geisteswissenschaften: Innenansichten. Suhrkamp-Taschenbuch Wissenschaft, 854 (Frankfurt/M. 1990) 279-305.

\section{Oberkrome 1993}

Willi Oberkrome, Volksgeschichte. Methodische Innovation und völkische Ideologisierung in der deutschen Geschichtswissenschaft 1918-1945. Kritische Studien zur Geschichtswissenschaft, 101 (Göttingen 1993).

\section{Pinn 1987}

Irmgard Pinn, Die „Verwissenschaftlichung“ völkischen und rassistischen Gedankenguts am Beispiel der Zeitschrift „Volk und Rasse“, in: 1999. Zeitschrift für Sozialgeschichte des 20. und 21. Jahrhunderts, Heft 4, 1987, 80-95.

\section{Paul 1999}

Peter Paul, Der „Rembrandtdeutsche“ in Dresden, in: Zwischen Nationalismus und „singender Revolution“. Visionen des 20. Jahrhunderts in Dresden. Dresdner Hefte, 57 (Dresden 1999) 4-13.

\section{Peters 1996}

Michael Peters, Der „Alldeutsche Verband“, in: Uwe Puschner/Walter Schmitz/Justus H. Ulbricht (Hrsg.), Handbuch zur „Völkischen Bewegung“ 1871-1918 (München 1996) 302-315.

Raulff $1989^{2}$

Ulrich Raulff, Vorwort. Mentalitäten-Geschichte, in: Ulrich Raulff et al. (Hrsg.), Mentalitäten-Geschichte: zur historischen Rekonstruktion geistiger Prozesse. Wagenbachs Taschenbücherei, 152 (Berlin 19892).

Rave 1940

Paul Ortwin Rave, Karl Blechen. Leben - Wirken - Werk (Berlin 1940).

Reichmann/Wegera 1988

Oskar Reichmann/Klaus-Peter Wegera (Hrsg.), Frühneuhochdeutsches Lesebuch (Tübingen 1988).

\section{Ringer 1987}

Fritz K. Ringer, Die Gelehrten. Der Niedergang der deutschen Mandarine 1890-1933 (München 1987).

\section{Romero 1990}

Andreas Romero, Baugeschichte als Auftrag. Karl Gruber: Architekt, Lehrer, Zeichner. Eine Biographie (Braunschweig 1990).

\section{Sachße/Tennstedt 1991}

Christoph Sachße/Florian Tennstedt, Armenfürsorge, soziale Fürsorge, Sozialarbeit, in: Christa Berg (Hrsg.), Handbuch der deutschen Bildungsgeschichte, 4. 1870-1914 Von der Reichsgründung bis zum Ende des Weltkriegs (München 1991) 411-440. 
Schaab 1992

Meinrad Schaab, Landesgeschichte in Heidelberg, in: Jürgen Miethke (Hrsg.), Geschichte in Heidelberg. 100 Jahre historisches Seminar. 50 Jahre Institut für Fränkisch-Pfälzische Geschichte und Landeskunde (Berlin/Heidelberg/New York) 175-200.

Schmitz-Berning 1998

Cornelia Schmitz-Berning, Vokabular des Nationalsozialismus (Berlin 1998).

Schöttler 1997a

Peter Schöttler, Geschichtsschreibung als Legitimationswissenschaft 1918-1945. Einleitende Bemerkungen, in: Peter Schöttler (Hrsg.), Geschichtsschreibung als Legitimationswissenschaft 1918-1945 (Frankfurt/M. 1997) 7-30.

Schöttler 1997b

Peter Schöttler, Die historische „Westforschung “ zwischen „Abwehrkampf“ und territorialer Offensive, in: Peter Schöttler (Hrsg.), Geschichtsschreibung als Legitimationswissenschaft 1918-1945 (Frankfurt/M. 1997) 204-261.

\section{Schöttler 1999}

Peter Schöttler, Von der rheinischen Landesgeschichte zur nazistischen Volksgeschichte oder Die „unhörbare Stimme des Blutes“, in: Winfried Schulze/Otto Gerhard Oexle (Hrsg.), Deutsche Historiker im Nationalsozialismus (Frankfurt/M. 1999) 89-113.

\section{von See 1994}

Klaus von See, Barbar, Germane, Arier. Die Suche nach der Identität der Deutschen (Heidelberg 1994).

\section{Seidel/Seidel-Slotty 1961}

Eugen Seidel/Ingeborg Seidel-Slotty, Sprachwandel im Dritten Reich. Eine kritische Untersuchung faschistischer Einflüsse (Halle 1961).

\section{Smith 1991}

Woodruff D. Smith, Politics and the Sciences of Culture in Germany: 1840-1920 (New York 1991).

\section{Sommer/Conze 1984}

Antje Sommer/Werner Conze, s. v. Rasse, in: Geschichtliche Grundbegriffe. Historisches Lexikon zur politisch-sozialen Sprache in Deutschland, 5 (Stuttgart 1984) 135-178.

Sontheimer $1994^{4}$

Kurt Sontheimer, Antidemokratisches Denken in der Weimarer Republik: die politischen Ideen des deutschen Nationalismus zwischen 1918 und 1933 (München 1994).

\section{Speitkamp 1996}

Winfried Speitkamp, Die Verwaltung der Geschichte. Denkmalpflege und Staat in Deutschland 1871-1933. Kritische Studien zur Geschichtswissenschaft, 114 (Göttingen 1996).

\section{Stark 1976}

Stark, Gary D., Der Verleger als Kulturunternehmer: Dr. J. F. Lehmanns Verlag und Rassenkunde in der Weimarer Republik, in: Archiv für die Geschichte des Buchwesens 16, 1976, 291-318. 
Strobel 1999

Michael Strobel, Lebendige und völkische Vorzeit - Ein Beitrag zur Geschichte der prähistorischen Archäologie in Württemberg zwischen 1918 und 1945, in: Christoph Kümmel/Nils Müller-Scheeßl/Almut Schülke (Hrsg.), Archäologie als Kunst. Darstellung - Wirkung Kommunikation (Tübingen 1999) 65-117.

\section{Thomann 1993}

Klaus-Dieter Thomann, Dienst am Deutschtum - der medizinische Verlag J. F. Lehmanns und der Nationalsozialismus, in: Johanna Bleker/Norbert Jachertz (Hrsg.), Medizin im „Dritten Reich“ (Köln 1993²) 54-69

Thimme 1969

Anneliese Thimme, Flucht in den Mythos. Die Deutschnationale Volkspartei und die Niederlage von 1918 (Göttingen 1969).

\section{Trippe 1995}

Christian F. Trippe, Konservative Verfassungspolitik 1918-1923: die DNVP als Opposition in Reich und Ländern. Beiträge zur Geschichte des Parlamentarismus und der politischen Parteien, 105 (Düsseldorf 1995).

\section{Ulbricht 1996}

Justus H. Ulbricht, Völkisches Verlagswesen, in: Uwe Puschner/Walter Schmitz/Justus H. Ulbricht (Hrsg.), Handbuch zur „Völkischen Bewegung“ 1871-1918 (München 1996) 277301.

\section{Wegeler 1996}

Cornelia Wegeler, „... wir sagen ab der internationalen Gelehrtenrepublik“. Altertumswissenschaft und Nationalsozialismus. Das Göttinger Institut für Altertumskunde 1921-1962 (Wien/Köln/Weimar 1996).

\section{Weisenburger 1997}

Elvira Weisenburger, „Der Rassepapst“ Hans Friedrich Karl Günther, Professor für Rassenkunde, in: Michael Kißener/Joachim Scholtyseck (Hrsg.), Die Führer der Provinz. NS-Biographien aus Baden und Württemberg (Konstanz 1997) 161-199.

\section{Wennemuth 1994}

Udo Wennemuth, Wissenschaftsorganisation und Wissenschaftsförderung in Baden: die Heidelberger Akademie der Wissenschaften 1909-1949. Supplemente zu den Sitzungsberichten der Heidelberger Akademie der Wissenschaften, Philosophisch-Historische Klasse, 8 (Heidelberg 1994).

\section{Wiwjorra 1996}

Ingo Wiwjorra, Die deutsche Vorgeschichtsforschung und ihr Verhältnis zu Nationalismus und Rassismus, in: Uwe Puschner/Walter Schmitz/Justus H. Ulbricht (Hrsg.), Handbuch zur „Völkischen Bewegung“ 1871-1918 (München 1996) 186-207.

\section{Wolgast 1986}

Eike Wolgast, Die Universität Heidelberg 1386-1986 (Heidelberg 1986).

\section{Wolgast 1987}

Eike Wolgast, Die Universität Heidelberg, in der Zeit des Nationalsozialismus, in: Zeitschrift für die Geschichte des Oberrheins 135, 1987, 359-406. 


\section{Abkürzungen}

aoProf. - nichtplanmäßiger außerordentlicher Professor

ARGK - Archiv der Römisch-Germanischen Kommission Frankfurt a. M.

BDC - Berlin Document Center

BAB - Bundesarchiv Berlin-Lichterfelde

DAI - Deutsches Archäologisches Institut

NSKOV - NS-Kriegsopferversorgung

NSLB - Nationalsozialistischer Lehrerbund

PD - Privatdozent

plaoProf. - planmäßiger außerordentlicher Professor

RGK - Römisch-Germanische Kommission

UAH - Universitätsarchiv Heidelberg

UBH - Universitätsbibliothek Heidelberg 


\section{Anhang}

Lehrveranstaltungen Ernst Wahles an der Universität Heidelberg 1920-1957

$\dagger$ für einen größeren Zuhörerkreis bestimmt

- auch für das Gesamtpublikum zugänglich

\begin{tabular}{lll} 
Jahr & Status & Lehrveranstaltung \\
\hline SS 1920 & PD & $\begin{array}{l}\text { Vor- und Frühgeschichte der Rheinlande } \\
\text { Praktische Übungen zur Einführung in die prähistorische } \\
\text { Forschung } 381\end{array}$ \\
WS 1920/21 & PD & $\begin{array}{l}\text { [unter: Geschichte, Geographie und Völkerkunde, neuere } \\
\text { Kunstgeschichte und Musik] Germanien und die Germanen } \\
\text { zur Römerzeit (aufgrund der prähistorischen Funde) } \\
\text { Uebungen zur Einführung in die prähistorische Forschung }\end{array}$
\end{tabular}

SS 1921 PD [unter: Geschichte, Geographie und Völkerkunde, neuere Kunstgeschichte und Musik] Der Mensch zur Eiszeit in Europa

Prähistorische Uebungen (nach Bedarf getrennt für Anfänger und Fortgeschrittene)

Lehrwanderungen zu vorgeschichtlichen Fundstätten in der Umgebung Heidelbergs

WS 1921/22 PD [unter: Philologie, Altertumskunde und Geschichte der antiken Kunst] Deutsche Altertumskunde (auf archäologischer Grundlage)

Prähistorische Uebungen

SS $1922 \quad$ PD

[unter: Geschichte, Geographie und Völkerkunde, neuere Kunstgeschichte und Musik] Archäologie der Merowingerzeit auf deutschem Boden

Uebungen über Terra sigillata und provinziale Keramik Unterrichtsausflüge zu vorgeschichtlichen Denkmälern in der Umgebung Heidelbergs

WS 1922/23 PD [unter: Philologie, Altertumskunde und Geschichte der antiken Kunst] Germanien und die Germanen zur Römerzeit Prähistorische Uebungen

380 Nicht im Vorlesungsverzeichnis SS 1920; Wahle 1930, 227, abweichend UAH Rep. 27/1372 [Quästurakten], SS 1920: Vor-und Frühgeschichte Südwestdeutschlands.

381 Nicht im Vorlesungsverzeichnis SS 1920, Angabe nach UAH Rep. 27/1372 [Quästurakten], SS 1920. 
SS 1923

PD

WS $1923 / 24$

PD

SS 1924

PD

WS 1924/25 aoProf.

SS 1925

WS 1925/26 aoProf.

SS 1926

WS 1926/27 aoProf.

SS 1927
aoProf.

aoProf.

aoProf. $\dagger$ Der Mensch zur Eiszeit in Europa

Geschichte und Methode der vorgeschichtlichen Forschung Prähistorische Uebungen

Das germanische Kunstgewerbe der Völkerwanderungszeit Vorgeschichte des deutschen Volkes im Ueberblick (von der älteren Steinzeit bis auf Karl den Großen)

Uebungen zur Einführung in die vorgeschichtliche Forschung unter Vorlage von Originalfunden

Uebungen über die Götterverehrung im römischen Germanien

Uebungen ueber terra sigillata und provinziale Keramik Prähistorischer Unterrichtsausflug (3-4mal im Semester) [unter: Geschichte, Geographie und Völkerkunde, neuere Kunstgeschichte und Musikwissenschaft] Wirtschaftsgeschichte des Altertums

Kulturgeschichte der Germanen bis zum Beginn der Völkerwanderung

Prähistorische Uebungen: a) für Anfänger: Einführung in die Methoden der vorgeschichtlichen Forschung b) für Fortgeschrittene: Referate und Besprechungen über das Neolithikum Südwestdeutschlands

Vorgeschichte Europas I: Der Mensch der älteren Steinzeit (Paläolithikum)

Prähistorische Uebungen: a) für Anfänger b) für Fortgeschrittene

Prähistorische Unterrichtsausflüge

Vorgeschichte Europas II: Die jüngere Steinzeit (Neolithikum) Archäologische Uebungen im Anschluß an die Germania des Tacitus

Uebungen im Bestimmen von vorgeschichtl. Funden

Die Entwicklung des geistigen Lebens im vorgeschichtlichen Europa

Uebungen über die Wirtschaft im vorgeschichtlichen Europa Vor- und frühgeschichtliche Unterrichtsausflüge

Uebungen über wichtigere vorrömische Fundstellen und Fundgruppen in Mitteleuropa

Uebungen für Anfänger an der Hand des merowingerzeitlichen Fundstoffes des kurpfälzischen Museums

†Einführung in die vorgeschichtliche Forschung

Uebungen über das Kunstgewerbe der Merowingerzeit

Uebungen für Anfänger: die provinzialrömische Keramik des Kurpfälzischen Museums

Archäologische Unterrichtsausflüge zu vor- und frühgeschichtlichen Fundstätten 
WS $1927 / 28$ aoProf.

[unter: Altertumskunde, Archäologie] Kulturgeschichte der germanischen Vorzeit

Uebungen über das Problem des Zusammenhanges des deutschen Mittelalters mit der provinzialrömischen Kultur auf deutschem Boden

Uebungen für Anfänger (in der vorgeschichtlichen Abteilung des kurpfälzischen Museums)

Archäologische Unterrichtsausflüge, an Samstagen oder Sonntagen

SS 1928

WS $1928 / 29$ aoProf

SS 1929

WS $1929 / 30 \quad$ aoProf.

SS 1930

WS $1930 / 31$ aoProf.

SS 1931

WS 1931/32 aoProf.
Uebungen über die germanische Kultur der Bronzezeit Archäologische Unterrichtsausflüge, nach besonderem Anschlag

Die Rheinlande in römischer Zeit [auch unter: Geschichte]

Archäologie der Merowingerzeit

Archäologische Uebungen über die freien Germanen in spätrömischer Zeit

aoProf. Uebungen zur provinzial-römischen Archäologie (Vergleich des Dekumatlandes mit den linksrheinischen Gebieten)

Prähistorische Uebungen für Fortgeschrittene: Vorgeschichtliche Forschung und historisches Denken

'Die vaterländische Altertumskunde und ihre Stellung im deutschen Geistesleben

Uebungen über die Archäologie der Kelten

aoProf. Deutsche Vorgeschichte (eine Einführung)

Uebungen für Anfänger (in der vorgeschichtlichen Sammlung des kurpfälzischen Museums)

Uebungen für Fortgeschrittene: Vorgeschichtliche Forschung und Romantik

Unterrichtsausflüge (gemeinsam mit Dr. Teske) [auch unter: Germanische Philologie]

[unter: Altertumskunde, Archäologie] Deutschland zur Römerzeit

Uebungen über die Kunst der vorgeschichtlichen Zeit

Archäologie der Merowingerzeit

Prähistorische Uebungen (Wirtschaft und Gesellschaft im vorrömischen Deutschland)

Unterrichtsausflüge

[unter: Geschichte] Einführung in die vorgeschichtliche Forschung

Prähistorische Uebungen:

Für Anfänger (Typologie, Chronologie und Ethnologie des vorgeschichtlichen Fundstoffes)

Für Fortgeschrittene (die vorgeschichtlichen Funde in der Geschichtsschreibung des 17. und 18. Jahrhunderts) 
SS 1932

WS 1932/33 aoProf.

SS 1933

WS 1933/34 aoProf.

SS 1934
aoProf.

aoProf.

aoProf.
Uebungen zur Geschichte der Völkerwanderung und der Merowingerzeit, vorwiegend aufgrund der Bodenfunde Uebungen für Fortgeschrittene: Die vorgeschichtliche Forschung in den geistigen Strömungen des 19. Jahrhunderts.

[unter: Geschichte] Vorgeschichtliche Heimatkunde des Neckar- und Oberrheingebietes

[unter: Geschichte, Im Lehrapparat für Vorgeschichte]

Uebungen über die jüngere Steinzeit Mitteleuropas

Uebungen für Fortgeschrittene: Vorgeschichtliche Forschung und Geschichtswissenschaft im 19. Jahrhundert

[unter: Geschichte] †Das Indogermanenproblem (vorwiegend auf Grund neuer archäologischer Ergebnisse)

[unter Geschichte, Im Lehrapparat für Vorgeschichte]

Uebungen über die wichtigsten Fundgruppen des außerdeutschen Neolithikums

[unter: Geschichte und Politik, Mittlere und Neue Geschichte] †Germanische Altertumskunde und deutsches Geistesleben

[unter: Geschichte mit besonderer Berücksichtigung der Kriegsgeschichte und Wehrkunde, Im Seminar für Vorgeschichte] Übungen zur Einführung in die Methoden der vorgeschichtlichen Forschung (am Beispiel frühalemannischer Funde vom Oberrhein)

Übungen für Fortgeschrittene: Die geschichtliche Darstellung in dem vorgeschichtlichen Schrifttum

Altgermanische Kultur [zusammen mit Hermann Güntert] [unter: Geschichte und Politik, Mittlere und neuere Geschichte] Europäische Völkergeschichte von der Urzeit bis auf Arminius

[unter: Lehrstätte für Frühgeschichte] Übungen an altsteinzeitlichen Fundgruppen (an Hand von Originalaltertümern)

Übungen zur Einführung in die Methoden der vorgeschichtlichen Forschung 382

Die geschichtliche Darstellung in dem vorgeschichtlichen Schrifttum ${ }^{383}$

382 Nicht im Vorlesungsverzeichnis SS 1934, Angabe nach UAH Rep. 27/1372 [Quästurakten], SS 1934.

383 Nicht im Vorlesungsverzeichnis SS 1934, Angabe nach UAH Rep. 27/1372 [Quästurakten], SS 1934. 
WS 1934/35 aoProf. [unter: Alte Geschichte] Die vor- und frühgeschichtlichen Grundlagen des deutschen Mittelalters

[unter: Lehrstätte für Frühgeschichte] Frühgeschichtliche Übungen (die wichtigsten keltischen Fundgruppen)

Übungen für Fortgeschrittene: Würdigung wichtigerer Werke des vorgeschichtlichen Schrifttums

SS 1935 aoProf.

[unter: Geschichte und Politik] Wanderungen und Siedlungen der germanischen Stämme

[unter: Lehrstätte für Frühgeschichte] Übungen zur Einführung in die frühgeschichtliche Forschung: Süddeutsche Fundgruppen des Hallstattkreises

WS 1935/36 384 aoProf. [unter: Deutschkunde, Geschichte und Staats- und wirtschaftswissenschaftliche Fakultät] Das alte Germanien [unter: Lehrstätte für Frühgeschichte] Übungen über Kelten und Germanen der vorrömischen Eisenzeit in Südwestdeutschland [mit Paul Hans Stemmermann]

Übungen über den Fundstoff der Merowingerzeit

Kolloquium: Die Rasse in der vorgeschichtlichen Forschung Wanderungen und Siedelungen der germanischen Stämme ${ }^{385}$ Übungen zur Einführung in die frühgeschichtliche Forschung 386

SS 1936 aoProf. [unter: Deutschkunde und Geschichte] Europäische Völkergeschichte von der Urzeit bis auf Arminius

Übungen über die jüngere Steinzeit Mitteleuropas für Fortgeschrittene

Übungen an dem Stoff der Lehrsammlung [mit Paul Hans Stemmermann]

[unter: In der Lehrstätte für Frühgeschichte] Kolloquium:

Die Entwicklung der Vorstellung von der nordischen Herkunft der Kultur

WS 1936/37 aoProf.

[unter: Deutschkunde und Geschichte] Kelten, Römer und Germanen im Kampf um den Rhein

[unter: In der Lehrstätte für Frühgeschichte] Einführung in die germanische Stammeskunde

Das Indogermanenproblem

384 In der Rubrik Wissenschafliche Anstalten, Institute, Kliniken wird das Heidelberger Institut jetzt unter „Lebrstätte für Frühgeschichte. Deutsches Haus der Universität, Marsiliusplatz. Leiter: Prof. Wable" geführt.

385 Nicht im Vorlesungsverzeichnis WS 1935/36, Angabe nach UAH Rep. 27/1372 [Quästurakten], WS 1935/36.

386 Nicht im Vorlesungsverzeichnis WS 1935/36, Angabe nach UAH Rep. 27/1372 [Quästurakten], WS 1935/36. 
aoProf.

Unterrichtsausflüge

[unter: Landschaftskunde] Übung: Ausgewählte Kapitel aus der Siedlungsgeschichte der Rheinlande

[unter: Deutschkunde und Geschichte] Die germanische Broncezeit

[unter: Geschichte] ${ }^{\circ}$ Lebendige Vorzeit (Die frühgeschichtliche Vergangenheit in der politischen Willensbildung)

[unter: In der Lehrstätte für Frühgeschichte] Ausgewählte Kapitel aus der Siedlungsgeschichte der Rheinlande

Probleme der frühgeschichtlichen Wirtschaft und Gesellschaft

Unterrichtsausflüge

WS 1937/38 aoProf. [unter: Deutschkunde und Geschichte] ${ }^{\circ}$ Die Römerzeit auf deutschem Boden vom Standpunkt deutscher Volksgeschichte

[unter: In der Lehrstätte für Frühgeschichte] AnfängerÜbungen: Einführung in die Formenkunde, an Hand der Lehrsammlung

Übungen für Fortgeschrittene: Slawen und Wikinger auf deutschem Boden Frühgeschichtliche Übungen ${ }^{387}$

SS 1938 aoProf. [unter: Deutschkunde] ${ }^{\circ}$ Wanderungen und Siedelungen der germanischen Stämme

[unter: In der Lehrstätte für Frühgeschichte] Übungen für Anfänger: Einführung in die Formenkunde an Hand der Lehrsammlung

Übungen für Fortgeschrittene: Die geistige Kultur der Germanen im Anschluß an die Germania des Tacitus

Die Römerzeit auf deutschem Boden ${ }^{388}$

WS $1938 / 39$ aoProf.

[unter: Deutschkunde und Geschichte] Altgermanische Kultur

[unter: Geschichte] ${ }^{\circ}$ Vorgeschichtliche Heimatkunde des unteren Neckarlandes

[unter: In der Lehrstätte für Frühgeschichte] Übungen für Anfänger: Einführung in die Formenkunde und Methode [mit Horst Kirchner] $]^{389}$

Übungen für Fortgeschrittene: Die frühgeschichtliche Vergangenheit in der zwischenstaatlichen Auseinandersetzung Wanderungen und Siedelungen der germanischen Stämme ${ }^{390}$

387 Nicht im Vorlesungsverzeichnis WS 1937/38, Angabe nach UAH Rep. 27/1372 [Quästurakten], WS 1937/38.

388 Nicht im Vorlesungsverzeichnis SS 1938, Angabe nach UAH Rep. 27/1372 [Quästurakten], SS 1938.

389 „Die Nennung von Horst Kirchner erfolgt lediglich, um ihn erstmals im Personalverzeichnis in Erscheinung zu bringen" (Wahle an die Universitätskasse Heidelberg, 15.11.1938, UAH Rep. 27/1372 [Quästurakten]).

390 Nicht im Vorlesungsverzeichnis WS 1938/39, Angabe nach UAH Rep. 27/1372 [Quästurakten], WS 1938/39. 
[unter: Geschichte] Das vorgeschichtliche Europa, Kulturen und Völker

[unter: In der Lehrstätte für Frühgeschichte] Übungen für Anfänger: Einführung in Formenkunde und Methode.

Übungen für Fortgeschrittene: Vorgeschichte und Nationalbewußtsein Altgermanische Kultur ${ }^{391}$

WS 1939/40 plaoProf. [unter: Griechisch-römische Altertumskunde und Philologie und Geschichte] †Die rheinländische Römerzeit, ihr Ergebnis für die deutsche Geschichte

[unter: Geschichte] Enzyklopädie und Methodologie in der Prähistorie

[unter: In der Lehrstätte für Frühgeschichte] Übungen für Anfänger: Einführung in Formenkunde und Methode Übungen für Fortgeschrittene: Die Bewertung von Keltenzeit, gallo-römischer und fränkischer Periode in der französischen Geschichtsauffassung

1. Trimester 1940 plaoProf.

2. Trimester 1940 plaoProf.

[unter: Geschichte] †Die frühgeschichtliche Grundlegung des deutschen Volksbodens

[unter: In der Lehrstätte für Frühgeschichte] Übungen für Anfänger: Einführung in Formenkunde und Methode [mit Horst Kirchner]

Übungen für Fortgeschrittene: Die Bewertung von Keltenzeit, gallo-römischer und fränkischer Periode in der französischen Geschichtsauffassung

[unter: Deutschkunde und Geschichte] †Die germanische Bronzezeit

[unter: In der Lehrstätte für Frühgeschichte] Übungen für Anfänger: Einführung in Schrifttum, Formenkunde und Methode

Übungen für Fortgeschrittene: Dreiperiodensystem und typologische Methode

3. Trimester 1940 plaoProf. [unter: Deutschkunde und Geschichte] †Wanderungen und Siedelung der germanischen Stämme

[unter: In der Lehrstätte für Frühgeschichte] Übungen für Anfänger: Einführung in Schrifttum, Formenkunde und Methode

Übungen für Fortgeschrittene: Die Darstellung der frühgeschichtlichen Vergangenheit

391 Nicht im Vorlesungsverzeichnis SS 1939, Angabe nach UAH Rep. 27/1374 [Quästurakten], SS 1939. 
Trimester 1941 plaoProf. [unter: Deutschkunde und Geschichte] †Die Germania des Tacitus im Spiegel des vaterländischen Altertums

[unter: Geschichte] †Einführung in das Studium der Frühgeschichte

[unter: In der Lehrstätte für Frühgeschichte] Übungen für Anfänger: Einführung in Schrifttum, Formenkunde und Methode [mit Horst Kirchner]

Übungen für Fortgeschrittene: Nordische Renaissance und Frühgeschichtsforschung

SS 1941 plaoProf. [unter: Geschichte] Europäische Frühgeschichte I: Vom Homo Heidelbergensis bis zum Abschluß der Indogermanisierung des Erdteils.

[unter: In der Lehrstätte für Frühgeschichte] Übungen für Fortgeschrittene: Frühgeschichtsforschung als Teilgebiet der wissenschaftlichen Heimatkunde (am Beispiel der oberrheinischen Entwicklung)

Einführung in das Studium der Frühgeschichte ${ }^{392}$

WS 1941/42 plaoProf. [unter: Geschichte] Europäische Frühgeschichte II: Die indogermanischen Völker bis zu ihrem Eingang in die städtisch-staatliche Zivilisation.

[unter: In der Lehrstätte für Frühgeschichte] Übungen für Anfänger: Einführung in das Studium der Frühgeschichte (Quellen, Methoden, Schriftum)

Übungen für Fortgeschrittene: Die Darstellung der frühgeschichtlichen Vergangenheit

SS 1942 plaoProf.

[unter: Deutschkunde und Geschichte] Die frühgeschichtliche Grundlegung des deutschen Volksbodens

[unter: Geschichte] ${ }^{\circ}$ Das Neckarland in römischer Zeit

[unter: In der Lehrstätte für Frühgeschichte] Übungen für Anfänger: Einführung in das Studium der Frühgeschichte (Quellen, Methoden, Schriftum)

Übungen für Fortgeschrittene: Frühgeschichte und Nationalbewußtsein

WS 1942/43 plaoProf. $^{393}$

[unter: Geschichte] Einführung in das Studium der Frühgeschichte

[unter: In der Lehrstätte für Frühgeschichte] Proseminar: Einführung in Quellen, Schriftum und Methode Seminar: Frühgeschichtliche Wehranlagen

Kolloquium: Das germanische Altertum in Geschichtsbild des 18. Jahrhunderts

392 Nicht im Vorlesungsverzeichnis SS 1941, Angabe nach UAH Rep. 27/1374 [Quästurakten], SS 1941.

393 „Im Prüfungsausschuß für das wissenschaftliche Lebramt an böberen Lebranstalten.“ 
SS 1943

WS 1943/44 plaoProf.

SS 1944

WS 1944/45 plaoProf.

SS $1947^{395}$

WS $1947 / 48$
plaoProf.

plaoProf.

plaoProf.

plaoProf. [unter: Geschichte] ${ }^{\circ}$ Das frühgeschichtliche Mitteleuropa mit seinen Fundstätten und Funden

[unter: In der Lehrstätte für Frühgeschichte] Proseminar: Einführung in Quellen, Schrifttum und Methode

Seminar: Die keltische Latène-Kultur.

Kolloquium: Formen der prähistorischen Geschichtsdarstellung

[unter: Geschichte] †Wanderungen und Siedlung der germanischen Stämme

[unter: In der Lehrstätte für Frühgeschichte] Proseminar: Einführung in Quellen, Schrifttum und Methode

Seminar: Hallstatt und Hallstattkultur

Kolloquium: Das Dreiperiodensystem

[unter: Geschichte] ${ }^{\circ}$ Die Stellung der frühgeschichtlichen Zeit im europäischen Geistesleben

[unter: In der Lehrstätte für Frühgeschichte] A. Unterstufe: Einführung in Quellen, Schrifttum und Methoden

B Oberstufe: Norden und Antike, Atlantis und Orient

Kolloquium: Die Darstellung der frühgeschichtlichen Vergangenheit ${ }^{394}$

[unter: Geschichte] ${ }^{\circ}$ Europäische Frühgeschichte I: Vom Homo Heidelbergensis bis zum Beginn unserer Zeitrechnung

[unter: In der Lehrstätte für Frühgeschichte] A. Unterstufe: Einführung in Quellen, Methoden und Schrifttum

B Oberstufe: Deutsche und Außerdeutsche Darstellungen der frühgeschichtlichen Zeit

Kolloquium: Die französische Prähistorie

[Vorlesung] Die gegenwärtige Lage der prähistorischen Forschung in Deutschland 396

Proseminar: Einführung in die frühgeschichtliche Forschung Repertitorium der archäologischen Formenkreise der Frühgeschichte Mitteleuropas

Seminar Oberstufe: Französische Darstellungen der frühgeschichtlichen Zeit ${ }^{397}$

[unter: Geschichte] Die frühgeschichtlichen Grundlagen des deutschen Mittelalters

[unter: Im Seminar für Frühgeschichte] A. Unterstufe: Einführung in Quellen, Methode und Schrifttum

B Oberstufe: Das Indogermanenproblem

Kolloquium

394 Fand offenbar nicht statt, keine Angabe in UAH Rep. 27/1374 [Quästurakten], SS 1944.

395 Vorlesungsverzeichnis lag nicht vor.

396 UBH, Heid. Hs. 3989, 4,B5.

397 Angaben nach UAH Rep. 27/1374 [Quästurakten], SS 1947. 
SS 1948 plaoProf.

WS 1948/49 plaoProf.

SS 1949

WS 1949/50 plaoProf.

SS 1950

WS 1950/51 plaoProf.

SS 1951

plaoProf.

plaoProf. [unter: Geschichte] Europäische Frühgeschichte II

[unter: Im Seminar für Frühgeschichte]

Oberseminar: Die frühgeschichtliche Stadt

Colloquium: Besprechung neuerer Literatur und der vorgelegten Arbeiten

[unter: Geschichte] Formen und Stufen der frühgeschichtlichen Wirtschaft

[unter: Im Seminar für Frühgeschichte] Oberseminar: Probleme der frühen Bronzezeit

[Colloquium:] Besprechung der Arbeiten

[unter: Geschichte] Die frühgeschichtlichen Grundlagen des deutschen Mittelalters

[unter: Im Seminar für Frühgeschichte] Oberseminar: Formenkreise der europäischen Bronzezeit 
WS 1951/52 plaoProf. [unter: Geschichte] Einführung in das Studium der Frühgeschichte

[unter: Im Seminar für Frühgeschichte] Oberseminar: Gold und Silber im frühgeschichtlichen Europa

1952 plaoProf. [unter: Geschichte] Die Römerzeit auf deutschem Boden [unter: Im Seminar für Frühgeschichte] Oberseminar: Herren und Hintersassen im archäologischen Stoff

WS 1952/53 plaoProf. [unter: Geschichte] Stadtwirtschaft und Stadt im frühgeschichtlichen Europa

[unter: Im Seminar für Frühgeschichte] Übungen für Fortgeschrittene: Probleme frühdeutscher Siedlungsgeschichte Kolloquium: Besprechung neuer Literatur

SS 1953 plaoProf.

[unter: Geschichte] Germanische Stammesgeschichte (auf Grundlage der Bodenfunde)

[unter: Im Seminar für Frühgeschichte] Oberseminar: die keltischen, Oppida' und ihre Vorstufen

Kolloquium: Probleme der außereuropäischen Prähistorie

WS 1953/54 plaoProf. [unter: Geschichte] Ur- und Frühgeschichte der Menschheit im Bildungsleben der Völker

[unter: Im Seminar für Frühgeschichte] Oberseminar: der Übergang vom Altertum zum Mittelalter im Licht der rheinländischen Archäologie (das Kontinuitätsproblem)

Kolloquium

SS $1954 \quad$ plaoProf.

[unter: Geschichte] Formen und Stufen der frühgeschichtlichen Wirtschaft

[unter: Im Seminar für Frühgeschichte] Oberseminar: Wichtigere paläolithische Fundstätten

Kolloquium

WS 1954/55 plaoProf. [unter: Geschichte] Die Anfänge der Kultur (die vor-bäuerlichen Zivilisationen)

[unter: Im Seminar für Frühgeschichte] Oberseminar: Das schöpferische Individuum in archäologischer Greifbarkeit Kolloquium

1955 plaoProf. [unter: Geschichte] Die prähistorischen Grundlagen der vorderasiatisch-europäischen Zivilisation

[unter: Im Seminar für Frühgeschichte] Oberseminar: Besprechung von Denkmälern der gesellschaftlichen Organisation Kolloquium

WS 1955/56 plaoProf. [unter: Geschichte] Der Werdegang ur- und frühgeschichtlicher Forschung

[unter: Im Seminar für Frühgeschichte] Oberseminar: Besprechung von Denkmälern der gesellschaftlichen Organisation (Fortsetzung)

Kolloquium 
SS 1956

plaoProf.

WS 1956/57 plaoProf.

SS 1957
plaoProf. [unter: Geschichte] Die prähistorische Kulturlandschaft [unter: Im Seminar für Frühgeschichte] Oberseminar: Denkmäler prähistorischen Bergbaus

Kolloquium

[unter: Geschichte] Die prähistorischen Grundlagen des deutschen Mittelalters

[unter: Im Seminar für Frühgeschichte] Oberseminar: Die Prähistorie als Bestandteil des historischen Atlasses

Proseminar Ur- und Frühgeschichte ${ }^{399}$

Kolloquium

[unter: Geschichte] Weltgeschichte der menschlichen Frühzeit

[unter: Im Seminar für Frühgeschichte] Oberseminar: Die prähistorische Menschheit in der Anschauung J. G. Herders Ur- und Frühgeschichte ${ }^{400}$

Quellen:

Anzeige der Vorlesungen der Badischen Ruprecht-Karls-Universität zu Heidelberg für das Winterhalbjahr 1920/21 [ff.] (Heidelberg 1920 [ff.]).

Verzeichnis der Vorlesungen sowie der Dozenten, Behörden und Institute der Badischen Ruprecht-Karls-Universität zu Heidelberg für das Sommerhalbjahr 1924 [ff.] (Heidelberg 1924 [ff.]).

Ruprecht-Karls-Universität Heidelberg. Verzeichnis der Vorlesungen Sommerhalbjahr 1926 [ff.] (Heidelberg 1926 [ff.]).

Ruprecht-Karls-Universität Heidelberg. Personalverzeichnis für das Winterhalbjahr 1930/31 (ff.) und Vorlesungsverzeichnis für das Sommerhalbjahr 1931 [ff.] (Heidelberg 1931 [ff.]).

Ruprecht-Karl-Universität Heidelberg. Personalverzeichnis und Vorlesungsverzeichnis für das Winterhalbjahr 1935/36 [ff.]. Heidelberg 1935 [ff.]).

Ruprecht-Karl-Universität Heidelberg. Vorlesungen 1. Trimester 1940 [ff.]. (Heidelberg 1940 [ff.]).

Ruprecht-Karl-Universität Heidelberg. Personal- und Vorlesungsverzeichnis Trimester 1941 (Heidelberg 1941).

399 Nicht im Vorlesungsverzeichnis WS 1956/57, Angabe nach UAH Rep. 27/1374 [Quästurakten], WS 1956/57.

400 Nicht im Vorlesungsverzeichnis SS 1957, Angabe nach UAH Rep. 27/1374 [Quästurakten], SS 1957. 
Ruprecht-Karl-Universität Heidelberg. Vorlesungsverzeichnis Sommer-Semester 1941 (Heidelberg 1941).

Ruprecht-Karl-Universität Heidelberg. Personal- und Vorlesungsverzeichnis für das Wintersemester1941/42 [ff.] Heidelberg 1941 [ff.]).

Ruprecht-Karl-Universität Heidelberg. Personal- und Vorlesungs-Verzeichnis Winter-Semester 1951/52 [ff.] Heidelberg 1951 [ff.]).

Personal-Verzeichnis der Badischen Ruprecht-Karls-Universität in Heidelberg. Winter-Halbjahr 1920/21 (Heidelberg 1920).

(11) Privatdozenten ... Wahle, Ernst, Dr. phil. (Prähistorie). Zwingerstrasse 7.

Personal-Verzeichnis der Badischen Ruprecht-Karls-Universität in Heidelberg. Sommer-Halbjahr 1922 (Heidelberg 1922).

(11) Privatdozenten ... Wahle, Ernst, Dr. phil. (Prähistorie). Hauptstrasse 235.

Ruprecht-Karls-Universität Heidelberg. Personalverzeichnis Winterhalbjahr 1925/26 (Heidelberg 1925).

(15) Nichtplanmäßige außerordentliche Professoren ... Wahle, Ernst, Dr. phil. (Prähistorie). Rohrbach Gartenstraße 18.

Ruprecht-Karls-Universität Heidelberg. Personalverzeichnis Winterhalbjahr 1926/27 (Heidelberg 1925).

(13) Außerordentliche Professoren ... Wahle, Ernst, Dr. phil. (Prähistorie). Rohrbach Gartenstraße 18.

Ruprecht-Karls-Universität Heidelberg. Personalverzeichnis Winterhalbjahr 1929/30. (Heidelberg 1929).

(11) Außerordentliche Professoren ... Wahle, Ernst, Dr. phil. (Vorgeschichte). Rohrbach Gartenstraße 18.

Ruprecht-Karls-Universität Heidelberg. Personalverzeichnis für das Sommerhalbjahr 1933 (Heidelberg 1933).

(11) Außerordentliche Professoren ... Wahle, Ernst, Dr. phil. (Frühgeschichte). Rohrbach, v. d. Tannstr. 37. 